UNIVERSIDADE DE SÃO PAULO

FACULDADE DE MEDICINA DE RIBEIRÃO PRETO

PROGRAMA DE PÓS-GRADUAÇÃO

MESTRADO PROFISSIONAL EM HEMOTERAPIA E BIOTECNOLOGIA

FELIPE CARLOS BRITO DE SOUZA

PESQUISA DE ANTICORPOS ANTILEUCOCITÁRIOS (ANTI-HLA E ANTI-HNA) EM HEMOCOMPONENTES COMO FERRAMENTA DE RACIONALIZAÇÃO DAS ESTRATÉGIAS DE REDUÇÃO DO RISCO DE TRALI 


\author{
UNIVERSIDADE DE SÃO PAULO \\ FACULDADE DE MEDICINA DE RIBEIRÃO PRETO \\ PROGRAMA DE PÓS-GRADUAÇÃO \\ MESTRADO PROFISSIONAL EM HEMOTERAPIA E BIOTECNOLOGIA
}

FELIPE CARLOS BRITO DE SOUZA

PESQUISA DE ANTICORPOS ANTILEUCOCITÁRIOS (ANTI-HLA E ANTI-HNA) EM HEMOCOMPONENTES COMO FERRAMENTA DE RACIONALIZAÇÃO DAS ESTRATÉGIAS DE REDUÇÃO DO RISCO

DE TRALI

RIBEIRÃO PRETO

2019 


\title{
PESQUISA DE ANTICORPOS ANTILEUCOCITÁRIOS (ANTI-HLA E ANTI-HNA) EM HEMOCOMPONENTES COMO FERRAMENTA DE RACIONALIZAÇÃO DAS ESTRATÉGIAS DE REDUÇÃO DO RISCO DE TRALI
}

Versão original

\begin{abstract}
Dissertação apresentada ao Programa de Mestrado Profissional em Hemoterapia e Biotecnologia, área de Hemoterapia e Medicina Transfusional da Faculdade de Medicina de Ribeirão Preto da Universidade de São Paulo para obtenção de título de Mestre em Ciências
\end{abstract}

Área de Concentração: Hemoterapia

Orientador: Prof. Dr. Eduardo Antônio Donadi 


\begin{abstract}
AUTORIZO A REPRODUÇÃO E DIVULGAÇÃO TOTAL OU PARCIAL DESTE TRABALHO, POR QUALQUER MEIO CONVENCIONAL OU ELETRÔNICO, PARA FINS DE ESTUDO E PESQUISA, DESDE QUE CITADA A FONTE.
\end{abstract}

Ficha Catalográfica

Souza, Felipe Carlos Brito de

Pesquisa de anticorpos antileucocitários (anti-HLA e anti-HNA) em hemocomponentes como ferramenta de racionalização das estratégias de redução do risco de TRALI

Ribeirão Preto, 2019.

$95 \mathrm{f}$.

Dissertação de mestrado apresentada à Faculdade de Medicina de Ribeirão Preto, Universidade de São Paulo.

Área de concentração: Hemoterapia e Medicina Transfusional

Orientador: Donadi, Eduardo Antônio

1.TRALI, 2.Anticorpos Antileucocitários, 3.HLA, 4.HNA 5.Hemocomponentes, 6.Gestação. 


\section{FOLHA DE APROVAÇÃO}

SOUZA, F.C.B. Pesquisa de anticorpos anti-HLA e anti-HNA em hemocomponentes como ferramenta de racionalização das estratégias de redução de risco de TRALI. 2019. 100f. Dissertação de Mestrado Profissional em Hemoterapia e Biotecnologia - Faculdade de Medicina de Ribeirão Preto, Universidade de São Paulo, Ribeirão Preto, 2019.

\section{Aprovado em:}

\section{Banca Examinadora}

Prof . Dr.

Instituição:

Julgamento:

Prof . Dr.

Instituição:

Julgamento:

Prof . Dr.

Instituição:

Julgamento:

Prof . Dr.

Instituição:

Julgamento: 
Dedico esse trabalho a minha filha Alice por me dar tanta vida desde que me escolheu como seu pai 


\section{AGRADECIMENTOS}

Aos meus pais Dona Cláudia e Seu Rogério por me darem, além de todo amor do mundo, apoio e força para seguir desde o primeiro respirar até hoje.

À Tia Ló, que é junto com meus pais responsável por cada vitória que eu já consegui ou que venha a alcançar.

À Tia Verinha, minha madrinha, e em nome dela a todos meus familiares que sempre se alegraram com as minhas (nossas) conquistas e foram solidários nas dificuldades.

Ao meu orientador Dr. Donadi, com o qual pude aprender muito mais do que é possível mostrar nessa dissertação. Muito obrigado Professor.

À equipe do Laboratório de HLA do Hemocentro de Ribeirão Preto, em nome da minha sempre amiga Dra. Neifi, pelo valoroso aprendizado e auxílio e carinho com que me acolheram.

Às doadoras e doadores de sangue que participaram da pesquisa por sua ajuda e disponibilidade tão valorosa.

À minha grande amiga top das galáxias de todas as horas, Milena, pelo companheirismo e ajuda indispensáveis para que isso acontecesse.

À minha amiga e colega de Mestrado Cibele, por fazer possível este trabalho com sua colaboração imprensindível para que ele tenha saído do papel.

À minha eterna amiga Nath, por seu apoio, torcida e ajuda quando foi preciso que eu me dedicasse ao projeto.

À equipe de amigos do Laboratório HLA (estagiários, técnicos, analistas), a equipe mais linda do planeta, com qual aprendo todos os dias e que não só ajudaram, fizeram esse projeto acontecer.

À equipe do Laboratório NAT, pelo apoio e ajuda de sempre.

Ao meu eterno chefe Fernando Basques pelo exemplo, incentivo e amizade em todos os momentos. 
À Fundação Hemominas, instituição a qual devo e dedico minha vida, em nome da minha pediatra e Presidenta Dra.Júnia, pelo apoio e confiança.

Aos colegas do Mestrado, por dividirem comigo todas as dúvidas, soluções, risadas e apertos nesse processo.

A todos meu amigos que com apoio e boas energias contribuíram muito para o objetivo.

À Tia Rita, pela ajuda e pelo exemplo de foco e determinação.

À Jéssica, meu par de vida, por todo amor, carinho, equilíbrio e óleos essenciais em todos os momentos que pareceu difícil, mas sempre me ajudou a ver que de fato era possível.

À minha filha Alice, pela compreesão em todos os momentos que a brincadeira teve que parar um pouco para que eu pudesse me dedicar ao trabalho. 
"Se não puder voar, corra. Se não puder correr, ande. Se não puder andar, rasteje, mas continue em frente de qualquer jeito."

Martin Luther King 


\section{LISTA DE TABELAS}

Tabela 1 - Características clínicas da lesão pulmonar aguda relacionada à transfusão .......34

Tabela 2 - Estratégias de redução do risco de TRALI empregadas em diferentes países....37

Tabela 3 - Risco relativo de desenvolvimento de TRALI para diferentes hemocomponentes em estudos prévios.

Tabela 4 - Estatística descritiva dos grupos de doadores incluídos no estudo, estratificados segundo gênero e número de gestações para as doadoras. 50

Tabela 5 - Distribuição de frequência absoluta e relativa dos anticorpos anti-HLA [antígenos de classe I (Cl) e de classe II (CII)] e anti-HNA encontrados nos grupos de doadores estudos, estratificados segundo gênero e número de gestações para as doadoras. 50

Tabela 6 - Distribuição e comparação de doadores de sangue, por presença de anticorpos anti-HLA/HNA, doadores do sexo masculino versus mulheres nuligestas

Tabela 7 - Distribuição e comparação de doadoras de sangue, por presença de anticorpos anti-HLA/HNA, segundo histórico de gestação (nulíparas e uma gestação)

Tabela 8 - Distribuição e comparação de doadoras de sangue, por presença de anticorpos anti-HLA/HNA, segundo histórico de gestação (nuligestas e duas gestações).

Tabela 9 - Distribuição e comparação de doadoras de sangue, por presença de anticorpos anti-HLA/HNA, segundo histórico de gestação (nuligestas e três ou mais gestações)

Tabela 10 - Distribuição e comparação de doadores de sangue, por presença de anticorpos anti-HLA/HNA, doadores do sexo masculino versus mulheres com histórico de uma ou zero gestações

Tabela 11 - Distribuição e comparação de doadoras de sangue, por presença de anticorpos anti-HLA/HNA, segundo histórico de gestação (mulheres com uma ou zero gestações versus mulheres com duas ou mais gestações) 
Tabela 12 - Distribuição e comparação de doadoras de sangue, por presença de anticorpos anti-HLA/HNA, segundo histórico de gestação (G) (mulheres com duas gestações de um mesmo pai versus mulheres com duas gestações de mais de um pai)

Tabela 13 - Distribuição e comparação de doadoras de sangue, por presença de anticorpos anti-HLA/HNA, segundo histórico de gestação (G) (mulheres com três gestações de um mesmo pai versus mulheres com três gestações de mais de um pai) .................................57

Tabela 14 - Distribuição e comparação de doadoras de sangue, por presença de anticorpos anti-HLA/HNA, segundo histórico de gestação (G) (mulheres com uma gestação a menos de 10 anos versus mulheres com uma gestação a mais de 10 anos)

Tabela 15 - Distribuição e comparação de doadoras de sangue, por presença de anticorpos anti-HLA/HNA, segundo histórico de gestação (G) (mulheres com duas gestações com a última a menos de 10 anos versus mulheres com duas gestações sendo a última a mais de 10 anos).

Tabela 16 - Dados completos do questionário e dos testes de anticorpos dos doadores participantes da pesquisa 75 


\section{LISTA DE SIGLAS E ABREVIATURAS}

AABB

ANVISA

BC

CD

CDC-NHI

$\mathrm{CH}$

CRIO

EDTA

ELISA

GAT

GIFT

HLA

HNA

Ic $95 \%$

ICAM-1

$\mathrm{Kb}$

$\mathrm{KDa}$

LMP

LPA

MAC

NBG

OR

PBS

PFC

PLQ

PRA

PMN

ROS

$\mathrm{RR}$

SDRA
Associação Americana de Bancos de Sangue

Agência Nacional de Vigilância Sanitária

Buffy coat

Cluster of Differentiation

Complement Dependent Cytotoxicity-National Institute of Health

Concentrado de Hemácias

Crioprecipitado

Ácido Etileno Tetra Acético

Enzyme-Linked Immunosorbent Assay

Teste de Aglutinação de Granulócitos

Teste de Imunofluorescência de Granulócitos

Antígeno Leucocitário Humano

Antígeno Neutrofílico Humano

Intervalo de Confiança de 95

Molécula de Adesão Celular 1

Kilobases

Kilodalton

Large Multipurpose Protease

Lesão Pulmonar Aguda

Complexo de ataque a Membrana

Normalized Background

Odds Ratio

Tampão fosfato salino

Plasma Fresco Congelado

Plaquetas

Panel Reactive Antibodies

Células Polimorfonucleares

Reactive oxygen species

Risco Relativo

Síndrome do Desconforto Respiratório Agudo 


\section{LISTA DE FIGURAS}

Figura 1 - Representação esquemática do sistema de antígenos leucocitários humanos (HLA)

Figura 2 - Estrutura plana e modelo de fita de uma molécula HLA de classe I .........23

Figura 3 - Estrutura plana e modelo de fita do MHC de classe II ............................24

Figura 4 - Mecanismos de desencadeamento da TRALI com o envolvimento de polimorfonucleares (PMNs) e anticorpos anti-HLA/HNA

Figura 5 - Radiografia de tórax de paciente antes e depois da transfusão de paciente com caso de TRALI.

Figura 6 - Porcentagem de doadores com anticorpos positivos para os anticorpos estudados....

Figura 7 - Distribuição da frequência de doadores com anticorpos positivos em cada grupo do estudo por tipo de anticorpo e combinação destes .53

Figura 8 - Prevalência de anticorpos anti-HLA/HNA em estudos prévios, relacionados ao número de gestações 66 
SOUZA, F.C.B. Pesquisa de anticorpos antileucocitários (anti-HLA e anti-HNA) em hemocomponentes como ferramenta de racionalização das estratégias de redução do risco de TRALI. 2019. 95f. Dissertação de Mestrado Profissional em Hemoterapia e Biotecnologia - Faculdade de Medicina de Ribeirão Preto, Universidade de São Paulo, Ribeirão Preto, 2019.

Uma das mais graves reações transfusionais relatadas é a lesão pulmonar aguda relacionada à transfusão ou TRALI (Transfusion related acute lung injury). Há algumas décadas, a TRALI vem sendo considerada rara complicação transfusional, porém dados recentes indicam que a síndrome representa a principal causa de mortalidade diretamente relacionada à transfusão. Trata-se de reação imune que é desencadeada pela transfusão de hemocomponentes contendo plasma com anticorpos contra antígenos de histompatibilidade (anti-HLA) e contra antígenos de neutrófilos (anti-HNA). Estes anticorpos aparecem nos doadores, na maioria das vezes em mulheres multigestas, que são frequentemente imunizadas contra antígenos leucocitários não maternos durante a gravidez. Considerando a gravidade da TRALI e a importância dos anticorpos anti-HLA/HNA na patogenia dessa síndrome, o presente estudo de caráter prospectivo experimental propos avaliar o panorama da presença de anticorpos anti-HLA/HNA nos hemocomponentes plasmáticos produzidos na Fundação Hemominas, para subsidiar a implantação de estratégias de prevenção da TRALI e definição de protocolos de rejeição seletiva de doadoras do sexo feminino. Foram realizados testes para identificação de anticorpos anti-HLA de classe I e II, além dos anticorpos anti-HNA contra os antígenos HNA-1a, HNA-1b, HNA-1c, HNA-2, HNA-3a, HNA-3b, HNA-4a, HNA-5a e HNA-5b. Foram testadas amostras de 190 doadores de sangue da Fundação Hemominas, sendo 50 homens, 140 mulheres (50 nuligestas, 30 com histórico de uma gestação, 30 com histórico de duas gestações e 30 com histórico de três ou mais gestações). A taxa de aloimunização total foi de $35 / 190$ (18,4 \%). Os anticorpos anti-HLA (classe I = 43,0\%, classe II = 48,0\%) foram mais frequentes que os anticorpos antineutrófilos (9,0\%). A análise do efeito da gestação no desenvolvimento de anticorpos foi concordante com diversos estudos anteriores, mostrando prevalência maior no grupo mulheres com três ou mais gestações $(43,3 \%)$, seguida do grupo de mulheres com histórico de duas gestações (36,7\%), uma gestação com $20,0 \%$ e mulheres nuligestas com a menor prevalência entre as mulheres (6,0\%). O grupo de doadores do sexo masculino apresentou frequência de aloimunização de 4,0\%. Os resultados apontam para a possibilidade de se valer de doação de mulheres não multigestas, em casos de contingenciamento de produção de hemocomponentes com alto conteúdo plasmático. 
SOUZA, F.C.B. Search for anti-leukocyte antibodies (anti-HLA and anti-HNA) in hemocomponents for the rationalization of strategies to reduce the risk of TRALI development. 2019. 95f. Dissertação de Mestrado Profissional em Hemoterapia e Biotecnologia - Faculdade de Medicina de Ribeirão Preto, Universidade de São Paulo, Ribeirão Preto, 2019.

One of the most serious transfusion reactions reported is the transfusion-related acute lung injury (TRALI). TRALI has been considered a rare transfusion complication for some decades, but recent data indicate that the syndrome represents the leading cause of mortality directly related to transfusion. It is an immune reaction that is triggered by the transfusion of plasmacontaining anti-HLA and anti-HNA antibodies. These antibodies appear in donors, most often in multigested women, who are often immunized against non-maternal leukocyte antigens during pregnancy. Considering the severity of TRALI and the importance of anti-HLA/HNA antibodies in the pathogenesis of this syndrome, the present prospective experimental study aimed to evaluate the presence of anti-HLA/HNA antibodies in plasma hemocomponents produced at the Hemominas Foundation to subsidize the implantation of strategies of prevention of the TRALI and definition of protocols of selective rejection of female donors. The anti-HNA antibodies against the antigens HNA-1a, HNA-1b, HNA-1c, HNA-2, HNA-3a, HNA3b, HNA-4a, HNA-5a and HNA-5b were tested as well as for anti-HLA class I and II antibodies. We sampled 190 blood donors from Hemominas Foundation, 50 men, 140 women (50 nulligests, 30 with a history of one pregnancy, 30 with a history of two pregnancies and 30 with a history of three or more pregnancies). The total alloimmunization rate was 35/190 (18.4\%). Anti-HLA antibodies (class I $=43.0 \%$, class II $=48.0 \%$ ) were more frequent than antineutrophil antibodies (9.0\%) Analysis of the effect of gestation on antibody development was consistent with several studies (43.3\%), followed by the group of women with a history of two pregnancies (36.7\%), a gestation with $20.0 \%$, and nulligest women with the lowest prevalence among women $(6.0 \%)$. The group of male donors presented aloimunization frequency of $4.0 \%$. The results point to the possibility of using as donors non-multigest women in cases of contingency of production of blood components with high plasma content.

Keywords: TRALI, anti-leukocyte antibodies, HLA, HNA, Hemocomponents, Pregnancy. 


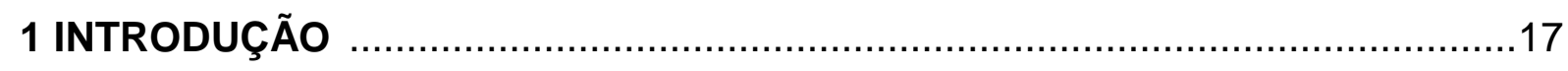

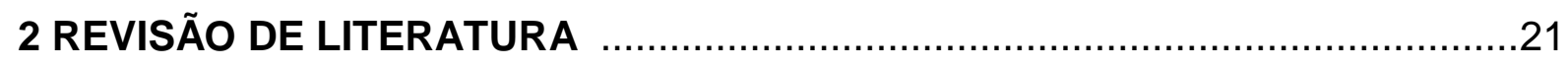

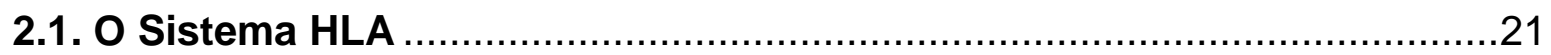

2.2. Sistema HNA

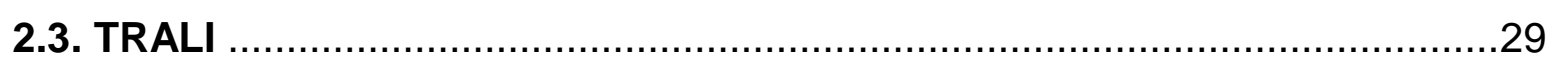

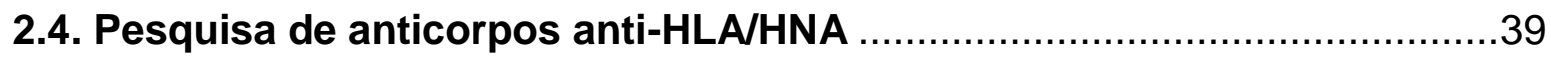

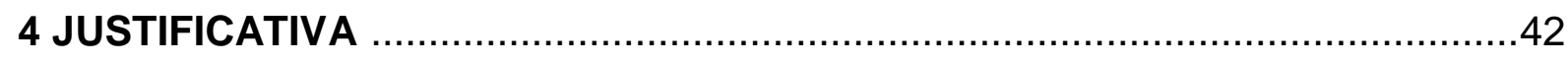

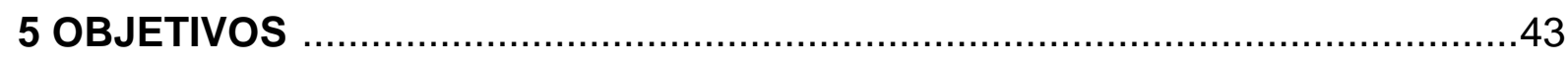

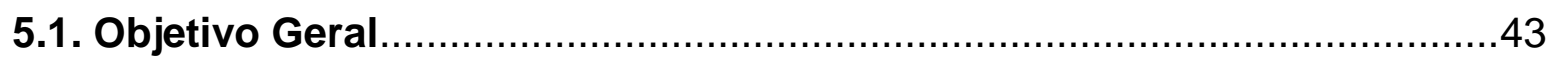

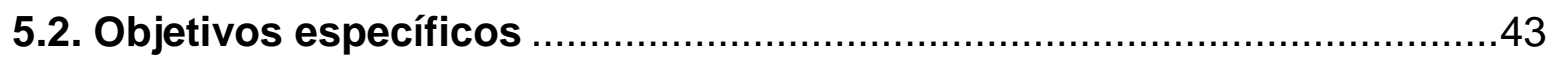

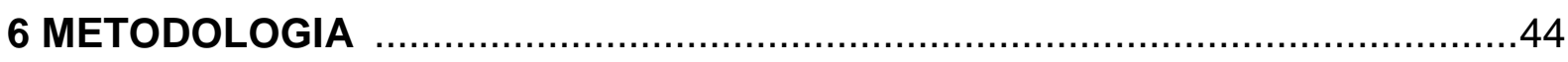

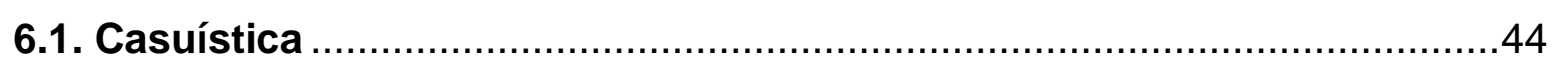

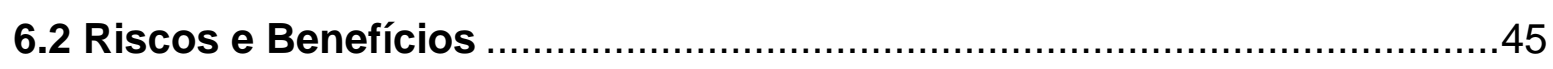

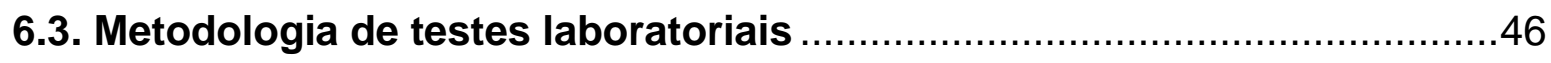

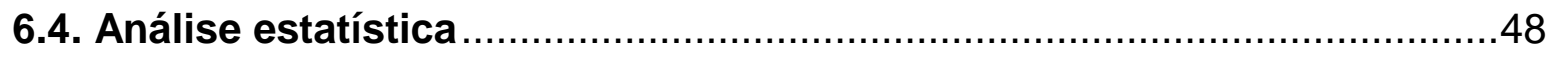

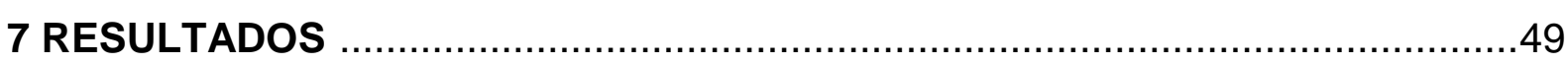

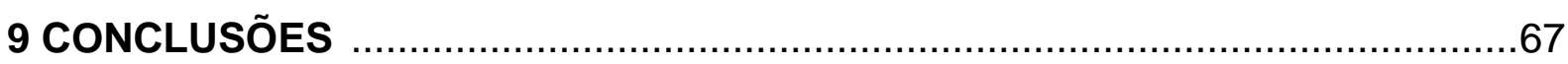

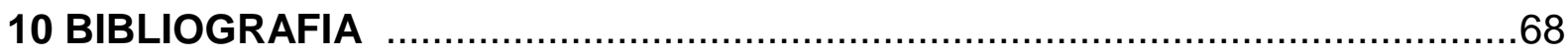

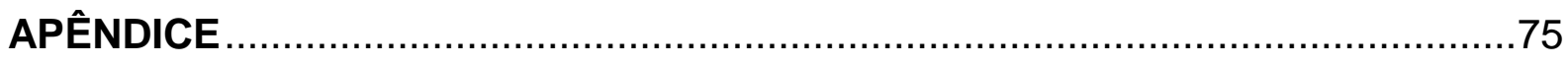

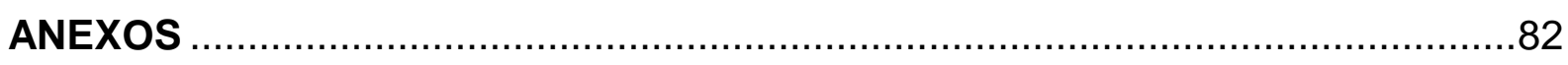


O sangue sempre teve papel de destaque na história da humanidade e desde a antiguidade já era considerado fluido que conferia vida e juventude. Entretanto, foram necessários muitos séculos para que se pudesse assumir papel terapêutico de importância, tal como se encontra na atualidade. A transfusão de um hemocomponente pode ser considerada 0 ato final de conjunto de atividades que constitui o processo transfusional (SILVA, 2008).

A transfusão é terapêutica de suporte importante para a prática da medicina atual. A forma de obtenção do sangue e de seus componentes para transfusão tem incorporado, ao longo do tempo, tecnologias que tornam o produto cada vez mais seguro, minimizando os riscos da transfusão. A despeito disso, a prática transfusional, mesmo que segura, apresenta inerentes riscos imediatos ou tardios, que podem complicar o prognóstico e a sobrevida do paciente que necessita desse procedimento (HEMOCE, 2014).

Diferentemente dos riscos infecciosos nos quais a ausência dos marcadores de certos vírus, bactérias e/ou protozoários pode conferir, na maioria dos casos, segurança à transfusão de hemocomponentes, os riscos não infecciosos podem não ser tão diretos, sendo por vezes complexos, envolvendo condições, como por exemplo, o sistema imune do receptor, do doador ou de ambos.

A Organização Mundial da Saúde (OMS) recomenda à autoridade governamental assumir a responsabilidade pela garantia do suprimento seguro de sangue à população. Assim sendo, avançar tecnologicamente no desenvolvimento de testes laboratoriais de alta sensibilidade e robustez se faz essencial nos centros produtores de hemocomponentes.

Nas últimas décadas, principalmente em vista do advento da aids, a segurança transfusional, do ponto de vista de transmissão de doenças infecto-contagiosas, evoluiu consideravelmente. Os riscos de complicações infecciosas, com a aplicação dos testes disponíveis na atualidade, são considerados muito baixos. No entanto, as reações transfusionais decorrentes de eventos metabólicos, imunológicos e hidro- 
eletrolíticos podem ocorrer e serem extremamente deletérias para o paciente. Uma das mais graves reações transfusionais é a lesão pulmonar aguda relacionada à transfusão ou TRALI (Transfusion related acute lung injury) (BRASIL, 2007).

Há algumas décadas, a TRALI vem sendo considerada rara complicação transfusional, porém dados recentes indicam que a síndrome representa a principal causa de mortalidade diretamente relacionada à transfusão. Em países como Reino Unido e Estados Unidos, a TRALI é apontada como a principal causa de morbimortalidade relacionada à transfusão, tendo sido responsável por $47 \%$ dos casos relacionados às mortes reportadas à Food and Drug Administration dos Estados Unidos de 2005 a 2010 (BUX, JÜRGEN, 2005; US FOOD AND DRUG ADMINISTRATION, 2016). Seu risco de aparecimento se dá, sobretudo, em transfusão de componentes do plasma e plaquetas (MIDDELBURG et al., 2011).

Dados de sistemas de hemovigilância de diversos países apontam a reação como sendo, apesar de grave, evento raro, que até hoje ainda tem sua incidência desconhecida de forma definitiva. Estudos anteriores já haviam sugerido que a TRALI pode ocorrer em 0,04 a 0,16\% de pacientes transfundidos ou 0,014 e 0,08\% por hemocomponente transfundido (POPOVSKY, M.; MOORE, 1985). No entanto, recentes estudos da Rede Internacional de Hemovigilância, que coleta dados de sete países (Austrália, Tailândia, Grécia, Dinamarca, Holanda, França e Canadá) acerca das reações transfusionais, relataram taxa de mortalidade por TRALI de 0,049 por 100.000 hemocomponentes transfundidos. (JUNIOR; LOPES, 2007; OTROCK; LIU; GROSSMAN, 2017; SACHS, ULRICH J.H.; KAUSCHAT; BEIN, 2005; WEBERT; BLAJCHMAN, 2005)

A TRALI é definida por aparecimento de insuficiência respiratória após transfusão sanguínea. Trata-se de reação imune que é desencadeada pela transfusão de hemocomponentes contendo plasma com anticorpos, que aparecem nos doadores, na maioria das vezes em mulheres multíparas, usualmente imunizadas contra antígenos leucocitários paternos durante a gravidez. Dentro desses antígenos leucocitários, destaca-se o sistema HLA (human leukocyte antigen). A identificação de anticorpos direcionados aos antígenos HLA pode ser ferramenta valiosa para o incremento de segurança transfusional, identificando pacientes mais graves já aloimunizados por hemocomponentes que não sejam capazes de gerar complicações 
como a TRALI (BUX, 2005). Além dos anticorpos dirigidos aos antígenos HLA, os antígenos específicos de neutrófilos (HNA) também têm sido implicados como causadores de TRALI. (REIL et al., 2008)

Estratégias de mitigação de risco de TRALI vêm sendo introduzidas em todo mundo. Por meio do estudo Serious Harzards of Tranfusion - SHOT, o Reino Unido definiu estratégias e introduziu critérios para exclusão de doadoras multíparas a fim de reduzir o risco de indução de TRALI. (BOLTON-MAGGS; COHEN, 2013)

Em novembro de 2006, boletim da Associação Americana de Bancos de Sangue $(A A B B)$ indicou diretrizes que recomendavam a introdução de medidas para minimizar o risco de TRALI, melhorando a preparação de componentes com alto volume plasmático, obtidos de doadores aloimunizados com antígenos leucocitários ou com risco aumentado de aloimunização. Em 2007, outro boletim da AABB relatou que cada instituição deveria elaborar programa de redução de risco da TRALI para a disponibilização dos componentes sanguíneos necessários. (AABB, 2014; KOPKO, P. et al., 2007)

Mais recentemente, a AABB, na 29ª edição do documento de Padrões para Serviços de Bancos de Sangue e Transfusão, acrescenta uma norma (5.4.1.2) que determina que o plasma e sangue total para transfusão alogênica devam ser de doadores homens, mulheres sem histórico de gravidez ou aquelas que tiveram, após a última gravidez, testagem para anticorpos anti-HLA. (AABB, 2014)

No Canadá, o Canadian Blood Service, em 2007, definiu o uso de forma preponderante de plasma de doadores do sexo masculino para a transfusão de plasma congelado e concentrado de plaquetas como prevenção de TRALI. Assim, em 2009, foi iniciada a coleta para aférese de plaquetas somente de doadores homens e mulheres sem histórico de gravidez. (ANDREU et al., 2017; TRIULZI et al., 2009)

O Ministério da Saúde do Brasil, por intermédio da ANVISA, publicou em 2010, Manual que aborda os aspectos hemoterápicos relacionados à TRALI e apresenta medidas para redução do risco do evento. Nesse documento, é definido que doadores do sexo masculino ou doadoras com histórico de até duas doações sejam considerados de baixo risco para o desencademanto de TRALI. Assim sendo, poderiam essas mulheres estar liberadas para doação de sangue total/aférese e preparo de qualquer 
hemocomponente. Por outro lado, as doadoras multigestas (três ou mais gestações) estariam liberadas para doação de sangue total, mas não para doação de plaquetas por aférese. Ademais, foi autorizado o preparo de todos os hemocomponentes, porém o plasma deve ser utilizado apenas para fracionamento industrial. (BRASIL, 2010)

A Fundação Hemominas, desde 2015, é certificada pela AABB e, desde então, iniciou o protocolo baseado nos requisitos que determinam o uso exclusivo de plasma masculino na prática hemoterápica. Assim sendo, todo plasma obtido de doadoras é encaminhado para o fracionamento industrial (Fundação Hemominas, Nota Técnica interna).

No entanto, tal prática pode ser um dificultador para a manutenção de estoques de hemocomponentes de grupos sanguíneos raros, incluindo indivíduos tipificados como $A B$ e nas doações por plaquetaférese, pois essa, por conter grande quantidade de plasma, também fica restrita aos hemocomponentes obtidos de doadores do sexo masculino.

Diante desse cenário, este estudo teve como alvo estudar as características de aloimunização HLA/HNA na população de doadoras de sangue da Fundação Hemominas, subsidiando o arcabouço informativo para as tomadas de decisão para definição das estratégias de mitigação do risco de TRALI, sem perder de vista a manutenção da eficiência hemoterápica. 


\subsection{O Sistema HLA}

Em humanos, os genes do Complexo Principal de Histocompatibilidade (do inglês Major Histocompatility Complex - MHC) se localizam no braço curto do cromossomo 6 (6p21.3) e são herdados em blocos, formando haplótipos (Figura 1A). No homem, - MHC é denominado sistema dos Antígenos Leucocitários Humanos (do inglês Human Leukocyte Antigen - HLA), codificando moléculas encontradas na superfície dos leucócitos. O sistema HLA ocupa região gênica com grande variabilidade, estendendo-se por cerca de 3600 kilobases $(\mathrm{Kb})$. Esses loci contêm a maior parte das informações genéticas necessárias para o desenvolvimento da atividade de apresentação de antígenos. (HOWELL; CARTER; CLARK, 2010).

O sistema HLA pode ser, didaticamente, dividido em três classes de antígenos, sendo que os de classes I e II são altamente polimórficos (Figura 1B). A região de classe I compreende os três mais importantes e mais polimórficos loci- HLA-A, HLA-B e HLAC. Os três loci são determinantes na rejeição de transplantes e são expressos por grande parte das células somáticas. A região de classe II, por sua vez, codifica moléculas essenciais ao processamento de antígenos para apresentação aos linfócitos. Compreende, dentre outros, os loci HLA-DRA1/B1, HLA-DQA1/B1 e HLA$D P A 1 / B 1$, que codificam moléculas expressas na superfície das células apresentadoras de antígenos. A região de classe III contém genes que codificam proteínas relacionadas ao sistema imune, como proteínas do sistema do complemento e citocinas próinflamatórias (VILELA, 2007) 
Figura 1 - Representação esquemática do sistema de antígenos leucocitários humanos (HLA)

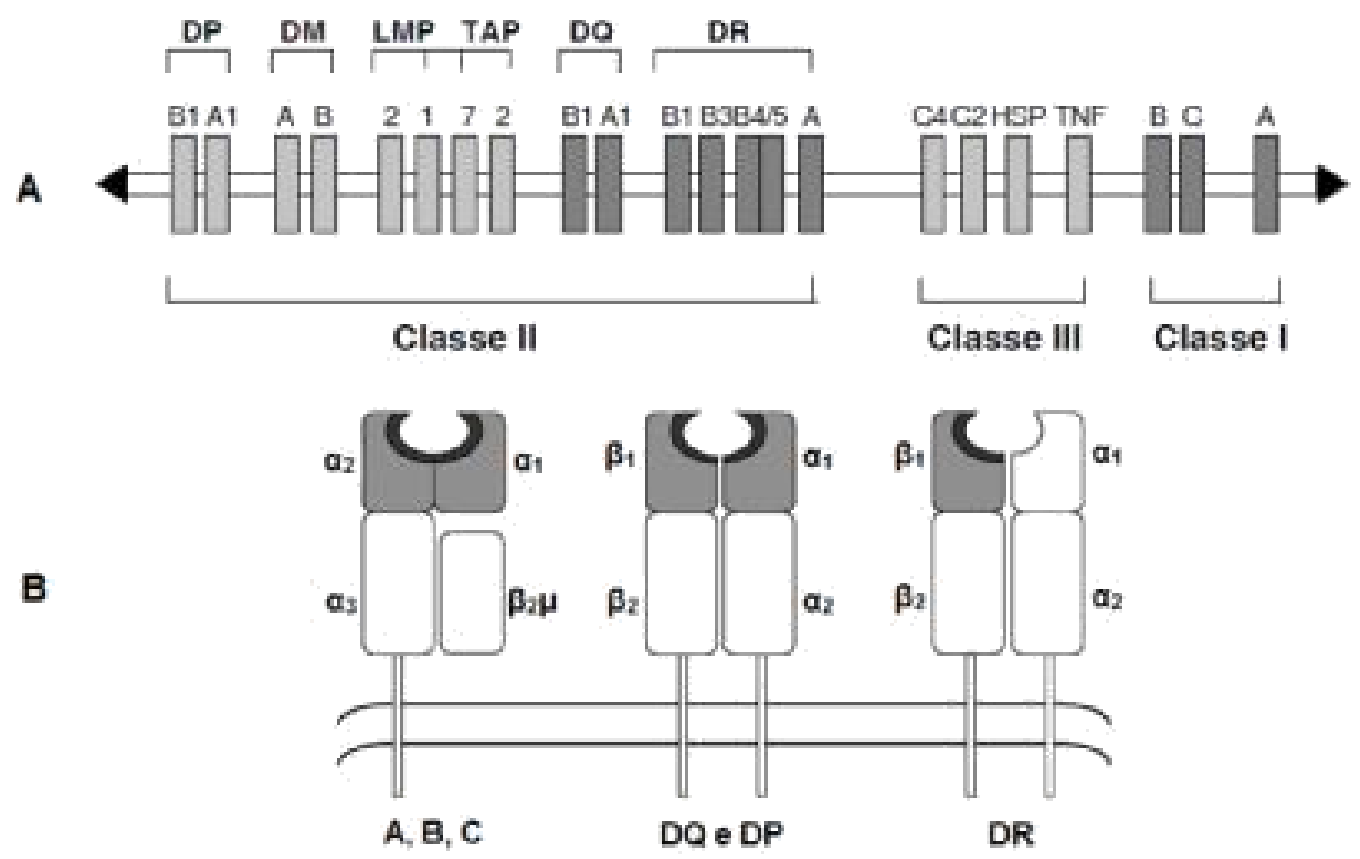

A. Estrutura gênica do braço curto do cromossomo 6 , identificando as regiões codificadoras do genes de Classe I, II e III. B. Moléculas HLA-I (HLA-A, B e C) e HLA-II (HLA-DQ, DP e DR). Nos domínios a1 e $\alpha 2$ das moléculas HLA de classe I e nos domínios $\alpha 1$ e $\beta 1$ das moléculas HLA-DQ e DP e no domínio $\beta 1$ das moléculas HLA-DR são os locais nos quais ocorre a maior taxa de polimorfismo (Adaptado de DONADI, 2000).

As moléculas classe l estão presentes em todas as células nucleadas e plaquetas. As moléculas de classe II apresentam distribuição mais restrita, sendo encontradas em linfócitos $B$, macrófagos, monócitos, células de Langerhans, células dendríticas, células endoteliais e linfócitos T ativados. (ABBAS; LICTHMAN, 2012)

As moléculas HLA de classe I possuem uma cadeia pesada $\alpha$, de peso molecular de $45 \mathrm{KDa}$, altamente polimórfica, associada à cadeia beta ( $\beta 2$-microglobulina), nãopolimórfica, de peso molecular de $12 \mathrm{KDa}$ e codificada por gene presente no cromossomo 15. A interação não covalente entre ambas as cadeias proporciona estabilidade e sustentação à molécula (Figura 1B) (PHELAN, 1999)

A cadeia pesada dobra-se em três domínios extracelulares ( $\alpha 1$, $\alpha 2$ e $\alpha 3)$ e é inserida na membrana celular por meio de uma sequência hidrofóbica, sendo seguida por uma região intracitoplasmática hidrofílica. Os domínios $\alpha 1$ e a2 interagem formando plataforma de oito alças beta pregueadas no topo das quais ocorrem duas a hélices, 
separadas por uma longa fenda, local de ligação ao antígeno processado. A extensão do domínio $\alpha 3$ se insere na membrana plasmática e se liga à cadeia $\beta$. A maior parte do polimorfismo dessas moléculas está situada nas $\alpha$-hélices e na porção da plataforma que forma a base da fenda (Figura 2) (ABBAS; LICTHMAN, 2012)

Figura 2 - Estrutura plana e modelo de fita de uma molécula HLA de classe I

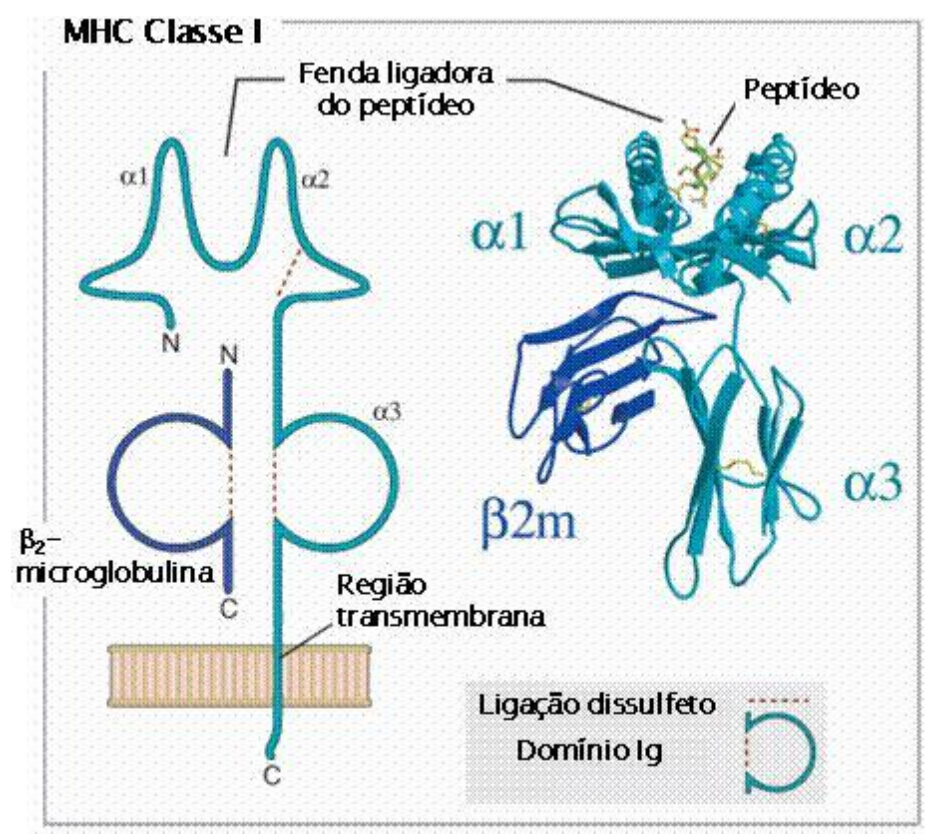

Adaptado de (ABBAS; LICHTMAN; POBER, 2003)

A cadeia pesada tem peso molecular de aproximadamente $45 \mathrm{KDa}$ e é composta por três domínios $\mathrm{N}$-terminais extracelulares de 90 aminoácidos cada, um segmento que atravessa a membrana hidrofóbica e um pequeno domínio C-terminal intracelular hidrofílico. O terceiro domínio, mais próximo da membrana, e a cadeia leve $\beta 2-$ microglobulina são altamente conservados. O peptídeo (em amarelo) fica encaixado na fenda, formada por duas cadeias a e um fundo de folhas beta ( ABBAS; LICTHMAN, 2012)

As moléculas de classe II possuem duas cadeias peptídicas, com pesos moleculares de $33 \mathrm{KDa}(\alpha)$ e $28 \mathrm{KDa}(\beta)$, inseridas na membrana plasmática por meio de regiões hidrofóbicas. As porções extracelulares dessas cadeias dobram-se em dois domínios: $\alpha 1$ e $\alpha 2$ ou $\beta 1$ e $\beta 2$ (Figura 3). Estruturalmente, a região de ligação de peptídeo da molécula HLA classe II possui abertura maior, tornando possível a ligação de peptídeo com 10 a 30 aminoácidos, enquanto que essa região da classe I consegue acomodar 
peptídeos de 9 a 11 resíduos de aminoácidos. Os resíduos polimórficos das moléculas HLA classe II estão concentrados nos segmentos $\alpha 1$ e $\beta 1$. As regiões formadas pelos segmentos $\alpha 2$ e $\beta 2$ apresentam homologia significativa com os domínios das regiões constantes das imunoglobulinas. Esses segmentos são pouco polimórficos entre os vários alelos do gene de classe II, mas mostram mais diferenças entre os diversos loci de classe II. Assim, a região $\alpha 2$ dos alelos DR é semelhante, porém DRa2 difere de DQa2 e de DPa2 (HOKAMA et al, 1997).

As moléculas MHC classe I e II reconhecem diferentes tipos de antígenos proteicos, intracelulares (peptídeos citosólicos) e extracelulares. As celulas T CD4+ reconhecem antígenos apresentados pelas moléculas HLA de classe II, enquanto que células CD8+ reconhecem antígenos que são apresentados pelas moléculas HLA de classe I (DONADI, 2000).

Figura 3 - Estrutura plana e modelo de fita do MHC de classe II

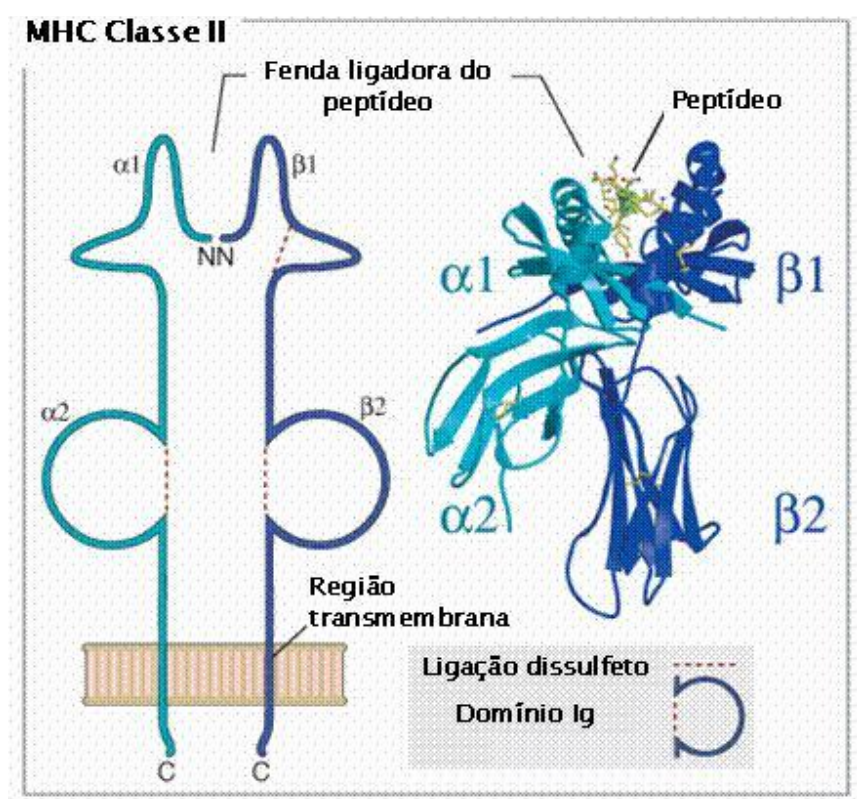

Adaptado de (ABBAS; LICHTMAN; POBER, 2003)

A função básica das moléculas HLA é promover o reconhecimento dos antígenos pelos linfócitos $T$, o que ocorre por duas vias distintas: a via citosólica e a via endossomal (FRAGA; NEUMANN, 1998). 
$\mathrm{Na}$ via citosólica, a molécula HLA classe I associa-se ao antígeno endógeno. Essa associação ocorre com o auxílio de três proteínas: a chaperonina, que mantém o complexo HLA estável até a ligação com a $\beta 2$ microglobulina; a TAP (Transporter of Associated Peptide, com seus alelos TAP1 e TAP2), que aproxima o antígeno da molécula HLA; e a LMP (Large Multipurpose Protease), cuja função é degradar as proteínas sintetizadas na célula em fragmentos constituídos por nove aminoácidos. As moléculas HLA classe I passam, então, a expressar, na superfície das células, peptídeos derivados do processamento de proteínas citosólicas. Se ocorrerem alterações nesses produtos do metabolismo, elas serão reconhecidas pelo sistema imune via linfócito T citotóxico (CD8+) (DONADI, 2000)

Na via endolítica, o antígeno exógeno, fagocitado pela célula e digerido por enzimas proteolíticas, origina diversos peptídeos que se associam às moléculas HLA classe II. O complexo formado migra para a superfície da célula onde é reconhecido pelo linfócito T helper (CD4+) (MARSH; PARHAM; BARBER, 2000)

Os receptores das células T reconhecem especificamente os peptídeos considerados como estranhos pelo organismo, e somente são capazes de reconhecer o self por meio das moléculas de HLA. Normalmente esse processo é selecionado pelo mecanismo de autotolerância, que consiste na deleção clonal, ainda no timo, de células $T$ autorreativas e na supressão de células $T$ e $B$ já maduras que porventura escapem à deleção na fase de maturação. A perda ou falha da capacidade de autotolerância se deve à regulação anormal da seleção de linfócitos autorreativos ou à apresentação anormal de antígenos ao sistema imune. Com isso, tem-se a expansão clonal desses linfócitos e a produção de autoanticorpos contra moléculas do self, podendo levar ao desenvolvimento de doenças autoimunes. (VON BOEHMER; TEH; P, 1989) 


\subsection{Sistema HNA}

Antígenos de neutrófilos humanos (HNAs) são moléculas imunogênicas, polimórficas, definidas geneticamente e expressas principalmente na superfície de neutrófilos, embora também possam ser expressas na superfície de outros tecidos. (BUX, J., 2008)

Estes antígenos são conhecidos desde a década de 60, quando Lalezari, descreveu o primeiro antígeno específico para granulócitos em um caso de neutropenia aloimune neonatal. (REIL et al., 2008)

Historicamente, anticorpos de granulócitos foram detectados em soros de pessoas que haviam recebido múltiplas tranfusões, mulheres após a gravidez, pacientes com neutropenia, pacientes com reações transfusionais febris e no sangue de doadores que causaram reações transfusionais pulmonares no receptor da transfusão. Até o momento já foram descritos cinco sistemas de antígenos HNA: HNA-1, -2, -3, -4 e -5, HNA-1d (BUX, J., 2008).

A nomenclatura dos antígenos HNA-1, -2, -3, -4 e -5 baseia-se nas glicoproteínas que os caracterizam, ou seja, CD16b, CD177, CTL2, CD11b/18 (Mac-1) e CD11a/18 (LFA1), respectivamente. Diferentes polimorfismos da mesma glicoproteína são designados alfabeticamente, em ordem sequencial de detecção, e a nomenclatura dos alelos é determinada de acordo com as Diretrizes do Workshop Internacional sobre Mapeamento do Genoma Humano. (BUX, J., 2008)

\subsubsection{HNA-1}

Esse sistema é o mais bem caracterizado na literatura. O HNA-1 possui três alelos, codificando as proteínas HNA-1a, -1b e -1c. Os antígenos HNA-1a e -1b foram os primeiros descritos em casos de neutropenia neonatal aloimune. Inicialmente chamado de antígeno $\mathrm{SH}$, o agora chamado de HNA-1c, foi o terceiro a ser descrito. (REIL et al., 2008)

O HNA-1 foi localizado no receptor Fcylllb (FcyRIIIb) que pertence à superfamília das imunoglobulinas, possuindo dois domínios extracelulares semelhantes à estrutura da imunoglobulina $\mathrm{G}(\mathrm{lg} \mathrm{G})$ e uma ponte dissulfeto. O FcyRIIlb é uma proteína fortemente 
glicosilada com diferentes pesos moleculares relativos de 50-65 $\mathrm{kDa}$ para as isoformas HNA-1a e 65-80 kDa para as isoformas HNA-1b. (BUX, J., 2008)

A FcyRlllb é uma glicoproteína transportadora e da mesma forma que os antígenos HNA-1 são exclusivamente expressas por neutrófilos, possuindo cerca de 100.000 a 400.000 cópias por célula. O FcyRIllb é expresso em neutrófilos maduros a partir do estágio metamielócito, sendo receptor de baixa afinidade para lgG1 e lgG3. (BUX, J., 2008)

Trinta por cento dos autoanticorpos antigranulócitos ligam-se ao FcyRIIIb com ligação preferencial à forma polimórfica do HNA-1a. Em casos de neutropenia imune induzida por drogas, o FcyRlllb pode estar implicado na formação de neoantígenos induzidos por drogas e reconhecidos por anticorpos. Os anticorpos dirigidos contra esses antígenos podem causar neutropenia neonatal aloimune e TRALI, no entanto, parecem não afetar o enxerto e a recuperação de neutrófilos em receptores aloimunizados de transplantes de medula óssea. (BUX, J., 2008; CURTIS; MCFARLAND, 2006; REIL et al., 2008)

\subsubsection{HNA-2}

Também descrito por Lalezari e colaboradores em 1971, o antígeno HNA-2 foi descrito como o antígeno específico de neutrófilos 'NB1'. (LALEZARI; MURPHY; ALLEN, 1971) O HNA-2 tem sua expressão apenas em uma subpopulação de neutrófilos. (BUX, J., 2008)

O HNA-2 é considerado antígeno de alta frequência em africanos, asiáticos e brancos, estando presente em mais de noventa porcento dos indivíduos estudados. (BUX, J., 2008)

HNA-2 tem sido caracterizado como uma glicoproteína de 56 a 64-kDa com uma contribuição de $7 \mathrm{kDa}$ de açúcares $\mathrm{N}$-ligados. Os anticorpos monoclonais dirigidos contra o HNA-2 foram agrupados como CD177. A glicoproteína possui dois domínios ricos em Cisteína e três sítios de glicosilação $\mathrm{N}$-ligados. A homologia dos domínios ricos em Cisteína sugere que CD177 pertence à família de proteínas Ly-6/uPAR/toxina de cobra. (KISSEL et al., 2002; REIL et al., 2008) 


\subsubsection{HNA-3}

Estudos citogenéticos indicam que o antígeno HNA-3a seja produto de um gene localizado no cromossomo 4. Antígenos do sistema HNA-3 (3a e 3b, antigos 5a e 5b) estão localizados em proteína transportadora de colina-like (CTL2), uma proteína transmembrana codificada pelo gene SLC44A2 no cromossomo 19p13.1 (BERTHOLD et al., 2015; GREINACHER et al., 2010)

HNA-3A e HNA-3B se diferenciam por polimorfismo único nucleotídeo (single nucletide polymorphism - SNP) (G461A), trocando uma Arginina por uma Glutamina na posição 154 da proteína. (CURTIS; MCFARLAND, 2006)

Presente em quase todos os grupos populacionais, o antígeno HNA-3a é expresso em linfócitos $B$, linfócitos $T$, neutrófilos e plaquetas, sendo antígeno de alta frequência, variando de 89 a 96\%. (DE HAAS et al., 2000; GREINACHER et al., 2010) Moritz e colaboradores encontraram no Brasil uma frequência de 95\% de HNA-3a entre doadores de sangue hígidos (MORITZ et al., 2009)

Anticorpos anti-HNA-3 já foram relatados como estando envolvidos na reação transfusional febril, neutropenia imune neonatal e em casos graves de TRALI, o que provavelmente é o resultado da capacidade de imunização dos neutrófilos para a produção de espécies reativas de oxigênio (KOPKO, P. M. et al., 2002; REIL et al., 2008).

\subsubsection{HNA-4 e HNA-5}

HNA-4 e HNA-5 são partes das subunidades da integrina aM (CD11b) e aL (CD11a) respectivamente, as quais formam heterodímeros com a subunidade $\beta 2$ da integrina (CD18). HNA-4 é codificado pelo gene ITGAM e HNA-5 pelo gene ITGAL, ambos localizados no cromossomo 16p11.2. A aM/ß2-37 integrina é uma proteína transmembrana expressa na superfície de neutrófilos, monócitos, células NK e leucócitos e está envolvida na adesão, transmigração, fagocitose e citotoxicidade (MORITZ et al., 2009; REIL et al., 2008)

A maioria da população é positiva para HNA-4a e somente uma pequena parte da população expressa o antígeno HNA-4b. A diferença entre os antígenos é causada por uma única variação nucleotídica na posição 230 do gene, o que causa a troca de 
uma Arginina por uma Histidina na proteína. O gene ITGAL codifica os antígenos HNA-5, consiste de duas isoformas de 5226 pb (31 exons) e 4974 pb (29 exons), respectivamente. A diferença entre os antígenos codificados pelos genes $H N A-5 A$ e HNA-5B é causada por uma mutação na posição 791 (exon 21, isoforma 1) ou posição 707 (exon 19, isoforma 2). A maioria da população, cerca de $85 \%$, é positiva para HNA-5a, enquanto aproximadamente $25 \%$ expressa o antígeno HNA-5b (MORITZ et al., 2009; SACHS, ULRICH J.H.; KAUSCHAT; BEIN, 2005; XIA et al., 2011)

\subsection{TRALI}

Descrita pela primeira vez em 1983 por Popovisk e colaboradores, a TRALI foi reconhecida como entidade clínica após estudo que descreveu uma serie de 36 pacientes com a condição. (POPOVSKY, M. A.; ABEL; MOORE, 1983; POPOVSKY, M.; MOORE, 1985)

A síndrome é caracterizada por insuficiência respiratória aguda, edema pulmonar bilateral e hipoxia grave com pressão parcial de oxigénio no sangue arterial/fração inspirada de oxigénio $<300 \mathrm{mmHg}$, ocorrendo durante ou dentro das 6 horas, após a transfusão (BUX, 2005).

\subsubsection{Epidemiologia}

Nos Estados Unidos e Reino Unido, TRALI é considerada a principal causa de morbidade e mortalidade relacionadas à transfusão. (BOLTON-MAGGS; COHEN, 2013; BUX, JÜRGEN, 2005; LUCAS et al., 2012)

A incidência de TRALI varia entre os países devido a dificuldades em diagnosticar a reação e de realizar o diagnóstico diferencial de doenças que se assemelham clinicamente. Os relatos históricos sugerem que a TRALI ocorra a uma taxa de 0,40 a $0,1 \%$ dos pacientes transfundidos, mas apresentando diminuição da sua incidência devido à instituição de estratégias de mitigação dos riscos. (FUNG; SILLIMAN, 2009; POPOVSKY, M.; MOORE, 1985) 
Estudo de caso-controle realizado pela Universidade da Califórnia em 2009, a incidência relatada de TRALI caiu de 1: 3.891 por unidade em 2006 para 1: 12.345 por unidade. (TOY et al., 2012) Um relatório da Rede Internacional de Hemovigilância, que compila dados de sete países (Austrália, Tailândia, Grécia, Dinamarca, Holanda, França e Canadá) sobre todas as reações transfusionais, mostrou uma taxa de mortalidade TRALI de 0,49 por 100.000 hemocomponentes transfundidos. (POLITIS et al., 2016)

\subsubsection{Fisiopatologia}

Embora tenha sido descrita pela primeira vez na década de 80 , a fisiopatologia da TRALI ainda não está completamente elucidada. Vários mecanismos já foram propostos para explicar a reação, no entanto, dois deles são os mais aceitos atualmente. O primeiro deles explica a gênese da TRALI apresentando origem imunológica, na qual ocorre ativação de neutrófilos pela infusão de aloanticorpos antiHLA e anti-HNA, presentes no hemocomponente transfundido. (CURTIS; MCFARLAND, 2006; REIL et al., 2008)

Embora ocorra a participação de aloanticorpos na maioria dos casos, em cerca de 10 a 39\% dos casos de TRALI não são encontrados anticorpos dirigidos contra antígenos leucocitários no doador ou no receptor. Nesses casos, a reação teria mecanismos não imunológicos, nos quais as moléculas inflamatórias liberadas durante a estocagem dos hemocomponentes seriam as responsáveis pelo início do processo. (SACHS, U. J. H., 2007)

Tanto para os mecanismos imunológicos como nos não imunológicos, é proposto um modelo de duas etapas para explicar a fisiopatologia da TRALI (BENSON, 2012) Nesse modelo, chamado de "two Hints" teríamos, primeiramente, uma etapa inicial que dependeria da condição clínica do paciente, incluindo trauma, cirurgias, câncer, infecção grave ou inflamação, ou qualquer condição que curse com a produção de mediadores inflamatórios capazes de ativar o endotélio pulmonar. A presença de anticorpos antineutrófilos associada com a liberação de fatores pró-inflamtórios promove o sequestro dos neutrófilos no pulmão, por meio da ligação de moléculas de adesão entre neutrófilos e epitélio pulmonar(Figura 4). De forma análoga, a presença 
inicial de anticorpos antineutrófilos pode liberar mediadores inflamatórios, propiciando a mesma cadeia de eventos pulmonares. (BUX, JÜRGEN; SACHS, 2007; FUNG; SILLIMAN, 2009; OTROCK; LIU; GROSSMAN, 2017)

O sequestro dos neutrófilos ocorre por intermédio das moléculas de adesão que diminuem a velocidade dos neutrófilos nos vasos capilares, particularmente, as Pselectinas e E-selectinas, que participam da adesão das células ao endotélio. $O$ processo de rolamento dos neutrófilos, ao reduzir a velocidade deles nos capilares, os aproxima da parede do vaso e potencializa a ação das moléculas de adesão. Os neutrófilos tornam-se firmemente aderidos pela interação da molécula $\beta 2$-integrina e a Molécula de Adesão Celular - 1 (ICAM-1), presente no endotélio. Ligados ao endotélio pulmonar, os neutrófilos estão sob a ação de citocinas inflamatórias capazes de ativá-los. (FUNG; SILLIMAN, 2009) 
Figura 4 - Mecanismos de desencadeamento da TRALI com o envolvimento de polimorfonucleares (PMNs) e anticorpos anti-HLA/HNA

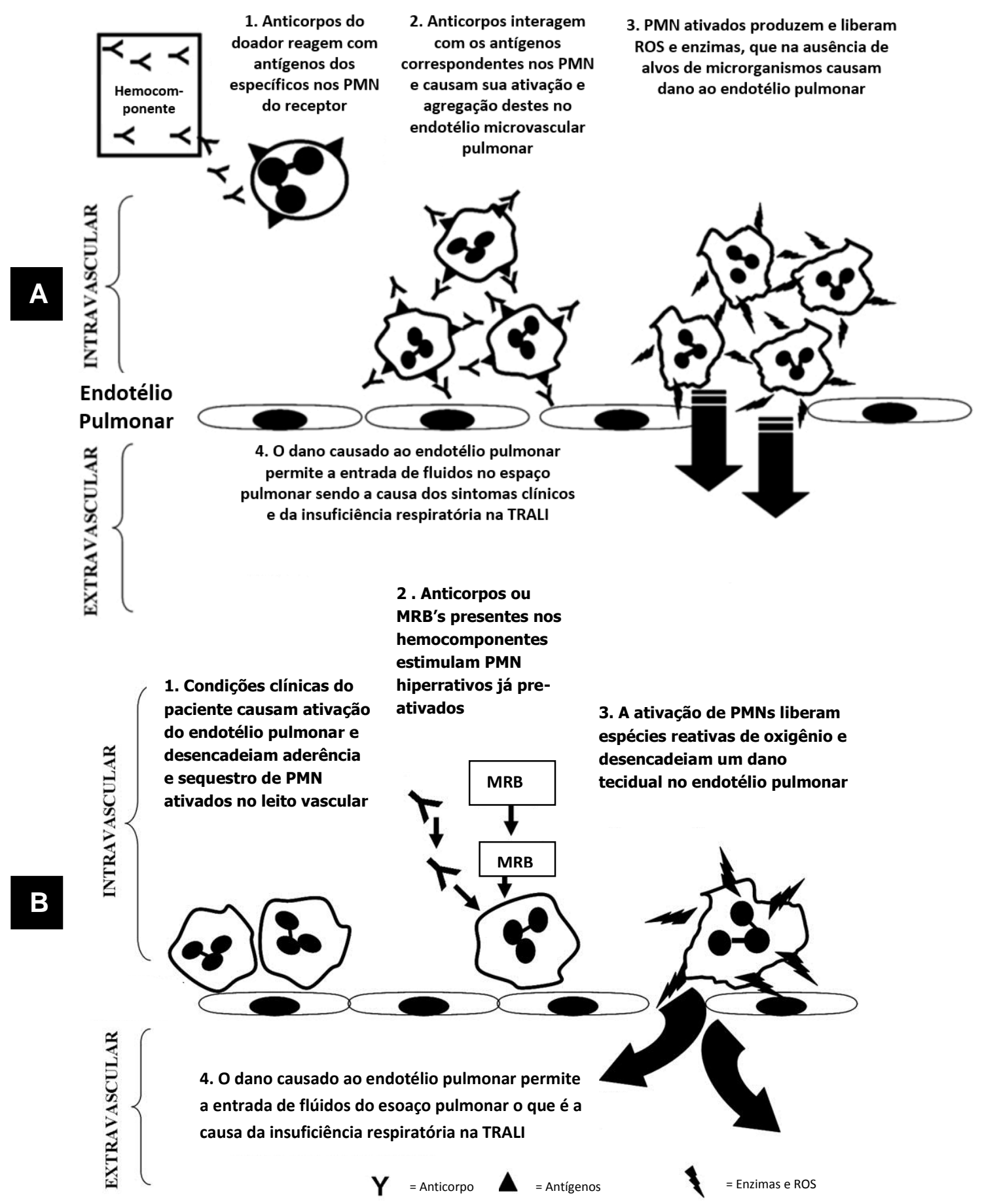

(Adaptado de Fung \& Silliman, 2009) 
Anticorpos do doador reagem com antígenos específicos nos PMNs do receptor e causam sua ativação e agregação no endotélio microvascular pulmonar. PMNs ativados produzem e liberam ROS e enzimas, que na ausência de alvos de microrganismos causam danos ao endotélio pulmonar, permitindo a entrada de fluidos no espaço pulmonar, propiciando o desenvolvimento da insuficiência respiratória na TRALI. (FUNG; SILLIMAN, 2009)

Resumindo, a primeira etapa ocorre por intermédio da reação mediada por anticorpos/mediadores solúveis e a outra ativada por mediadores solúveis/anticorpos. Ambos os mecanismos envolvem a ativação de granulócitos e o desencadeamento do processo inflamatório que leva ao sequestro de neutrófilos polimorfonucleares (PMN) no pulmão. ( FUNG; SILLIMAN, 2009; VLAAR; ERMANS, 2013)

\subsubsection{Quadro Clínico}

Embora os sintomas geralmente iniciem dentro de 1 a 2 horas após a transfusão, alguns pacientes podem desenvolver dispneia até 48 horas após a transfusão, chamada TRALI atípica. (ZUPANSKA; UHRYNOWSKA; KONOPKA, 1999)

O quadro clínico de TRALI se caracteriza por dificuldade respiratória que surge durante ou nas 6 horas após a transfusão de hemocomponentes que contenham alto volume de plasma, como transfusão de sangue total, de plasma fresco congelado ou de concentrado de plaquetas. (JUNIOR; LOPES, 2007)

O exame radiológico tem bastante importância e pode evidenciar mais achados do que o exame clínico, mostrando infiltrados pulmonares bilaterais, compatíveis com edema pulmonar. As radiografias podem ser irregulares nas primeiras horas, com progressão dos infiltrados alveolares e intersticiais, de tal forma que pode haver aparência esbranquiçada do pulmão inteiro. A forma fulminante de TRALI é indistinguível da síndrome do desconforto respiratório agudo (SDRA), que não está relacionada com a transfusão. No entanto, ao contrário da SDRA que tem alta mortalidade, a lesão na TRALI é, na maioria dos casos, transitória e mostra regressão do infiltrado radiológico em 96 horas em $81 \%$ dos pacientes afetados. (POPOVSKY, M.; MOORE, 1985) 
Figura 5 - Radiografia de tórax de paciente antes e depois da transfusão de paciente com caso de TRALI
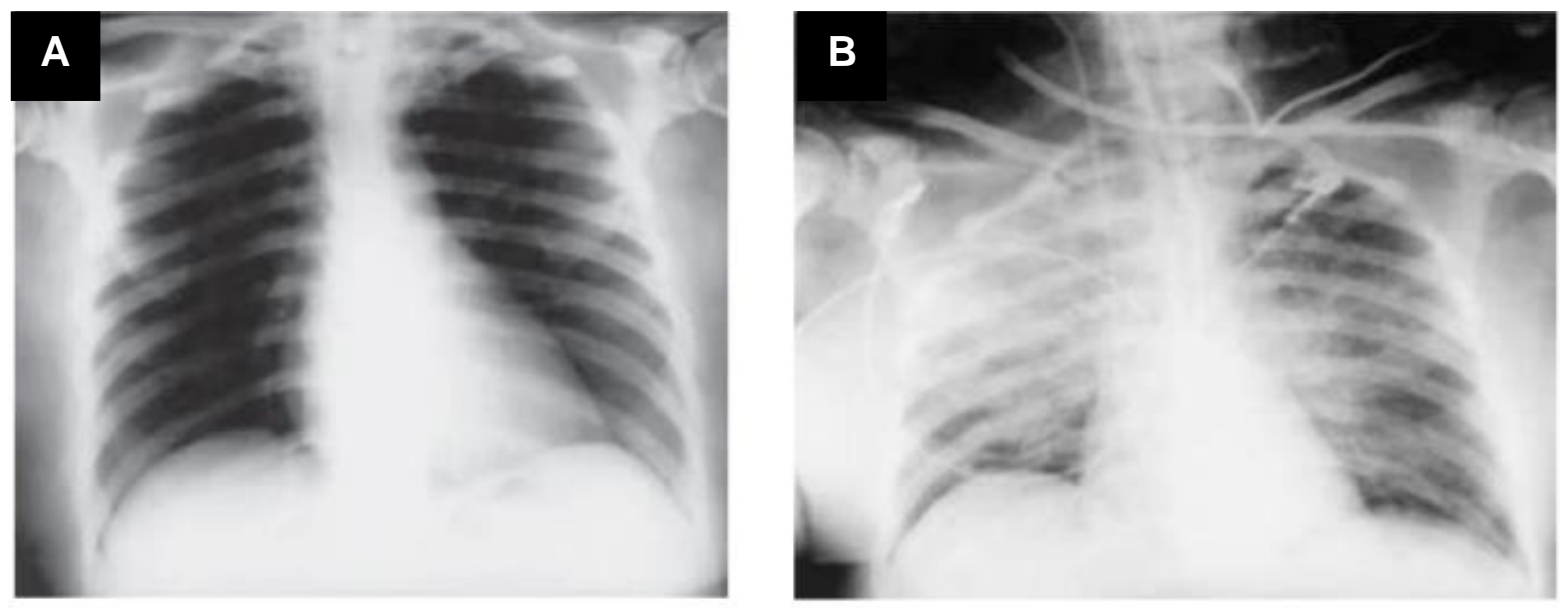

(Adaptado de Fabron, 2007)

A figura 5A, mostra imagem radiogrpafica de pulmão sem infiltrado aparente de um pacientes antes da transfusão. A figura 5B mostra radriografia com intenso infiltrado pulmonar bilateral e edema de pulmão.

Tabela 1 - Características clínicas da lesão pulmonar aguda relacionada à transfusão

\begin{tabular}{ll}
\hline SINAIS E SINTOMAS & FREQUÉNCIA \\
\hline Sofrimento respiratório & Muito frequente \\
Hipoxemia & Muito frequente \\
Infiltrações pulmonares bilaterais na radiografia de tórax & Muito frequente \\
Hipotensão & Comum \\
Febre & Comum \\
Hipertensão & Incomum \\
Ocorrência $>$ h h após o início da transfusão & Incomum \\
\hline & (POPOVSKY, M.; MOORE, 1985)
\end{tabular}




\subsubsection{Diagnóstico Laboratorial}

A disfunção pulmonar é achado inespecífico, portanto a TRALI é diagnóstico de exclusão e depende de alto grau de suspeição. Além disso, não há teste rápido que seja conclusivo para o diagnóstico. (MORITZ et al., 2009) O diagnóstico da TRALI pode ser confundido clinicamente com a SDRA, como já explicitado. (JUNIOR; LOPES; BORDIN, 2007)

Informações dos doadores para Hemovigilância são extremamente importantes para identificar os doadores que porventura estejam implicados na reação por terem sido doadores de algum hemocomponente utilizado pelo paciente, no entanto, em alguns casos, isso pode ser complexo, uma vez que podem estar envolvidos diversos doadores simultaneamente quando, por exemplo, temos um evento desencadeado pela infusão de pool de hemocomponentes.

As amostras de todos os doadores implicados na reação devem ser testadas para a presença de aloanticorpos. (REIL et al., 2008)

Atualmente, a pesquisa de aloanticorpos tem sido realizada, utilizando-se amostras de soro ou plasma fresco, por meio de testes imunoenzimáticos, imunofluorescência de linfócitos ou por citometria de fluxo, utilizando beads, como proposto no presente trabalho. (JUNIOR; LOPES, 2007; REIL et al., 2008)

O diagnóstico definitivo de TRALI induzido por mecanismo imunológico é confirmado quando existe concordância entre os anticorpos detectados no doador com os antígenos de linfócitos e/ou granulócitos do receptor. Quando essa concordância não acontece, somente a presença do aloanticorpo no soro do doador significa evidência importante de TRALI. Devido aos mecanismos não imunes responsáveis pelo desencadeamento da TRALI, não é possível excluir a ocorrência da reação quando não existe a prova cruzada positiva ou quando não são encontrados aloanticorpos no doador. (BUX, JÜRGEN, 2005; LOPES et al., 2010) 


\subsubsection{Tratamento}

O tratamento para a TRALI é prioritariamente de suporte. Embora completamente sem consenso, a manutenção do equilíbrio hemodinâmico e o suporte ventilatório precoce são as principais estratégias. Os casos mais graves, que perfazem cerca de $70 \%$ dos pacientes acometidos, podem demandar intubação orotraqueal com ventilação mecânica. Já para os casos moderados, somente o suporte com oxigênio é suficiente. (BUX, JÜRGEN, 2005; POPOVSKY, M. A., 2008)

A hipotensão pode ser tratada com uso de medicamentos vasopressores. (BUX, JÜRGEN, 2005) O uso de medicamentos diuréticos é controverso, pois como alguns pacientes são beneficiados com a infusão de fluidos, o uso desses medicamentos pode tornar-se prejudicial. A utilização de anti-inflamatórios não esteroides, corticosteroides, surfactantes e outros, não apresentam os mesmos resultados já conhecidos para SDRA. (BUX, JÜRGEN, 2005; JUNIOR; LOPES; BORDIN, 2007)

A TRALI apesar de grave e ter mortalidade de 5 a $10 \%$ dos casos, chegando a cerca de $47 \%$ em populações com comorbidades, muitos pacientes têm expressiva melhora do quadro de 48 a 96 horas após o início dos sintomas. Em cerca de $80 \%$ dos pacientes, ocorre resolução do infiltrado pulmonar de 24 a 96 horas, apesar de que a hipoxemia e o infiltrado pulmonar podem persistir por mais de 7 dias em alguns casos. (TSALIS et al., 2005)

\subsubsection{Prevenção e medidas de mitigação de risco de TRALI}

As estratégias para reduzir o risco para TRALI concentraram-se principalmente na TRALI mediada por anticorpos. Já foi demonstrada, em vários estudos, a relação entre hemocomponentes, principalmente plasmáticos de mulheres doadoras, contendo anticorpos, como fator de risco para TRALI. (BUX, JÜRGEN, 2005; DE CLIPPEL et al., 2014; TRIULZI et al., 2009)

Assim, a estratégia mais comum utilizada pelos bancos de sangue para mitigação do risco para TRALI é a utilização de plasma e sangue total de doadores do sexo 
masculino, ou doadoras nuligestas dos grupos A, B e O (OTROCK; LIU; GROSSMAN, 2017)

\author{
A tabela abaixo mostra compilado das estratégias utilizadas para redução do risco \\ de TRALI em diferentes centros:
}

Tabela 2 - Estratégias de redução do risco de TRALI empregadas em diferentes países

\begin{tabular}{|c|c|c|c|c|}
\hline REFERÊNCIAS & PAÍS & PERÍODO & ESTRATÉGIA & EFEITO NO RISCO TRALI \\
\hline $\begin{array}{l}\text { (WRIGHT et al., } \\
\text { 2008) }\end{array}$ & $\begin{array}{l}\text { Reino } \\
\text { Unido }\end{array}$ & $\begin{array}{l}1998- \\
2006\end{array}$ & $\begin{array}{l}\text { Plasma masculino } \\
\text { apenas para PLQ, } \\
\text { PFC e PLQ por BC }\end{array}$ & $\downarrow$ LPA por paciente: OR $0,39(0,16-0,9)$ \\
\hline $\begin{array}{l}\text { (CHAPMAN et } \\
\text { al., 2009) }\end{array}$ & $\begin{array}{l}\text { Reino } \\
\text { Unido }\end{array}$ & $\begin{array}{l}1996- \\
2006\end{array}$ & $\begin{array}{l}\text { Plasma masculino } \\
\text { apenas para PLQ, } \\
\text { PFC e PLQ por BC }\end{array}$ & $\begin{array}{c}\downarrow \text { TRALI: de } 15,5 \text { para } 3,2 \text { por milhão de } \\
\text { unidades para PFC }(P=0,0079) \text {; de } 14 \\
\text { para } 5,8 \text { por milhão de unidades para } \\
\text { Plaquetas }(P=0,068)\end{array}$ \\
\hline $\begin{array}{l}\text { (IIJIMA et al., } \\
\text { 2009) }\end{array}$ & Japão & $\begin{array}{l}2007- \\
2008\end{array}$ & $\begin{array}{l}\text { Doador de plasma } \\
\text { apenas masculino }\end{array}$ & $\begin{array}{l}\downarrow \text { Desconforto Respiratório por paciente: } \\
\text { OR } 0,219(0,06-0,8), P=0,022\end{array}$ \\
\hline $\begin{array}{l}\text { (EDER et al., } \\
\text { 2010) }\end{array}$ & $\begin{array}{l}\text { Estados } \\
\text { Unidos }\end{array}$ & $\begin{array}{l}2006- \\
2008\end{array}$ & $\begin{array}{l}\text { Doador de plasma } \\
\text { apenas masculino }\end{array}$ & $\begin{array}{c}\downarrow \text { TRALI por transfusão: OR } 0,21(0,08- \\
0,45), P<0,05\end{array}$ \\
\hline $\begin{array}{l}\text { (VLAAR et al. } \\
\text { 2010) }\end{array}$ & A Holanda & $\begin{array}{l}2004- \\
2007\end{array}$ & $\begin{array}{l}\text { Doador de plasma } \\
\text { apenas masculino }\end{array}$ & $\begin{array}{c}\downarrow \text { TRALI por unidade: RR } 0,35(0,14- \\
0,88), P<0,03\end{array}$ \\
\hline $\begin{array}{l}\text { (WIERSUM- } \\
\text { OSSELTON et } \\
\text { al., 2011) }\end{array}$ & A Holanda & $\begin{array}{c}2002- \\
2009\end{array}$ & $\begin{array}{l}\text { Doador de plasma } \\
\text { apenas masculino }\end{array}$ & $\begin{array}{c}\downarrow \text { TRALI por transfusão: Fração Atribuível } \\
\text { Populacional 0,33 }(0,09-0,51)\end{array}$ \\
\hline $\begin{array}{l}\text { (ARINSBURG et } \\
\text { al., 2012) }\end{array}$ & $\begin{array}{l}\text { Estados } \\
\text { Unidos }\end{array}$ & $\begin{array}{l}2005- \\
2008\end{array}$ & $\begin{array}{l}\text { Doador de plasma } \\
\text { apenas masculino }\end{array}$ & $\begin{array}{c}\text { Incidência de TRALI } \downarrow \text { de } 0,0084 \% \text { a zero } \\
\text { por transfusão para PFC }(P=0,052)\end{array}$ \\
\hline $\begin{array}{l}\text { (FUNK et al., } \\
\text { 2012) }\end{array}$ & Alemanha & $2006-2010$ & $\begin{array}{l}\text { Doador de Plasma } \\
\text { Masculino e/ou } \\
\text { mulheres sem } \\
\text { gravidez ou anti- } \\
\text { HLA/HNA }\end{array}$ & $\begin{array}{c}\downarrow \text { TRALI por unidade: OR } 0,06(0,01- \\
0,41)\end{array}$ \\
\hline $\begin{array}{l}\text { (LIN et al., } \\
\text { 2012) }\end{array}$ & Canadá & $2001-2009$ & $\begin{array}{l}\text { Doador de plasma } \\
\text { apenas masculino }\end{array}$ & $\downarrow$ nos casos relatados TRALI \\
\hline $\begin{array}{l}\text { (TOY et al., } \\
\text { 2012) }\end{array}$ & $\begin{array}{l}\text { Estados } \\
\text { Unidos }\end{array}$ & $\begin{array}{l}2006- \\
2009\end{array}$ & $\begin{array}{l}\text { Doador de plasma } \\
\text { apenas do sexo } \\
\text { masculino e PLQ } \\
\text { predominantemente } \\
\text { do sexo masculino }\end{array}$ & $\begin{array}{c}\text { Incidência de TRALI } \downarrow \text { de } 0,0257 \% \text { a } \\
0,0081 \% \text { por unidade }(P=0,002)\end{array}$ \\
\hline $\begin{array}{l}\text { (CLIFFORD et } \\
\text { al., 2015) }\end{array}$ & $\begin{array}{l}\text { Estados } \\
\text { Unidos }\end{array}$ & $\begin{array}{l}2004 \text { e } \\
2011\end{array}$ & $\begin{array}{l}\text { Doador de plasma } \\
\text { apenas masculino }\end{array}$ & $\begin{array}{c}\text { Não houve diferença significante na } \\
\text { diminuição da TRALI }\end{array}$ \\
\hline
\end{tabular}

PLQ - Plaquetas, BC - Buffy coat, PFC - Plasma Fresco Congelado, RR - Risco Relativo, OR - Odds Ratio 
Fica evidente que as estratégias do uso exclusivo de hemocomponentes com conteúdo plasmático somente de doadores do sexo masculino ou de mulheres sem histórico de gestações se mostra robusta para a diminuição dos casos de TRALI.

Tabela 3 - Risco relativo de desenvolvimento de TRALI para diferentes hemocomponentes em estudos prévios

\begin{tabular}{|c|c|c|c|c|c|c|c|}
\hline Autor (país) & Período & PFC & $\begin{array}{c}\text { Plaquetas } \\
\text { Randômicas }\end{array}$ & $\begin{array}{l}\text { Plaquetas } \\
\text { por aférese }\end{array}$ & CRIO & $\mathrm{CH}$ & Todos \\
\hline $\begin{array}{c}\text { (FUNG; SILLIMAN, } \\
\text { 2009) } \\
\text { Pacientes } \\
\text { Canadenses }\end{array}$ & $\begin{array}{l}1991- \\
1995\end{array}$ & $1: 19,411$ & $1: 432$ & $1: 1,224$ & - & $1: 4,410$ & $1: 1,120$ \\
\hline $\begin{array}{l}\text { (POPOVSKY, M.; } \\
\text { CHAPLIN; } \\
\text { MOORE, 1992) } \\
\text { (EUA) }\end{array}$ & $\begin{array}{c}\text { Meados } \\
\text { dos anos } \\
80\end{array}$ & - & - & - & - & - & $\sim 1: 5,000$ \\
\hline $\begin{array}{l}\text { (KOPKO, P. M. et } \\
\text { al., 2002) (EUA) }\end{array}$ & $\begin{array}{l}2001- \\
2003\end{array}$ & - & - & - & - & - & $\sim 1: 25,000$ \\
\hline $\begin{array}{c}\text { Hemovigilância } \\
\text { de Quebec } \\
\text { (Canadá) (GOLDM } \\
\text { AN et al., 2005) }\end{array}$ & $\begin{array}{l}2000- \\
2003\end{array}$ & $1: 61,006$ & $1: 9,306$ & - & $1: 25,073$ & $1: 58,279$ & - \\
\hline $\begin{array}{c}\text { SHOT (BOLTON- } \\
\text { MAGGS; COHEN, } \\
\text { 2013) } \\
\text { (Reino Unido) }\end{array}$ & $\begin{array}{l}1996- \\
2002\end{array}$ & $1: 74,000$ & \multicolumn{2}{|c|}{$1: 88,000$} & $1: 500,000$ & $1: 557,000$ & - \\
\hline $\begin{array}{l}\text { (WALLIS et al., } \\
\text { 2003) Reino } \\
\text { Unido) }\end{array}$ & $\begin{array}{l}1991- \\
2002\end{array}$ & $1: 7,896$ & - & - & - & - & - \\
\hline $\begin{array}{l}\text { (SILLIMAN et al., } \\
\text { 1997) (EUA) }\end{array}$ & $\begin{array}{c}\text { Início dos } \\
\text { anos } 90\end{array}$ & - & - & - & - & - & $1: 2,000$ \\
\hline
\end{tabular}

Adaptado de (KLEINMAN et al., 2004) 


\subsection{Pesquisa de anticorpos anti-HLA/HNA}

Testes de triagem para anticorpos leucocitários tem extrema importância para os transplantes de órgãos e vem se tornando também importante para a prática hemoterápica.

As primeiras detecções de anticorpos antileucócitos tinham como objetivo a viabilização dos transplantes de órgãos, o que restringia a busca, no primeiro momento aos anticorpos anti-HLA. O primeiro método para detecção de anticorpos anti-HLA foi realizado pela técnica de CDC clássico, também denominado CDC-NIH (do inglês, Complement Dependent Cytotoxicity-National Institute of Health). Esse ensaio se baseia na incubação de linfócitos do doador com soro do receptor, seguida de adição de complemento de coelho e posterior verificação da lise celular por meio de corantes vitais com leitura da reação em microscópio óptico.

Mais recentemente, foram desenvolvidos ensaios de fase sólida, tais como o teste PRA-ELISA (do inglês, Panel Reactive Antibodies by Enzyme-Linked Immuno Sorbent Assay). O ensaio de PRA-ELISA baseia-se na utilização de moléculas HLA solúveis aderidas em placas. Para a realização desse ensaio, são utilizados anticorpos secundários que podem detectar anticorpos do isotipo $\operatorname{lgM}$ ou lgG, além de permitir a diferenciação de anticorpos anti-HLA de classe I ou II

O padrão ouro atual na triagem de anticorpos de granulócitos é uma combinação do teste de imunofluorescência de granulócitos (GIFT) e teste de aglutinação de granulócitos (GAT) com células previamente tipificadas, como recentemente relatado pelo Grupo Internacional de Imunologia de Granulócitos (LOPES, 2010).

Atualmente, o método mais usado para detecção de anticorpos anti-HLA/HNA é baseado em microesferas fluorescentes com a tecnologia Luminex devido a sua alta sensibilidade e especificidade, especialmente para detecção de anticorpos mesmo que em baixos títulos. (DE CLIPPEL et al., 2014) Trata-se de ferramenta para triagem de anticorpos contra antígenos HLA e HNA. Utiliza microesferas revestidas com 
antígenos purificados HLA de classe I e II, antígenos HNA e reagentes pré-otimizados para detecção de anticorpos HLA/HNA. (Fromont et al., 2010). 
- A identificação de anticorpos HLA/HNA pode ser utilizada no controle de qualidade de hemocomponentes para traçar perfil de risco de aloimunização leucocitária e TRALI;

- A partir da avaliação do perfil de anticorpos leucocitários pode ser possível determinar estratégia mais flexível para o uso de hemocomponentes plasmáticos introduzindo, porventura, a utilização de hemocomponentes de doadoras de sangue não multigestas. 
4 JUSTIFICATIVA |

A Fundação Hemominas utiliza protocolo de mitigação de TRALI definido pela AABB. Nesse protocolo, são utilizados somente plasmas de doadores do sexo masculino. (AABB, 2014)

Embora esse procedimento já venha sendo utilizado em diversos Hemocentros do Brasil e do mundo, especificamente, para a população de doadores do Hemominas, não havia ainda sido avaliada a frequência de anticorpos anti HLA/HNA. É sabido que tal informação é importante para que, não só a estratégia em uso possa ser avaliada, bem como seja possível vislumbrar panorama em relação à presença dos anticorpos reponsáveis pelo desenvolvimento da TRALI nos doadores que estão sendo utilizados, e nas doadoras que, atualmente têm tido seus hemocomponentes enviados para a produção industrial.

Considerando a gravidade da TRALI e a importância dos anticorpos anti-HLA/HNA na patogenia dessa síndrome, o presente estudo se propõe avaliar o panorama da presença ou não de anticorpos anti-HLA/HNA em doadores de hemocomponentes plasmáticos da Fundação Hemominas com foco a dar subsídio para a implantação de estratégias de prevenção da TRALI e definição de possível protocolo de rejeição seletiva de doadoras do sexo feminino que poderia ser utilizado em situações contingenciais, quando a estratégia de exclusão absoluta vier a impactar a manutenção da disponibilidade de hemocomponentes. 


\subsection{Objetivo Geral}

Avaliar a presença de anticorpos leucocitários em hemocomponentes para subsidiar estratégias de mitigação de risco de TRALI na prática hemoterápica

\subsection{Objetivos específicos}

- Avaliar a frequência de anticorpos antileucocitários (anti-HLA/HNA) em amostra selecionada de doadores de sangue da Fundação Hemominas;

- Avaliar a frequência de anticorpos antileucocitários (anti-HLA/HNA) em amostras estratificadas segundo o gênero e número de gestações;

- Correlacionar o número de gestações com a frequência de anticorpos antileucocitários (anti-HLA/HNA);

- Definir ponto de corte para o risco aumentado da presença de anticorpos antleucocitários (anti-HLA/HNA) de acordo com histórico gestacional. 
6 METODOLOGIA

\subsection{Casuística}

Integraram o estudo de caráter prospectivo experimental 190 doadores de sangue da Fundação Hemominas. Os doadores foram divididos em cinco grupos de acordo com o gênero e número de gestações, no caso das mulheres. Integraram os grupos 50 doadores do sexo masculino e 140 mulheres (50 nuligestas, 30 com histórico de uma gestação, 30 com duas gestações e 30 com três ou mais gestações).

Foram selecionadas amostras de hemocomponentes, processados na Fundação Hemominas, colhidas dos doadores e doadoras que apresentavam sorologias negativas para agentes infecciosos (HBV, HCV, HIV 1/2, HTLVI/II, Tripanossoma cruzi, Treponema pallidum,) e sem histórico de transfusão de hemocomponentes. Os tamanhos amostrais foram definidos pautados na quantidade de doadores que puderam ser coletados e na disponibilidade dos insumos para a realização dos testes, dado que os kits foram recebidos em doação. Assim sendo, foram recrutadas doadoras e doadores até que completassem o demandado para cada grupo.

As coletas de dados e amostras foram autorizadas pelo Comitê de Ética em Pesquisa da Fundação Hemominas e do Hospital das Clínicas da Faculdade de Medicina da USP de Ribeirão Preto através dos pareceres consubstanciados CAAE 62359816.1.0000.5118 (ANEXO A) e 62359816.1.3001.5440 (ANEXO B), respectivamente. Foi apresentado ao Comitê de Ética solicitação de dispensa de TCLE (ANEXO C).

Os doadores foram abordados durante a consulta de triagem clínica pelos triagistas e foi utilizado o Formulário de coleta de dados (ANEXO D), contendo as informações de identificação da amostra, data de nascimento do doador, número de gestações (partos/abortos), quando aplicável, e possível histórico transfusional.

Os dados completos dos participantes da pesquisa estão descritos na Tabela 16 do APENDICE A 
As bolsas de Plasma Fresco foram descongeladas e realizada aliquotagem em tubo criogênico de $2 \mathrm{~mL}$ (KASVI, São José dos Pinhais, PR, Brasil) e armazenamento a $30^{\circ} \mathrm{C}$ em caixa para armazenamento.

\subsection{Riscos e Benefícios}

Em consonância com a Resolução 466/12, que dispõe sobre os requisitos éticos na pesquisa científica, não podemos negar a existência de algum possível dano gerado pelo projeto, dado que é inerente ao mesmo, pois, embora pequeno, o risco é indissociável da natureza do ato de se realizar pesquisa com seres humanos. Dado o exposto, todas as medidas possíveis foram tomadas para minimizar os riscos e a dimensão de eventual dano que este trabalho possa ter ocasionado.

O estudo em questão propôs a utilização de amostras de hemocomponentes que por validade e ou outros motivos vierem a ser segregadas do estoque para descarte. O único risco existente seria o de quebra de sigilo, todavia foi muito pequeno, uma vez que os dados que foram utilizados para a análise não permitiam identificação do doador completa, somente sendo necessários para caracterização dos grupos. Assim, foram tomadas providências para permitir total anonimato dos participantes da pesquisa.

Os doadores, dos quais seus materiais foram selecionados para o projeto, não tiveram benefícios diretos nem mesmo receberam os resultados dos testes realizados. Posto que fossem doadores hígidos, os exames realizados não tiveram relevância clínica, pois não eram candidatos a receber alguma transfusão. No entanto, caso fosse encontrado algum resultado de interesse do doador, ou seja, algum resultado que representasse risco eminente para o doador, o Serviço Médico de Atendimento ao Doador (SAMD) seria notificado para avaliar a situação. Os participantes desta pesquisa contribuíram, sobremaneira, com o conhecimento da qualidade dos hemocomponentes produzidos pela Fundação Hemominas. Além disso, com a conclusão do estudo, permitiram encontrar alternativas de obtenção de hemocomponentes em casos de escassez absoluta desses produtos. 


\subsection{Metodologia de testes laboratoriais}

As amostras foram testadas utilizando o Kit Labscreen Multi ${ }^{\circledR}$ (One Lambda Inc., Canoga Park, CA, EUA e gentilmente cedido pela Biometrix, São Carlos dos Pinhais, PR, Brasil) para identificação da presença de anticorpos anti-HLA/HNA. O teste consiste em microesferas recobertas com antígenos de granulócitos específicos: HNA-1a (Bead 62), HNA-1b (Bead 63), HNA-1c (Bead 64), HNA-2 (Bead 65), HNA-4 (Bead 66), HNA-4+5 (Bead 56), e antígenos HLA de Classe I e Classe II. O soro ou plasma dos pacientes e o controle negativo foram incubados com mistura de beads em placas de 96 poços, conjugadas à ficoeritrina ligada a IgG anti-humana. Após procedimentos de flicagem e lavagem do material não ligante, a medida da fluorescência média foi analizada com a utilização do analisador de fluxo Luminex 100/200 (Luminex Corp., Austin, TX, EUA). Os resultados foram expressos como média de background normalizado por meio da seguinte expressão:

\section{Razão NBG= S\#N / SNC Bead \\ BG\#N / BGNC Bead}

NBG (normalized background): razão entre os valores de fluorescência de fundo normalizada, usada para atribuir a potência de cada reação anti-HLA/HNA

S\#N: Valor da fluorescência específica da amostra para cada bead \#N

Bead SNC: Valor da fluorescência média específica da amostra para a bead de controle negativo

BG\#N: Valor da fluorescência do soro Controle Negativo de fundo para a bead \#N

BEAD/BGNC: Valor da fluorescência do soro Controle Negativo de fundo para a bead de controle negativo

SNC: Soro de Controle Negativo validado para um determinado lote de beads LABScreen

Foi utilizado o valor de corte para positividade de 2,5 NBG com zona cinza de 2,2 a 2,5 . 
O software HLA Fusion ${ }^{\mathrm{TM}}$ e as ferramentas LABScreen ${ }^{\circledR}$ e Labtype ${ }^{\circledR}$ (One-Lambda) foram utilizados para a interpretação dos dados brutos gerados pelo analisador de fluxo Luminex 100/200.

\subsubsection{Protocolo do teste de anticorpos Labscreen MULTI}

As amostras de plasma fresco congelado foram testadas utilizando o seguinte protocolo:

As amostras dos soros foram centrifugadas a $10.000 \mathrm{~g}$ por 10 minutos. Em seguida, foram retirados $10 \mu \mathrm{L}$ do sobrenadante dos soros e colocados em microplacas (microplacas de PCR com 96 poços), acrescentando-se $5 \mu \mathrm{L}$ das microesferas do teste para cada amostra. Em seguida, a solução foi homogeneizada e incubada por 30 minutos à temperatura ambiente, protegida da luz. Após incubação, foram realizadas três lavagens com $200 \mu \mathrm{L}$ do tampão de lavagem diluído para $1 \mathrm{X}$, com centrifugação a $1300 \mathrm{~g}$ por 5 minutos.

O sobrenadante da centrifugação foi retirado, invertendo-se a placa vigorosamente, deixando-se aproximadamente $5 \mu \mathrm{L}$ de material no fundo da placa. Durante a última lavagem, foi preparado o anticorpo secundário contendo $0,5 \mu \mathrm{L}$ de conjugado concentrado diluído 100X em 49,5 $\mu \mathrm{L}$ de tampão concentrado $1 \mathrm{X}$ (proveniente do kit do anticorpo secundário), para cada uma das amostras.

Terminadas as lavagens, foram acrescentados $50 \mu \mathrm{L}$ do anticorpo secundário em cada poço. Após homogeneização, a solução foi incubada por 30 minutos à temperatura ambiente e protegida da luz. Após incubação, foram acresentados 200 $\mu \mathrm{L}$ de tampão de lavagem e centrifugação para retirada do sobrenadante por flicagem. Após isso, foram realizadas três lavagens com $200 \mu \mathrm{L}$ do tampão de lavagem intercaladas com centrifugações de 5 minutos a $1300 \mathrm{~g}$ seguidas de flicagem para retirada do sobrenadante. Entre cada etapa de flicagem, foi realizada homogeneização vigorosa a seco para que o pellet de beads se desprendesse do fundo do tubo e a lavagem fosse efetiva.

Após as lavagens, as beads foram ressuspendendidas em $65 \mu \mathrm{L}$ de PBS e transferidas para a placa de leitura transparente, de fundo em $\mathrm{V}$, com 96 poços (Kasvi). As amostras foram lidas no analisador de fluxo Luminex 100/200 (Luminex) e os resultados interpretados com uso do software HLA Fusion (One-Lambda) 


\subsection{Análise estatística}

Para análise estatística foi utilizado o programa GraphPad Prisma 7 for Windows (GraphPad Software Inc, https://www.graphpad.com/company/). Foram utilizadas medidas de tendência central e de dispersão para caracterização dos grupos (Média, mediana, desvio padrão). Foi utilizado teste de normalidade de D'Agostino e Pearson para a varíavel idade dos grupos estudados. As análises de comparação dos grupos foram realizadas com a utilização dos testes Qui-quadrado e Teste Exato de Fisher com um grau de liberdade, utilizando tabelas de contingência bidimensional ( $2 \times 2)$, a depender dos critérios de frequência esperada nos grupos, sendo que em grupos nos quais a frequência de uma das variáveis nas caselas foi menor que 5 , foi utilizado o Teste Exato de Fisher. Em ambos cenários, o nível de significância estatística definida foi $P<0,05$. Todas as análises foram feitas para um Intervalo de Confiança de $95 \%$ (IC $95 \%)$. 
Os testes de anticorpos foram realizados nas amostras coletadas das bolsas de Plasma Fresco dos doadores, seguindo a metodologia recomendada pelo fabricante dos kits. Foram realizados testes para identificação de anticorpos anti-HLA de classe I e II, além dos anticorpos anti-HNA contra os antígenos (HNA-1a, HNA-1b, HNA-1c, HNA-2, HNA-3a, HNA-3b, HNA-4a, HNA-5a, HNA-5b)

A tabela 4 mostra os dados da estatística descritiva de idade, paridade e tempo após última gestação dos grupos do estudo.

Os resultados para anticorpos são apresentados agrupados segundo o tipo de anticorpo, se anti-HLA de classe I, II ou HNA. A frequência de anticorpos antiHLA/HNA é apresentada na tabela 5. 
Tabela 4 - Estatística descritiva dos grupos de doadores incluídos no estudo, estratificados segundo gênero e número de gestações para as doadoras.

\begin{tabular}{|c|c|c|c|c|c|c|c|}
\hline Descritiva & Homens & Mulheres 0G & Mulheres 1G & Mulheres 2G & Mulheres $\geq 3 G$ & Mulheres $\leq 1 \mathrm{G}$ & Mulheres $\geq 2 \mathrm{G}$ \\
\hline n & 50 & 50 & 30 & 30 & 30 & 80 & 60 \\
\hline Média & 36,6 & 24,0 & 33,8 & 41,1 & 42,9 & 27,7 & 42,0 \\
\hline Desvio Padrão & 10,29 & 6,837 & 8,525 & 9,619 & 7,007 & 8,858 & 8,394 \\
\hline IC $95 \%$ & $33,63-39,48$ & $22,06-25,95$ & $30,62-36,99$ & $37,5-44,68$ & $40,29-45,52$ & $25,71-29,65$ & $39,83-44,17$ \\
\hline Mínimo & 19,6 & 16,1 & 21,1 & 21,5 & 27,9 & 16,1 & 21,5 \\
\hline Percentil 25 & 29,6 & 18,35 & 27,68 & 33,93 & 38,15 & 21,2 & 36,2 \\
\hline Mediana & 35,3 & 22,5 & 33,55 & 39 & 42,2 & 25,65 & 42 \\
\hline Percentil 75 & 43,85 & 27,63 & 38,78 & 50 & 44,65 & 33,5 & 46,43 \\
\hline Máximo & 61 & 47,5 & 53,8 & 59,1 & 58,3 & 53,8 & 59,1 \\
\hline $\begin{array}{c}\text { Normalidade }^{*} \\
P \text { valor }\end{array}$ & 0,4322 & 0,001 & 0,3255 & 0,5839 & 0,1308 & 0,0084 & 0,9615 \\
\hline $\begin{array}{c}\text { Gestações } \\
(\mathrm{n} \mid \overline{\boldsymbol{x}})\end{array}$ & - & - & 30 & 60 & $112 \mid 3,7$ & $30 \mid 0,375$ & $172 \mid 2,87$ \\
\hline \multicolumn{8}{|l|}{ Partos } \\
\hline Pai 1 & - & - & 26 & 49 & 79 & 26 & 128 \\
\hline Pai 2 & - & - & - & 3 & 19 & - & 22 \\
\hline Pai 3 & - & - & - & - & 4 & - & 4 \\
\hline \multicolumn{8}{|l|}{ Abortos } \\
\hline Pai 1 & - & - & 4 & 8 & 10 & 4 & 18 \\
\hline \multicolumn{8}{|c|}{ Tempo após último parto/aborto } \\
\hline Média & - & - & 10,0 & 13,6 & 15,5 & 10,0 & 14,6 \\
\hline Desvio padrão & - & - & 7,9 & 8,1 & 12,5 & 7,9 & 10,5 \\
\hline
\end{tabular}

Fonte: Dados do estudo 
Tabela 5 - Distribuição de frequência absoluta e relativa dos anticorpos anti-HLA [antígenos de classe I (CI) e de classe II (CII)] e anti-HNA encontrados nos grupos de doadores estudos, estratificados segundo gênero e número de gestações para as doadoras.

\begin{tabular}{|c|c|c|c|c|c|c|c|c|c|}
\hline GRUPOS & $\begin{array}{c}\text { NEGATIVO } \\
n \mid \%\end{array}$ & $\begin{array}{l}\text { HLA/HNA } \\
n \mid \%\end{array}$ & $\begin{array}{c}\mathrm{Cl} \\
\mathrm{n} \mid \%\end{array}$ & $\begin{array}{c}\text { Cll } \\
\mathrm{n} \mid \%\end{array}$ & $\begin{array}{l}\mathrm{Cl}+\mathrm{Cll} \\
\mathrm{n} \mid \%\end{array}$ & $\begin{array}{l}\text { HNA } \\
n \mid \%\end{array}$ & $\begin{array}{l}\text { Cl+HNA } \\
n \mid \%\end{array}$ & $\begin{array}{l}\text { Cll+HNA } \\
n \mid \%\end{array}$ & $\begin{array}{l}\text { Cl+Cll+HNA } \\
n \mid \%\end{array}$ \\
\hline $\begin{array}{l}\text { HOMENS } \\
(\mathrm{N}=50)\end{array}$ & $48 \mid 96,0 \%$ & $2 \mid 4,0 \%$ & $0 \mid 0,0 \%$ & $1 \mid 2,0 \%$ & $0 \mid 0,0 \%$ & $1 \mid 2,0 \%$ & $0 \mid 0,0 \%$ & $0 \mid 0,0 \%$ & $0 \mid 0,0 \%$ \\
\hline $\begin{array}{l}\text { MULHERES OG } \\
(\mathrm{N}=50)\end{array}$ & $47 \mid 94,0 \%$ & $3 \mid 6,0 \%$ & $0 \mid 0,0 \%$ & $2 \mid 4,0 \%$ & $0 \mid 0,0 \%$ & $1 \mid 2,0 \%$ & $0 \mid 0,0 \%$ & $0 \mid 0,0 \%$ & $0 \mid 0,0 \%$ \\
\hline $\begin{array}{l}\text { MULHERES 1G } \\
\quad(\mathrm{N}=30)\end{array}$ & $24 \mid 80,0 \%$ & $6 \mid 20,0 \%$ & $3 \mid 10,0 \%$ & $2 \mid 6,7 \%$ & $0 \mid 0,0 \%$ & $1 \mid 3,3 \%$ & $0 \mid 0,0 \%$ & $0 \mid 0,0 \%$ & $0 \mid 0,0 \%$ \\
\hline $\begin{array}{l}\text { MULHERES 2G } \\
\qquad(\mathrm{N}=30)\end{array}$ & 19 | 63,3\% & $11 \mid 36,7 \%$ & $4 \mid 13,3 \%$ & $2 \mid 6,7 \%$ & $5 \mid 16,7 \%$ & $0 \mid 0,0 \%$ & $0 \mid 0,0 \%$ & $0 \mid 0,0 \%$ & $0 \mid 0,0 \%$ \\
\hline $\begin{array}{c}\text { MULHERES } \geq 3 G \\
\left(\begin{array}{l}\mathrm{N}=30) \\
\end{array}\right.\end{array}$ & $17 \mid 56,7 \%$ & 13 | 43,3\% & $3 \mid 10,0 \%$ & $5 \mid 16,7 \%$ & $4 \mid 13,3 \%$ & $0 \mid 0,0 \%$ & $0 \mid 0,0 \%$ & $0 \mid 0,0 \%$ & $1 \mid 3,3 \%$ \\
\hline $\begin{array}{c}\text { MULHERES } \leq 1 \mathrm{G} \\
\qquad(\mathrm{N}=80)\end{array}$ & $71 \mid 88,7 \%$ & $9 \mid 11,3 \%$ & $10 \mid 12,5 \%$ & $12 \mid 15 \%$ & $9 \mid 11,3 \%$ & $3 \mid 3,8 \%$ & $0 \mid 0,0 \%$ & $0 \mid 0,0 \%$ & $1 \mid 1,3 \%$ \\
\hline $\begin{array}{c}\text { MULHERES } \geq 2 \mathrm{G} \\
(\mathrm{N}=60)\end{array}$ & $36 \mid 60 \%$ & $24 \mid 40,0 \%$ & $20 \mid 33,3 \%$ & $24 \mid 40,0 \%$ & $18 \mid 30,0 \%$ & $6 \mid 10,0 \%$ & $0 \mid 0,0 \%$ & $0 \mid 0,0 \%$ & $1 \mid 1,7 \%$ \\
\hline TOTAL & 155 | 81,6\% & $35 \mid 18,4 \%$ & $10 \mid 5,3 \%$ & 12 | 6,3\% & $9 \mid 4,7 \%$ & $3 \mid 1,6 \%$ & $0 \mid 0,0 \%$ & $0 \mid 0,0 \%$ & $1 \mid 0,5 \%$ \\
\hline
\end{tabular}

Fonte: Dados do estudo 
O estudo levou em consideração o número de gestações, agrupando partos a termo e abortos para a maioria das análises, no entanto, também foram discriminadas as quantidades de partos e abortos para cada mulher, levando em consideração também as gestações que advinham de relacionamento com um ou mais pais. O estudo incluiu 18 mulheres que tinham histórico de abortos. Foram relatados 22 abortos prévios nas 140 mulheres participantes do estudo, sendo que a taxa mais alta foi nas mulheres com três ou mais gestações (10 abortos em 8 mulheres, 33\%), seguida por mulheres com duas gestações com $26,6 \%$ e uma taxa de $13,3 \%$ de abortos.

A taxa de aloimunização total foi 35/190 (18,4\%). Quando analisamos a distribuição destes doadores por tipo de anticorpo, observamos que 43,0\% deles apresentaram anticorpos anti-HLA de classe I, 48,0\% tiveram anticorpos anti-HLA de classe II e somente $9,0 \%$ anticorpos anti-HNA. O resultado é apresentado na figura abaixo:

Figura 6 - Porcentagem de doadores com anticorpos positivos para os anticorpos estudados

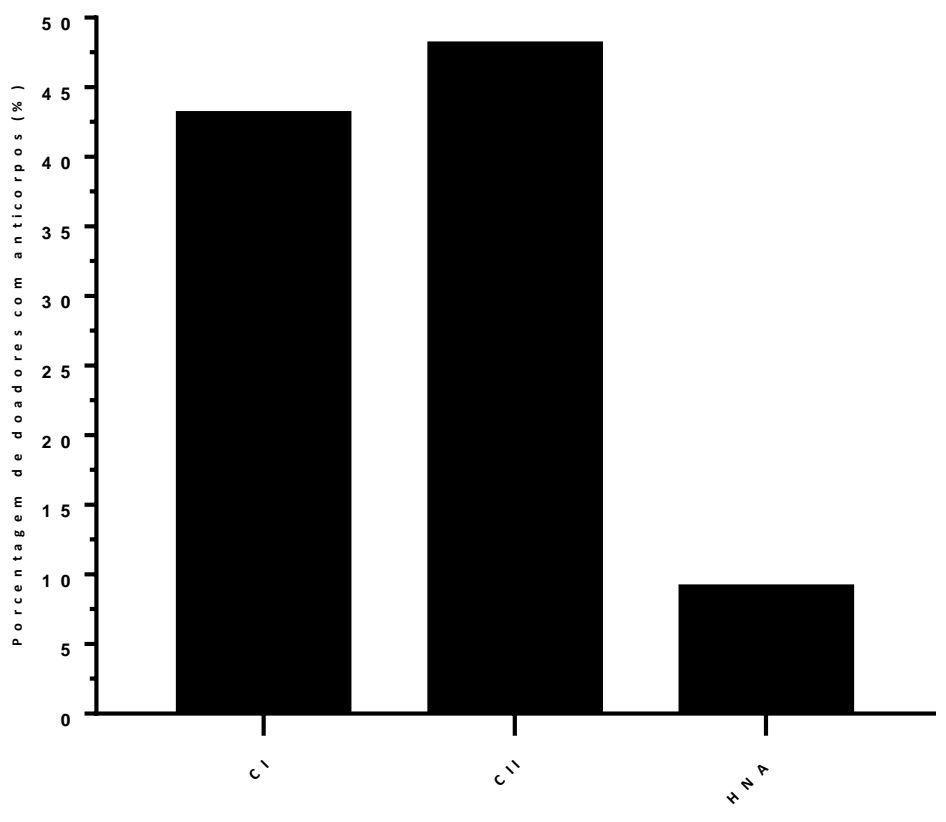

O gráfico mostra a frequência de doadores com anticorpos positivos nos grupos do estudo. Os resultados são mostrados distinguindo a combinação de anticorpos positivos nos doadores (HLA classe I/II e/ou HNA. 
Figura 7 - Distribuição da frequência de doadores com anticorpos positivos em cada grupo do estudo por tipo de anticorpo e combinação destes

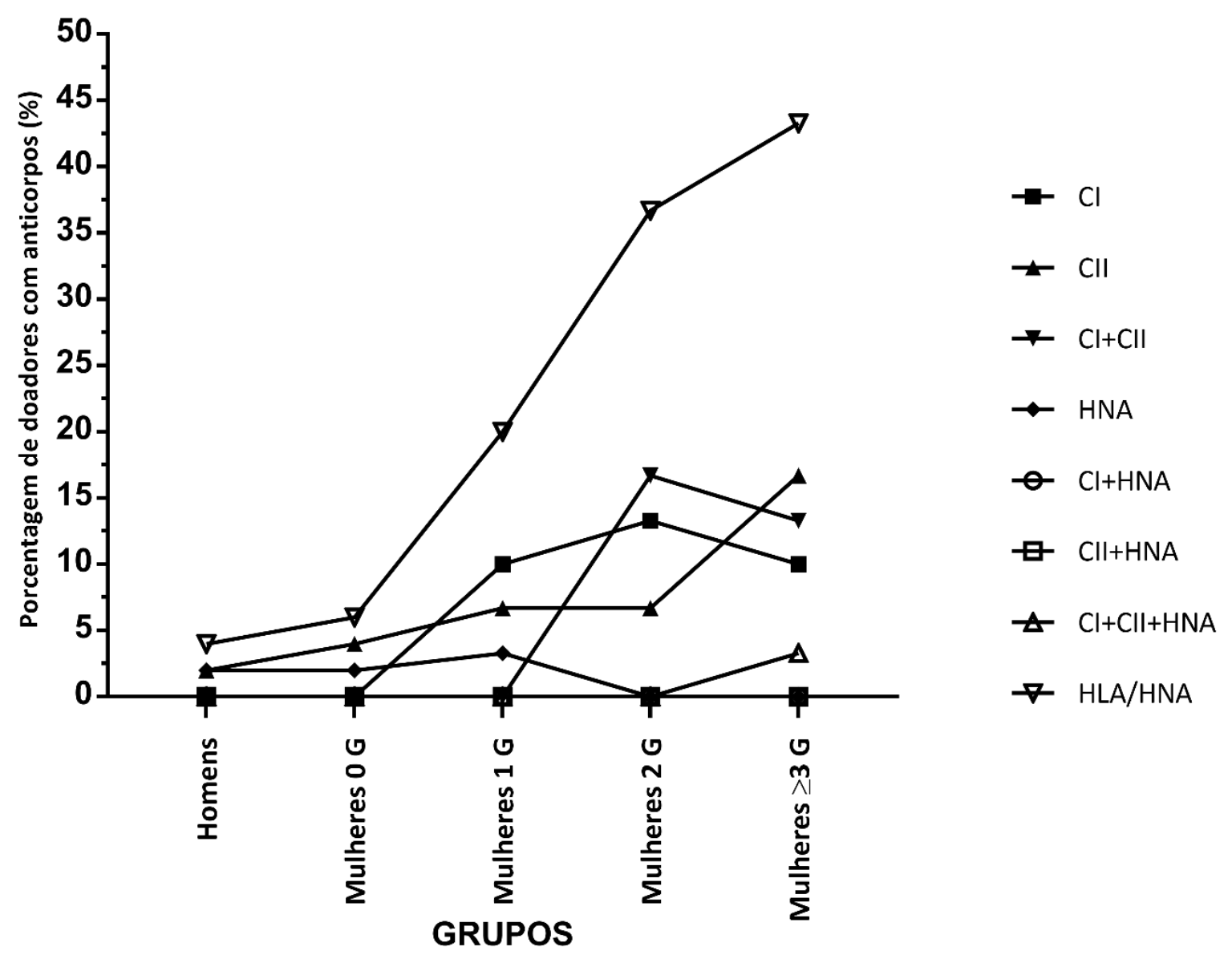

As análises estatísticas foram realizadas utilizando testes de significância estatística por tabelas de contingência, fazendo cruzamento de grupos dois a dois. Podemos identificar nos resultados que seguem: 
Tabela 6 - Distribuição e comparação de doadores de sangue, por presença de anticorpos anti-HLA/HNA, doadores do sexo masculino versus mulheres nuligestas

\begin{tabular}{cccc}
\hline GRUPO & \multicolumn{2}{c}{ ANTICORPOS ANTI-HLA/HNA } & TOTAL \\
& NEGATIVO & POSITIVO & \\
\hline HOMENS & 48 & 2 & 50 \\
MULHERES 0G & 47 & 3 & 100 \\
TOTAL & 95 & 5 & \\
\hline Teste Exato de Fisher bilateral para 1 grau de liberdade & & \\
$\mathbf{P}>0,9999 \quad$ OR $=1,532$ & IC 95\% $=0,3005-8,897$ & \\
\hline
\end{tabular}

Tabela 7 - Distribuição e comparação de doadoras de sangue, por presença de anticorpos anti-HLA/HNA, segundo histórico de gestação (nulíparas e uma gestação)

\begin{tabular}{cccc}
\hline \multirow{2}{*}{ GRUPO } & \multicolumn{2}{c}{ ANTICORPOS ANTI-HLA/HNA } & TOTAL \\
& NEGATIVO & POSITIVO & \\
\hline MULHERES 0G & 47 & 3 & 50 \\
MULHERES 1G & 24 & 6 & 80 \\
TOTAL & 71 & 9 & \\
\hline Teste Exato de Fisher bilateral para 1 grau de liberdade & & \\
$\mathbf{P}=0,1204 \quad$ OR $=3,917$ & IC 95\% = 1,026-15 & & \\
\hline
\end{tabular}


Tabela 8 - Distribuição e comparação de doadoras de sangue, por presença de anticorpos anti-HLA/HNA, segundo histórico de gestação (nuligestas e duas gestações)

\begin{tabular}{cccc}
\hline \multirow{2}{*}{ GRUPO } & \multicolumn{2}{c}{ ANTICORPOS ANTI-HLA/HNA } & TOTAL \\
& NEGATIVO & POSITIVO & \\
\hline MULHERES 0G & 47 & 3 & 50 \\
MULHERES 2G & 19 & 11 & 30 \\
TOTAL & 66 & 14 & \\
\hline Teste Exato de Fisher bilateral para 1 grau de liberdade & & \\
$\mathbf{P}=\mathbf{0 , 0 0 1 4} \quad$ OR $=9,07$ & IC $95 \%=2,217-32,07$ & \\
\hline
\end{tabular}

Tabela 9 - Distribuição e comparação de doadoras de sangue, por presença de anticorpos anti-HLA/HNA, segundo histórico de gestação (nuligestas e três ou mais gestações)

\begin{tabular}{cccc}
\hline GRUPO & \multicolumn{2}{c}{ ANTICORPOS ANTI-HLA $/$ HNA } & TOTAL \\
& NEGATIVO & POSITIVO & \\
\hline MULHERES 0G & 47 & 3 & 30 \\
MULHERES $\geq \mathbf{3 G}$ & 17 & 13 & 80 \\
TOTAL & 64 & 16 & \\
\hline Teste Exato de Fisher bilateral para 1 grau de liberdade & & \\
$\mathbf{P = 0 , 0 0 0 1} \quad$ OR $=\mathbf{1 1 , 9 8}$ & IC $95 \%=3,075-41,78$ & \\
\hline
\end{tabular}


Tabela 10 - Distribuição e comparação de doadores de sangue, por presença de anticorpos anti-HLA/HNA, doadores do sexo masculino versus mulheres com histórico de uma ou zero gestações

\begin{tabular}{cccc}
\hline \multirow{2}{*}{ GRUPO } & \multicolumn{2}{c}{ ANTICORPOS ANTI-HLA/HNA } & TOTAL \\
& NEGATIVO & POSITIVO & \\
\hline HOMENS & 71 & 9 & 60 \\
MULHERES $\leq 1 \mathbf{G}$ & 36 & 24 & 140 \\
TOTAL & 107 & 33 & \\
\hline Teste Exato de Fisher bilateral para 1 grau de liberdade & & \\
$\mathbf{P}=\mathbf{0 , 2 0 2 2} \quad$ OR $=\mathbf{3 , 0 4 2}$ & IC $95 \%=0,7331-14,44$ & \\
\hline
\end{tabular}

Tabela 11 - Distribuição e comparação de doadoras de sangue, por presença de anticorpos anti-HLA/HNA, segundo histórico de gestação (mulheres com uma ou zero gestações versus mulheres com duas ou mais gestações)

\begin{tabular}{cccc}
\hline GRUPO & \multicolumn{2}{c}{ ANTICORPOS ANTI-HLA/HNA } & TOTAL \\
\hline MULHERES $\leq 1 \mathrm{G}$ & 71 & POSITIVO & \\
MULHERES $\geq \mathbf{2 G}$ & 36 & 9 & 60 \\
TOTAL & 107 & 24 & 140 \\
\hline
\end{tabular}

Teste Qui-quadrado bilateral para 1 grau de liberdade

$\mathrm{X}^{2}{ }_{1 \mathrm{gl}}=\mathbf{1 5 , 7 3} \quad \mathrm{P}<0,0001 \quad$ OR $=\mathbf{5 , 2 5 9} \quad$ IC $95 \%=2,178-12,13$ 
Tabela 12 - Distribuição e comparação de doadoras de sangue, por presença de anticorpos anti-HLA/HNA, segundo histórico de gestação (G) (mulheres com duas gestações de um mesmo pai versus mulheres com duas gestações de mais de um pai)

\begin{tabular}{cccc}
\hline \multirow{2}{*}{ GRUPO } & \multicolumn{2}{c}{ ANTICORPOS ANTI-HLA/HNA } & TOTAL \\
& NEGATIVO & POSITIVO & \\
\hline MULHERES 2G 1 PAI & 17 & 10 & $\mathbf{3}$ \\
MULHERES 2G >1 PAI & 2 & 1 & $\mathbf{2 7}$ \\
TOTAL & $\mathbf{1 9}$ & $\mathbf{1 1}$ & $\mathbf{3 0}$ \\
\hline Teste Exato de Fisher bilateral para 1 grau de liberdade & & \\
$\mathbf{P}>\mathbf{0 , 9 9 9 9} \quad$ OR $=0,85$ & IC 95\% $=0,05381-8,078$ & \\
\hline
\end{tabular}

Tabela 13 - Distribuição e comparação de doadoras de sangue, por presença de anticorpos anti-HLA/HNA, segundo histórico de gestação (G) (mulheres com três gestações de um mesmo pai versus mulheres com três gestações de mais de um pai)

\begin{tabular}{lccc}
\hline \multicolumn{1}{c}{ GRUPO } & \multicolumn{2}{c}{ ANTICORPOS ANTI-HLA/HNA } & TOTAL \\
& NEGATIVO & POSITIVO & \\
\hline MULHERES 3G 1 PAI & 7 & 4 & 11 \\
MULHERES 3G >1 PAI & 7 & 6 & 13 \\
Total & 14 & 10 & 24 \\
\hline Teste Exato de Fisher bilateral para 1 grau de liberdade & & \\
$\mathbf{P}>\mathbf{0 , 6 9 6 8} \quad$ OR $=1,5$ & IC 95\% $=0,2632-6,671$ & \\
\hline
\end{tabular}


Tabela 14 - Distribuição e comparação de doadoras de sangue, por presença de anticorpos anti-HLA/HNA, segundo histórico de gestação (G) (mulheres com uma gestação a menos de 10 anos versus mulheres com uma gestação a mais de 10 anos)

\begin{tabular}{|c|c|c|c|}
\hline GRUPO & ANTICORP & -HLA/HNA & \\
\hline MULHERES 1G & NEGATIVO & POSITIVO & \\
\hline $\begin{array}{l}\text { Última gestação <10 } \\
\text { anos }\end{array}$ & 13 & 5 & 18 \\
\hline $\begin{array}{l}\text { Última gestação } \geq 10 \\
\text { anos }\end{array}$ & 11 & 1 & 12 \\
\hline Total & 24 & 6 & 30 \\
\hline Teste Exato de Fisher bilateral & a 1 grau de lit & & \\
\hline OR $=0,2364$ & IC $95 \%=0$ & ,725 & \\
\hline
\end{tabular}

Tabela 15 - Distribuição e comparação de doadoras de sangue, por presença de anticorpos anti-HLA/HNA, segundo histórico de gestação (G) (mulheres com duas gestações com a última a menos de 10 anos versus mulheres com duas gestações sendo a última a mais de 10 anos)

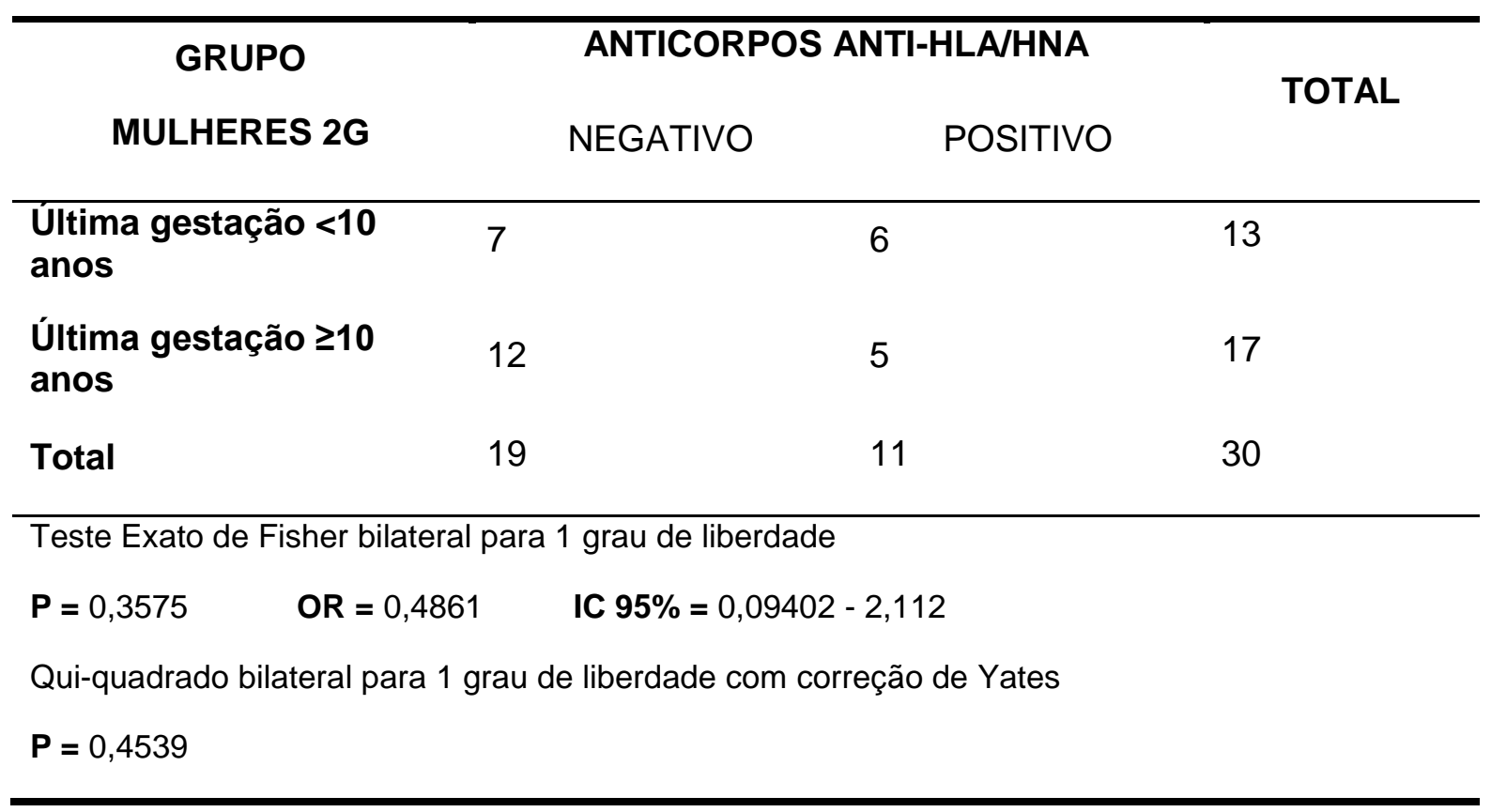




\section{DISCUSSÃO ||}

A média de idade geral para os doadores incluídos no estudo foi 35,4 anos. O grupo com a menor idade média foram as mulheres nuligestas, 24,0 anos, com idade mínima neste grupo de 16,1 e máxima de 47,5 anos. Com idade média um pouco maior tivemos o grupo de mulheres com histórico de uma gestação, 33,8 anos, com mínima de 21,1 e máxima de 53,8 anos.

O grupo de doadores do sexo masculino teve média de idade de 36,6 anos, com mínimo de 19,6 e máxima de 61 anos. Em sequência da média de idade, o grupo de doadoras do sexo feminino com histórico de duas gestações teve média de 41,1 e dados variando do mínimo de 21,5 e máximo de 59,1.

O grupo com maior idade média foi o de mulheres multigestas, com três ou mais doações, mostrando uma média de 42,9 anos e dados que variaram de um mínimo de 27,9 e máximo de 58,3 anos.

Esses resultados eram esperados dado que a chance de uma mulher acumular gestações e abortos aumenta com a idade que ela tem ao integrar o estudo.

Os fatores de risco para o desenvolvimento da TRALI podem ser divididos em fatores relativos ao receptor do hemocomponente e fatores ligados ao hemocomponente em si e à transfusão. A existência de gestações prévias da doadora é um fator que agrega risco ao hemocomponente quando se fala de TRALI. (DENSMORE, TAMARA L. et al., 1999)

Diversos estudos têm mostrado relação direta entre a multigestação e presença de anticorpos contra antígenos leucocitários. CURTIS; MCFARLAND, 2006; FUNG; SILLIMAN, 2009; IIJIMA et al., 2009; TRIULZI et al., 2009)

Dentre o grupo de doadores do sexo masculino, tivemos dois doadores $(4,0 \%)$ nos quais foram identificados anticorpos positivos, sendo um deles com anticorpos dirigidos para antígenos HLA de classe II e outro doador com anticorpos positivos para HNA-2a. 
Estudos anteriores já mostraram taxas até mais altas para anticorpos anti-HLA em populações de homens sem histórico de transfusão. Morales e colaboradores realizaram estudo com 424 doadores do sexo masculino utilizando a metodologia de Luminex. Foram encontrados anticorpos da classe I em $42 \%$ dos doadores, classe II em $11 \%$ e ambos em $12 \%$ dos homens incluídos no estudo. O resultado foi explicado pelos pesquisadores como sendo devido à exposição a antígenos microbianos, ou vacinais que possuem reatividade cruzada com epítopos HLA específicos, ou seja, seriam anticorpos heterófilos. (MORALES-BUENROSTRO et al., 2008)

Clippel e colaboradores, ao pesquisar aloimunização em doadores do sexo masculino e com histórico de transfusão, encontraram 1,3\% de postitividade para anti-HLA. (DE CLIPPEL et al., 2014) Essa discrepância nos resultados encontrados em diferentes estudos pode se dever às diferenças nos pontos de corte utilizados para a definição de positivos, bem como na própria sensibilidade dos testes utilizados no estudo.

O grupo de doadoras com 0 gestações apresentou positividade para os anticorpos anti-HLA/HNA de 6,0\%. Sendo que, desses anticorpos encontrados, 4,0\% são dirigidos para antígenos de classe II e 2,0 \% para epítopos do complexo HNA.

Densmore e colaboradores também encontraram positividade em mulheres sem histórico de eventos aloimunizantes. Foi relatada taxa de positividade de 1/12 (8,3\%) em mulheres nuligestas. (DENSMORE, et al., 1999)

Em estudo realizado nos EUA, Triulzi e colaboradores encontraram pequena proporção $(1,7 \%)$ de mulheres com baixo risco de aloimunização (nuligesta sem histórico de transfusão, $n=1732$ ) com anticorpos anti-HLA. Essa prevalência foi semelhante a dos homens transfundidos $(1,7 \%)$ ou não transfundidos $(1,0 \%), P=$ 0,29. (TRIULZI et al., 2009)

Clippel e colaboradores encontraram valores semelhantes para a população de mulheres sem histórico de gestações (4,2\%).(DE CLIPPEL et al., 2014)

Em recente estudo, 3,5\% $(n=96)$ de 2762 mulheres sem história de gravidez e em $2,1 \%$ ( $n=154)$ de 7369 homens, também foram detectados anticorpos contra antígenos de granulócitos ( $n=13,0,47 \%$ e $n=45,0,6 \%$ ), HLA Classe I e / ou II ( $n=$ $83,3 \%$ e $n=109,1,4 \%$, respectivamente). (NGUYEN et al., 2018) 
Já no grupo de doadoras com histórico de uma gestação foi encontrado $6,0 \%$ de positividade para os anticorpos procurados. Desses, 50,0\% das doadoras tinham anticorpos anti-HLA de classe I, 33,0\% dirigidos contra antígenos de classe II e 16\% das doadoras possuíam anticorpos direcionados à epítopos do sistema HNA.

Para o grupo de doadoras com histórico de 2 gestações, foram encontradas 11 doadoras com anticorpos positivos (36,7\%). Dessas, 36,4\% possuíam anticorpos dirigidos a antígenos de HLA de classe I, 18,2\% para antígenos HLA de classe II e $45 \%$ das mulheres positivas para anticorpos HLA de classe I e II, concomitantemente.

Quando realizamos o agrupamento de doadoras nuligestas com mulheres com uma gestação, observamos o índice de positividade de 11,3\% de anticorpos. Dados de estudos anteriores já mostraram valores semelhantes de aloimunização para este agrupamento. (TRIULZI et al., 2009)

Em nosso estudo, para o grupo de doadoras com histórico de 3 ou mais gestações, a taxa de positividade de anticorpos foi $43,3 \%$. Dessas doadoras com anticorpos, $23,1 \%$ apresentavam anticorpos anti-HLA de classe I, 38,5\% anti-HLA de classe II, 30,8 \% possuíam concomitantemente anticorpos anti-HLA de classes I e II, além de 7,7\% que possuíam anticorpos anti-HNA.

Triulzi e colaboradores realizaram estudo prospectivo com 8171 doadores de sangue em seis bancos de sangue dos Estados Unidos, durante os anos de 2006 e 2007. O objetivo do estudo foi avaliar o efeito da gestação prévia no desenvolvimento de anticorpos anti-HLA e as possíveis implicações na gênese da TRALI. Avaliando a presença de anticorpos anti-HLA, o estudo mostrou presença de anticorpos em 1,0\% dos doadores do sexo masculino sem histórico de transfusional e 1,7\% dos doadores com algum histórico de transfusão prévia, porém, essa diferença não se apresentou estatisticamente significativa. Para as mulheres, o estudo detectou presença de 17,3\% de doadoras com anticorpos, sendo que a prevalência desses anticorpos foi maior quanto maior a quantidade de gestações. Doadoras nuligestas tiveram $1,7 \%$ de positividade, 11,2\% para mulheres com uma gestação, 22,5\% para doadoras com duas gestações, 27,5\% três gestações e 32,2\% quatro gestações. (TRIULZI et al., 2009) 
A prevalência de anticorpos é maior quanto maior é a exposição ao evento gravidez, uma vez que o evento gestação pode ser estatisticamente correlacionado com maior frequência de anticorpos quando vemos que mulheres nuligestas tiveram somente uma taxa de 6,0 \% de positividade para anticorpos, passando a 20,0\% com uma gestação, 36,7\% e chegando à 43,3 \% para mulheres com três ou mais gestações, como observado no presente estudo.

Esse achado corrobora estudos prévios, nos quais também foi descrito o efeito cumulativo de gestações para o incremento da prevalência de anticorpos. (GOTTSCHALL et al., 2011; KAKAIYA et al., 2010; TRIULZI et al., 2009)

Em nosso estudo, observamos em três doadoras nuligestas a presença de anticorpos, duas com anticorpos dirigidos contra antígenos de classe II e uma delas dirigidos contra antígenos HNA-5a. As três doadoras em questão não relatam histórico transfusional ou abortos. O fato poderia ser explicado pela dissimulação na resposta em caso de aborto, devido ao preconceito relacionado ao tema, ou ainda abortos que não puderam ser identificados pela mulher.

Densmore e colaboradores mostraram em estudo realizado com 332 doadoras de plaquetaférese que $17 \%$ das mulheres doadoras demonstraram sensibilização HLA. A gestação e sensibilização HLA foram significativamente correlacionadas ( $P$ $<0,0001)$, com doadores sensibilizados com uma média de 2,9 $( \pm 0,695 \% \mathrm{Cl}$ ) gestações anteriores e doadores não sensibilizados com média de 1,8 $( \pm$ 0,2 95\% Cl) gestações anteriores. A porcentagem de mulheres sensibilizadas por HLA com 0, 1 a 2 e $\geq 3$ gravidezes foi de 7,8, 14,6 e 26,3, respectivamente. (Densmore, 1999)

Em estudo conduzido no sudoeste da Alemanha, Nguyen e colaboradores analisaram 14.343 doadores de sangue sem histórico de transfusão quanto à presença de anticorpos HNA e HLA Classe I e II, 924 (21,9\%) das 4212 mulheres com história de gravidez possuíam anticorpos contra antígenos de granulócitos ou antígenos HLA de classe I ou II. Sendo que dessas, 62 (1,5\%) eram contra antígenos HNA e 5686 (20,5\%) eram anticorpos dirigidos contra antígenos HLA de classe I ou II. Dentre as 2762 doadoras sem histórico gestacional, 13 (0,47\%) apresentaram anticorpos contra 
antígenos de granulócitos e 82 (2,98\%) tinham anticorpos anti HLA classe I ou II. Na população dos doadores do sexo masculino, em 2,1\% $(n=154)$ foram identificados anticorpos dirigidos a antigenos HNA e HLA Classe I e II, sendo que, em 0,6\% deles $(n=45)$ foram encontrados anticorpos antigranulócitos. Esses anticorpos foram dirigidos contra HNA-1a, -1b, -2, -3a, -5a, -CD16 e -CD32 e anticorpos de especificidades desconhecidas. Anticopos contra os HNA-2 e o CD16 foram os mais frequentes entre os dadores de sangue $(n=44)$. (Nguyen, 2018)

A comparação do grupo de mulheres nuligestas não mostrou significância estatística quando comparado com o grupo de doadores do sexo masculino. O valor da estatística do teste exato de Fisher foi igual a 1 e o valor de $P$ foi maior que 0,05 .

Este resultado é concordante com o que foi encontrado pelo estudo de Nguyen, que também não encontrou diferença significativa da prevalência de anticorpos entre a população de doadores do sexo masculino e mulheres sem histórico de gestação, apesar dos valores de aloimunização serem pouco maiores nas mulheres, como também ocorreu no nosso estudo. (NGUYEN et al., 2018)

Em relação às mulheres nuligestas comparadas ao grupo de doadoras com histórico de uma gestação, embora exista diferença de frequência de doadoras positivas $(6,0 \%$ para nuligestas frente $20,0 \%$ mulheres com uma gestação), a comparação entre esses grupos não mostrou diferença estatística. Foram 3 doadoras com anticorpos positivos no grupo de nuligestas e 6 doadoras positivas para os anticorpos pesquisados. $O$ valor de $P=0,1204$ com $\mathrm{OR}=3,917$, IC95\%=1,026 - 15. Esse resultado difere de estudos pregressos que identificaram diferença estatística quando comparadas as duas populações. (DENSMORE, T L et al., 1999; TRIULZI et al., 2009)

Anticorpos são mais frequentes em uma segunda gestação e isso pode justificar a ausência de diferença estatística entre a frequência de anticorpos nas mulheres nuligestas frente às mulheres com uma gestação.

Resultado semelhante foi encontrado por Kakaiya e colaboradores em estudo com doadoras de sangue nas quais o efeito do segundo aborto foi significativo para determinar a maior frequência de anticorpos positivos a partir do segundo evento. Assim, o primeiro evento poderia servir como sensibilização e o segundo para estímulo efetivo do sistema imune. (KAKAIYA et al., 2010) 
A análise realizada, comparando o grupo de doadoras nuligestas frente às doadoras com histórico de 2 gestações, apresentou diferença estatisticamente significante ( $P$ $=0,0014)$. Esse resultado também corrobora os estudos anteriores e permite que tracemos um ponto de inflexão entre a significância estatística a partir do segundo evento gestação. (DENSMORE, T L et al., 1999; TRIULZI et al., 2009)

A comparação entre a taxa de positividade de anticorpos do grupo de mulheres nuligestas frente às mulheres com 3 ou mais gestações mostrou significância estatística para o teste exato de Fisher com diferenças significantes $(P=0,0014)$, resultado que confirma a intensa diferença esperada em relação à presença de anticorpos nos dois grupos de mulheres com menor e maior efeito do evento gestacional.

Ao fazermos um agrupamento das mulheres com histórico de até uma gestação (0 e 1) versus o grupo de doadores do sexo masculino não temos significância estatística, $P=0,2022$.

Levando em consideração a análise frente ao grupo dos doadores do sexo masculino e os resultados de significância estatística entre os grupos de doadoras nuligestas versus doadoras com uma gestação, e doadoras com duas gestações frente doadoras com três ou mais gestações percebemos que esses grupos têm certo nível de homogeneidade, indicando que possam ser agrupados na tentativa de estabelecimento de "ponto de viragem" para a alta prevalência de anticorpos.

Quando confrontados os grupos de mulheres com nenhuma até uma gestação, frente às mulheres com histórico de duas ou mais gestações, também obtivemos diferença estatística significativa com valor de $P<0,0001$. Nessa análise, foi utilizado teste do qui-quadrado, pois os grupos coadunados permitiram o uso deste teste em detrimento do teste exato de Fisher devido ao tamanho dos grupos exigidos.

Outro dado levantado pelo estudo foi a quantidade de mulheres que haviam engravidado de mais de um pai, o que, em teoria, poderia aumentar a disponibilidade de a gestante ter contato com antígenos de neutrófilos distintos. (DE CLIPPEL et al., 2014) A análise foi realizada utilizando a estratégia de comparação intragrupo para os grupos de duas e três gestações para não incutir em sobreposição de variáveis, dado que existe relação evidente entre a quantidade de gestações e a frequência de 
anticorpos positivos. Foram excluídos dessa análise as mulheres com mais de 3 gestações pois formam grupos muito diminutos.

Para o grupo de mulheres com duas gestações prévias foi encontrado $P>0,9999$, valor este que descarta a diferença entre os grupos. De forma semelhante, para o grupo de mulheres com três gestações, o valor de $P=0,6968$, também foi não significativo.

Foi avaliada a relação entre o tempo decorrido entre a última gestação e a coleta. Com objetivo de não causar sobreposição de variáveis, essa análise foi realizada de forma individualizada nos grupos de mulheres com uma e duas gestações divididas em subgrupos que haviam tido a última gestação há menos de 10 anos e há mais de 10 anos. Densmore e colaboradores, em estudo com mulheres doadoras de sangue, encontraram relação estatisticamente significante do tempo desde a última gestação e a prevalência de anticorpos anti-HLA. O resultado encontrado corrobora os achados de Clippel e colaboradores que, da mesma forma, não encontrarm diferença estatística quando foram comparadas mulheres que tiveram a última gestação há menos de 10 anos versus mulheres com último evento gestacional há mais de 10 anos. (DE CLIPPEL et al., 2014) 
Figura 8 - Prevalência de anticorpos anti-HLA/HNA em estudos prévios, relacionados ao número de gestações

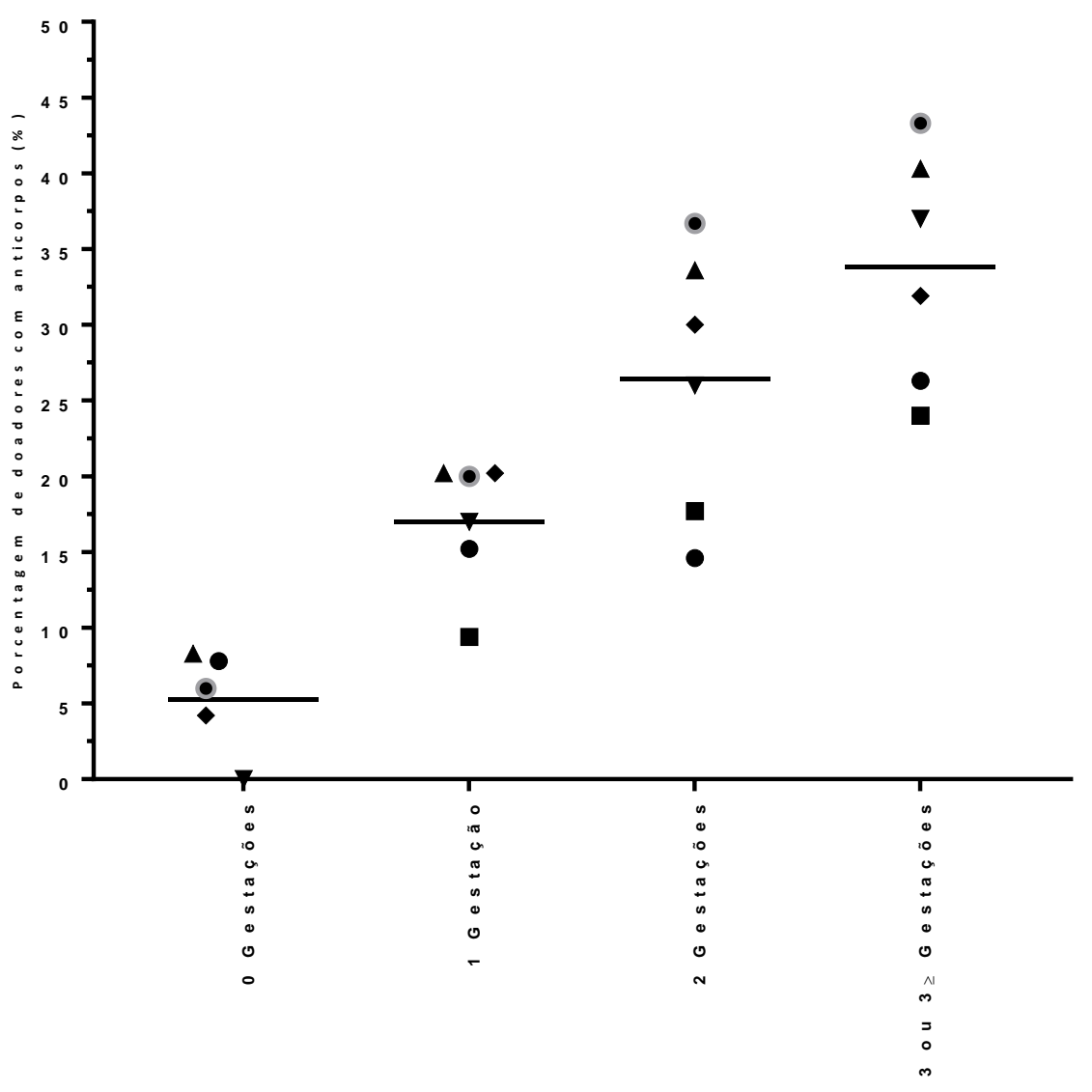

O gráfico mostra a distribuição dos valores de prevalência de mulheres com anticorpos positivos para anti-HLA/HNA em vários estudos. Podemos perceber que, em cada estudo, embora tenha alguma variação mantém a relação direta entre o efeito do evento gestação e a maior prevalência de anticorpos. O estudo realizado com as doadoras da Fundação Hemominas se insere no mesmo cenário dos estudos prévios encontrados na literatura. (DE CLIPPEL et al., 2014; INSUNZA et al., 2004; LOPES et al., 2010; TRIULZI et al., 2009) 


\section{CONCLUSÕES}

A taxa de aloimunização total dos doadores da Fundação Hemominas foi 35/190 (18,4 \%). Os anticorpos anti-HLA (classe I - 43,0\%, classe II - 48,0\%) foram mais prevalentes do que anticorpos antineutrófilos $(9,0 \%)$, o que era o esperado de acordo com estudos prévios em protocolos semelhantes.

A análise do efeito da gestação no desenvolvimento de anticorpos foi concordante com diversos estudos anteriores, mostrando frequência maior no grupo mulheres com três ou mais gestações (43,3\%), seguida do grupo de mulheres com histórico de duas gestações (36,7\%), uma gestação com 20,0\% e mulheres nuligestas com a menor prevalência entre as mulheres (6,0\%). O grupo de doadores do sexo masculino apresentou frequência de aloimunização de 4,0\%.

Foi possível identificar ponto de inflexão para a frequência de aloimunização quando agrupamos mulheres com até uma gestação $(11,3 \%)$ versus mulheres multigestas $(40,0 \%, P<0,0001)$.

Os resultados mostraram que a estratégia utilizada hoje em dia na Fundação Hemominas de uso exclusivo de doadores do sexo masculino para a redução do risco de TRALI é válida, face à alta frequência de anticorpos anti-HLA/HNA em doadoras de sangue multigestas. No entanto, as análises de comparação entre os grupos mostraram que os doadores do sexo masculino, mulheres nuligestas ou com uma gestação não apresentam diferenças estatisticamente significantes entre si. Por sua vez, quando comparados ao grupo de mulheres com duas ou mais gestações as diferenças significativas aparecem $(P<0,001)$.

Diante do exposto, a presente pesquisa aponta para a possibilidade de se valer de doação de mulheres não multigestas, em casos de contingenciamento, para a produção de hemocomponentes com alto conteúdo plasmático. Ressalta-se, no entanto, que devem ser feitos estudos complementares que se valham de amostras mais amplas desse recorte populacional, no intuito de ratificar os achados e subsidiar definitivas alterações nas estratégias de seleção de doadores, para mitigação de risco de TRALI. 
10 BIBLIOGRAFIA

AABB. AABB Association Bulletin. [S.I.]: American Association of Blood Banks, 2014. p. 14.

Disponível

em:

<https://www.aabb.org/programs/publications/bulletins/Documents/ab14-02.pdf>.

Acesso em: 17 mar. 2019.

ABBAS, A. K.; LICHTMAN, A.; POBER, J. S. Imunologia Celular e Molecular. 4. ed. Rio de Janeiro: [s.n.], 2003.

ABBAS, A. K.; LICTHMAN, A. H. The Major Complex Histocompatibility. In: Cellular and molecular immunology. In: ELSEVIER/SAUNDERS (Org.). . Cellular and molecular immunology. 7. ed. Philadelphia: [s.n.], 2012. p. 64-83.

ANDREU, G. et al. Analysis of Transfusion-Related Acute Lung Injury and Possible Transfusion-Related Acute Lung Injury Reported to the French Hemovigilance Network From 2007 to 2013. Transfusion Medicine Reviews, v. 32, n. 1, p. 16-27, 1 jan. 2017. Disponível em: <https://www.tmreviews.com/article/S0887-7963(17)300603/pdf>. Acesso em: 11 maio 2018.

ARINSBURG, S. A. et al. Conversion to low transfusion-related acute lung injury (TRALI)-risk plasma significantly reduces TRALI. Transfusion, v. 52, n. 5, p. 946-952, maio 2012. Disponível em: <http://doi.wiley.com/10.1111/j.1537-2995.2011.03403.x>. Acesso em: 18 mar. 2019.

BENSON, A. B. Pulmonary Complications of Transfused Blood Components. Critical Care Nursing Clinics of North America, v. 24, n. 3, p. 403-418, set. 2012. Disponível em: <https://linkinghub.elsevier.com/retrieve/pii/S089958851200055X>. Acesso em: 18 mar. 2019.

BERTHOLD, T. et al. HNA antibody-mediated neutrophil aggregation is dependent on serine protease activity. Vox Sanguinis, v. 109, n. 4, p. 366-374, nov. 2015. Disponível em: <http://doi.wiley.com/10.1111/vox.12292>. Acesso em: 18 mar. 2019.

BOLTON-MAGGS, P. H. B.; COHEN, H. Serious Hazards of Transfusion (SHOT) haemovigilance and progress is improving transfusion safety. British journal of haematology, v. 163, n. 3, p. 303-14, nov. 2013. Disponível em: <http://www.ncbi.nlm.nih.gov/pubmed/24032719>. Acesso em: 17 mar. 2019.

BRASIL. Aspectos hemoterápicos relacionados a Trali (Lesão Pulmonar Aguda Relacionada à Transfusão): medidas para redução do risco. Brasília: Secretaria de Vigilância em Saúde. Departamento de Atenção Especializada., 2010.

BUX, J. Human neutrophil alloantigens. Vox Sanguinis, v. 94, n. 4, p. 277-285, 1 maio 2008. Disponível em: <http://doi.wiley.com/10.1111/j.1423-0410.2007.01031.x>. Acesso em: 18 mar. 2019. 
BUX, JÜRGEN. Transfusion-related acute lung injury (TRALI): A serious adverse event of blood transfusion. Vox Sanguinis, v. 89, n. 1, p. 1-10, 1 jul. 2005. Disponível em: <http://doi.wiley.com/10.1111/j.1423-0410.2005.00648.x>. Acesso em: 18 mar. 2019.

BUX, JÜRGEN; SACHS, U. J. H. The pathogenesis of transfusion-related acute lung injury (TRALI). British Journal of Haematology, v. 136, n. 6, p. 788-799, mar. 2007. Disponível em: <http://doi.wiley.com/10.1111/j.1365-2141.2007.06492.x>. Acesso em: 18 mar. 2019.

CHAPMAN, C. E. et al. Ten years of hemovigilance reports of transfusion-related acute lung injury in the United Kingdom and the impact of preferential use of male donor plasma. Transfusion, v. 49, n. 3, p. 440-452, mar. 2009. Disponível em: <http://doi.wiley.com/10.1111/j.1537-2995.2008.01948.x>. Acesso em: 18 mar. 2019.

CLIFFORD, L. et al. Characterizing the Epidemiology of Postoperative Transfusionrelated Acute Lung Injury. Anesthesiology, v. 122, n. 1, p. 12-20, jan. 2015. Disponível em: <http://www.ncbi.nlm.nih.gov/pubmed/25611652>. Acesso em: 22 mar. 2019.

CURTIS, B. R.; MCFARLAND, J. G. Mechanisms of transfusion-related acute lung injury (TRALI): anti-leukocyte antibodies. Critical care medicine, v. 34, n. 5 Suppl, p. S118-23, 2006.

DE CLIPPEL, D. et al. Screening for HLA antibodies in plateletpheresis donors with a history of transfusion or pregnancy. Transfusion, v. 54, n. 12, p. 3036-3042, 1 dez. 2014. Disponível em: <http://doi.wiley.com/10.1111/trf.12727>. Acesso em: 15 mar. 2019.

DE HAAS, M. et al. Neutrophil antigen $5 b$ is carried by a protein, migrating from 70 to $95 \mathrm{kDa}$, and may be involved in neonatal alloimmune neutropenia. Transfusion, v. 40, n. 2, p. 222-7, fev. 2000. Disponível em: <http://www.ncbi.nlm.nih.gov/pubmed/10686007>. Acesso em: 18 mar. 2019.

DENSMORE, T L et al. Prevalence of HLA sensitization in female apheresis donors. Transfusion, v. 39, n. 1, p. 103-6, jan. 1999. Disponível em: <http://www.ncbi.nlm.nih.gov/pubmed/9920173>. Acesso em: 10 fev. 2019.

DENSMORE, TAMARA L. et al. Prevalence of HLA sensitization in female apheresis donors. Transfusion, v. 39, n. 1, p. 103-106, jan. 1999. Disponível em: <http://doi.wiley.com/10.1046/j.1537-2995.1999.39199116901.x>. Acesso em: 8 fev. 2019.

DONADI, E. A. How to understand the nomenclature and the mechanisms involved on the association between histocompatibility antigens and alleles with disease. Medicina (Ribeirão Preto), v. 33, n. 1, p. 7-18, 2000. 
EDER, A. F. et al. Effective reduction of transfusion-related acute lung injury risk with male-predominant plasma strategy in the American Red Cross (2006-2008). Transfusion, v. 50, n. 8, p. 1732-1742, 12 fev. 2010. Disponível em: <http://doi.wiley.com/10.1111/j.1537-2995.2010.02652.x>. Acesso em: 18 mar. 2019.

FRAGA, R. S.; NEUMANN, J. Complexo de Histocompatibilidade Principal. In: SCROFERNEKER, M. L.; POHLMANN, P. R. In: SAGRA LUZZATTO (Org.). . Imunologia básica e aplicada. Porto Alegre: [s.n.], 1998. p. 110-112.

FUNG, Y. L.; SILLIMAN, C. C. The Role of Neutrophils in the Pathogenesis of Transfusion-Related Acute Lung Injury. Transfusion Medicine Reviews, v. 23, n. 4, p. 266-283, 2009. Disponível em: <http://dx.doi.org/10.1016/j.tmrv.2009.06.001>.

FUNK, M. B. et al. Benefit of transfusion-related acute lung injury risk-minimization measures - German haemovigilance data (2006-2010). Vox Sanguinis, v. 102, n. 4, p. 317-323, maio 2012. Disponível em: <http://doi.wiley.com/10.1111/j.14230410.2011.01556.x>. Acesso em: 18 mar. 2019.

GOLDMAN, M. et al. Proceedings of a Consensus Conference: Towards an Understanding of TRALI. Transfusion Medicine Reviews, v. 19, n. 1, p. 2-31, jan. 2005.

<https://linkinghub.elsevier.com/retrieve/pii/S0887796304000768>. Acesso em: 16 mar. 2019.

GOTTSCHALL, J. L. et al. The frequency and specificity of human neutrophil antigen antibodies in a blood donor population. Transfusion, v. 51, n. 4, p. 820-827, abr. 2011. Disponível em: <http://doi.wiley.com/10.1111/j.1537-2995.2010.02913.x>. Acesso em: 10 fev. 2019.

GREINACHER, A. et al. Characterization of the human neutrophil alloantigen-3a. Nature Medicine, v. 16, n. 1, p. 45-48, 27 jan. 2010. Disponível em: <http://www.nature.com/articles/nm.2070>. Acesso em: 18 mar. 2019.

HOKAMA, P. O. M.; X; Y. Tipagem HLA classe II por técnicas de biologia molecular. Jornal Brasileiro de Medicina, v. 72, n. 4, p. 95-106, 1997.

HOWELL, W. M.; CARTER, V.; CLARK, B. The HLA system: immunobiology, HLA typing, antibody screening and crossmatching techniques. Journal of Clinical Pathology, v. 63, n. 5, p. 387-390, 2010.

IIJIMA, T. et al. Impact of fresh-frozen plasma from male-only donors versus mixedsex donors on postoperative respiratory function in surgical patients: A prospective case-controlled study. Transfusion, v. 49, n. 11, p. 2434-2441, nov. 2009. Disponível em: <http://doi.wiley.com/10.1111/j.1537-2995.2009.02321.x>. Acesso em: 18 mar. 2019.

INSUNZA, A. et al. Implementation of a strategy to prevent TRALI in a regional blood 
centre. Transfusion Medicine, v. 14, n. 2, p. 157-164, 1 abr. 2004. Disponível em: <http://doi.wiley.com/10.1111/j.0958-7578.2004.00492.x>. Acesso em: 24 mar. 2019.

JUNIOR, A. F.; LOPES, L. B. Lesão pulmonar aguda associada à transfusãoão. Jornal Brasileiro de Pneumoloia, v. 33, n. 2, p. 206-212, 2007.

JUNIOR, A. F.; LOPES, L. B.; BORDIN, J. O. Lesão pulmonar aguda associada à transfusão. Jornal Brasileiro de Pneumologia, v. 33, p. 206-212, 2007.

KAKAIYA, R. M. et al. Prevalence of HLA antibodies in remotely transfused or alloexposed volunteer blood donors. Transfusion, v. 50, n. 6, p. 1328-1334, 8 jan. 2010. Disponível em: <http://doi.wiley.com/10.1111/j.1537-2995.2009.02556.x>. Acesso em: 15 mar. 2019.

KISSEL, K. et al. Molecular basis of NB1 (HNA-2a, CD177) deficiency. Blood, v. 99, n. $11, \quad$ p. 4231-3, 1 jun. 2002. Disponível em: <http://www.ncbi.nlm.nih.gov/pubmed/12010833>. Acesso em: 18 mar. 2019.

KLEINMAN, S. et al. Toward an understanding of transfusion-related acute lung injury: Statement of a consensus panel. , 1 dez. 2004, p. 1774-1789. Disponível em: <http://doi.wiley.com/10.1111/j.0041-1132.2004.04347.x>. Acesso em: 18 mar. 2019.

KOPKO, P. et al. AABB survey of transfusion-related acute lung injury policies and practices in the United States. Transfusion, v. 47, n. 9, p. 1679-1685, set. 2007. Disponível em: <http://doi.wiley.com/10.1111/j.1537-2995.2007.01403.x>. Acesso em: 18 mar. 2019.

KOPKO, P. M. et al. Transfusion-Related Acute Lung Injury. JAMA, v. 287, n. 15, p. 1968, 17 abr. $2002 . \quad$ Disponível em: <http://jama.jamanetwork.com/article.aspx?doi=10.1001/jama.287.15.1968>. Acesso em: 18 mar. 2019.

LALEZARI, P.; MURPHY, G. B.; ALLEN, F. H. NB1, a new neutrophil-specific antigen involved in the pathogenesis of neonatal neutropenia. Journal of Clinical Investigation, v. 50, n. 5, p. 1108-1115, 1 maio 1971. Disponível em: <http://www.ncbi.nlm.nih.gov/pubmed/5552408>. Acesso em: 18 mar. 2019.

LIN, Y. et al. Transfusion-related acute lung injury prevention measures and their impact at Canadian Blood Services. Transfusion, v. 52, n. 3, p. 567-574, mar. 2012. Disponível em: <http://www.ncbi.nlm.nih.gov/pubmed/21895676>. Acesso em: 18 mar. 2019.

LOPES, L. B. et al. Impact of using different laboratory assays to detect human leukocyte antigen antibodies in female blood donors. Transfusion, v. 50, n. 4, p. 902908, 1 abr. 2010. Disponível em: <http://doi.wiley.com/10.1111/j.15372995.2009.02523.x>. Acesso em: 18 mar. 2019.

LUCAS, G. et al. Reducing the incidence of TRALI in the UK: the results of screening 
for donor leucocyte antibodies and the development of national guidelines. Vox Sanguinis, v. 103, n. 1, p. 10-17, jul. 2012. Disponível em: <http://www.ncbi.nlm.nih.gov/pubmed/22150747>. Acesso em: 18 mar. 2019.

MARSH, S.; PARHAM, P.; BARBER, L. The HLA Facts Book. London: [s.n.], 2000.

MORALES-BUENROSTRO, L. E. et al. Natural human leukocyte antigen antibodies found in nonalloimmunized healthy males. Transplantation, v. 86, n. 8, p. 1111-5, 27 out. 2008. Disponível em: <http://www.ncbi.nlm.nih.gov/pubmed/18946350>. Acesso em: 22 mar. 2019.

MORITZ, E. et al. Human neutrophil alloantigens systems. Anais da Academia Brasileira de Ciências, v. 81, n. 3, p. 559-569, set. 2009. Disponível em: $<$ http://www.scielo.br/scielo.php?script=sci_arttext\&pid=S0001-

37652009000300019\&lng=en\&tlng=en>. Acesso em: 18 mar. 2019.

NGUYEN, X.-D. et al. Granulocyte antibodies in male blood donors: can they trigger transfusion-related acute lung injury? Transfusion, v. 58, n. 8, p. 1894-1901, ago. 2018. Disponível em: <http://doi.wiley.com/10.1111/trf.14630>. Acesso em: 10 fev. 2019.

OTROCK, Z. K.; LIU, C.; GROSSMAN, B. J. Transfusion-related acute lung injury risk mitigation: an update. Vox Sanguinis, v. 112, n. 8, p. 694-703, 1 nov. 2017. Disponível em: <http://doi.wiley.com/10.1111/vox.12573>. Acesso em: 10 maio 2018.

PHELAN, D. L. Modern blood banking and transfusion pratices. 4.ed. In: COMPANY, F. A. D. (Org.). . The HLA System. 4. ed. Philadelphia: [s.n.], 1999. p. 489-506.

POLITIS, C. et al. The International Haemovigilance Network Database for the Surveillance of Adverse Reactions and Events in Donors and Recipients of Blood Components: technical issues and results. Vox Sanguinis, v. 111, n. 4, p. 409-417, nov. 2016. Disponível em: <http://doi.wiley.com/10.1111/vox.12447>. Acesso em: 18 mar. 2019.

POPOVSKY, M. A. Transfusion-related acute lung injury: Incidence, pathogenesis and the role of multicomponent apheresis in its prevention. Transfusion Medicine and Hemotherapy, v. 35, n. 2, p. 76-79, 2008.

POPOVSKY, M. A.; ABEL, M. D.; MOORE, S. B. Transfusion-related Acute Lung Injury Associated with Passive Transfer of Antileukocyte Antibodies 1, 2. American Review of Respiratory Disease, v. 128, n. 1, p. 185-189, jul. 1983. Disponível em: <http://www.ncbi.nlm.nih.gov/pubmed/6603182>. Acesso em: 18 mar. 2019.

POPOVSKY, M.; CHAPLIN, H.; MOORE, S. Transfusion-related acute lung injury: a neglected, serious complication of hemotherapy. Transfusion, v. 32, n. 6, p. 589-592, jul. 1992. Disponível em: <http://doi.wiley.com/10.1046/j.15372995.1992.32692367207.x>. Acesso em: 18 mar. 2019. 
POPOVSKY, M.; MOORE, S. Diagnostic and pathogenetic considerations in transfusion-related acute lung injury. Transfusion, v. 25, n. 6, p. 573-577, nov. 1985. Disponível em: <http://doi.wiley.com/10.1046/j.1537-2995.1985.25686071434.x>. Acesso em: 18 mar. 2019.

REIL, A. et al. Specificities of leucocyte alloantibodies in transfusion-related acute lung injury and results of leucocyte antibody screening of blood donors. Vox Sanguinis, v. 95, n. 4, p. 313-317, nov. 2008. Disponível em: <http://doi.wiley.com/10.1111/j.14230410.2008.01092.x>. Acesso em: 15 mar. 2019.

SACHS, U. J. H. Pathophysiology of TRALI: current conceptsSACHS, U. J. H. Pathophysiology of TRALI: current concepts. Intensive Care Medicine, v. 33, n. S1, p. S3-S11, jun. 2007. Disponível em: <http://link.springer.com/10.1007/s00134-0072873-3 >. Acesso em: 18 mar. 2019. Intensive Care Medicine, v. 33, n. S1, p. S3S11, jun. 2007. Disponível em: <http://link.springer.com/10.1007/s00134-007-28733>. Acesso em: 18 mar. 2019.

SACHS, ULRICH J.H.; KAUSCHAT, D.; BEIN, G. White blood cell-reactive antibodies are undetectable in solvent/detergent plasma. Transfusion, v. 45, n. 10, p. 16281631, 1 out. 2005. Disponível em: <http://doi.wiley.com/10.1111/j.15372995.2005.00587.x>. Acesso em: 17 mar. 2019.

SILLIMAN, C. et al. The association of biologically active lipids with the development of transfusion-related acute lung injury: a retrospective study. Transfusion, v. 37, n. 7, p. 719-726, jul. 1997. Disponível em: <http://doi.wiley.com/10.1046/j.15372995.1997.37797369448.x>. Acesso em: 18 mar. 2019.

TOY, P. et al. Transfusion-related acute lung injury: incidence and risk factors. Blood, v. $119, \quad$ n. $7, \quad$ p. 1757-1767, 16 fev. 2012. Disponível em: <http://www.ncbi.nlm.nih.gov/pubmed/22117051>. Acesso em: 22 mar. 2019.

TRIULZI, D. J. et al. The effect of previous pregnancy and transfusion on HLA alloimmunization in blood donors: implications for a transfusion-related acute lung injury risk reduction strategy. Transfusion, v. 49, n. 9, p. 1825-1835, 1 set. 2009. Disponível em: <http://doi.wiley.com/10.1111/j.1537-2995.2009.02206.x>. Acesso em: 9 mar. 2019.

TSALIS, K. et al. Transfusion-related acute lung injury: a life-threatening transfusion reaction. Medical science monitor : international medical journal of experimental and clinical research, v. 11, n. 5, p. CS19-22, maio 2005. Disponível em: <http://www.ncbi.nlm.nih.gov/pubmed/15874891>. Acesso em: 19 mar. 2019.

US FOOD AND DRUG ADMINISTRATION. Fatalities Reported to FDA Following Blood Collection and Transfusion: Annual Summary for FY2016. . . Fatalities reported to FDA following blood collection and transfusion, annual summary for fiscal year 2010 . Rockville (MD): [s.n.], 2016. Disponível em: <http://www.fda.gov/downloads/BiologicsBloodVaccines/SafetyAvailability/ReportaPr 
oblem/TransfusionDonationFatalities/UCM459461.pdf>. Acesso em: 17 mar. 2019.

VILELA, A. L. M. A diversidade genética do complexo principal de histocompatibilidade (MHC) e sua relação com a susceptibilidade para doenças autoimunes e câncer. Ribeirão Preto: Sociedade Brasileira de Genética, 2007.

VLAAR, A. P. et al. The practice of reporting transfusion-related acute lung injury: a national survey among clinical and preclinical disciplines. Transfusion, v. 50, n. 2, p. 443-451, fev. 2010. Disponível em: <http://doi.wiley.com/10.1111/j.15372995.2009.02415.x>. Acesso em: 18 mar. 2019.

VLAAR, A. P. J.; ERMANS, N. P. J. Transfusion-related acute lung injury: a clinical review. The Lancet, p. 1-9, 2013.

VON BOEHMER, H.; TEH, H. S.; P, K. The thymus selects the useful, neglects the useless and destroys the harmful. ImmunollogyToday, v. 10, n. 2, p. 57-61, 1989.

WALLIS, J. P. et al. Single hospital experience of TRALI. Transfusion, v. 43, n. 8, p. 1053-1059, 22 jul. 2003. Disponível em: <http://doi.wiley.com/10.1046/j.15372995.2003.00466.x>. Acesso em: 18 mar. 2019.

WEBERT, K. E.; BLAJCHMAN, M. A. Transfusion-related acute lung injury. Curr Opin Hematol., v. 12, p. 480-487, 2005.

WIERSUM-OSSELTON, J. C. et al. Male-only fresh-frozen plasma for transfusionrelated acute lung injury prevention: before-and-after comparative cohort study. Transfusion, v. 51, n. 6, p. 1278-1283, jun. 2011. Disponível em: <http://doi.wiley.com/10.1111/j.1537-2995.2010.02969.x>. Acesso em: 18 mar. 2019.

WRIGHT, S. E. et al. Acute lung injury after ruptured abdominal aortic aneurysm repair: The effect of excluding donations from females from the production of fresh frozen plasma*. Critical Care Medicine, v. 36, n. 6, p. 1796-1802, jun. 2008. Disponível em: $<$ https://insights.ovid.com/crossref?an=00003246-200806000-00016>. Acesso em: 21 mar. 2019.

$\mathrm{XIA}, \mathrm{W}$. et al. The frequencies of human neutrophil alloantigens in the Chinese Han population of Guangzhou. Transfusion, v. 51, n. 6, p. 1271-1277, jun. 2011. Disponível em: <http://doi.wiley.com/10.1111/j.1537-2995.2010.02979.x>. Acesso em: 18 mar. 2019.

ZUPANSKA, B.; UHRYNOWSKA, M.; KONOPKA, L. Transfusion-related acute lung injury due to granulocyte-agglutinating antibody in a patient with paroxysmal nocturnal hemoglobinuria. Transfusion, v. 39, n. 9, p. 944-947, set. 1999. Disponível em: <http://doi.wiley.com/10.1046/j.1537-2995.1999.39090944.x>. Acesso em: 18 mar. 2019. 
APÊNDICE

\begin{tabular}{|c|c|c|c|c|c|c|c|c|c|c|c|c|c|c|c|c|c|c|c|}
\hline \multirow[b]{2}{*}{ ID } & \multirow[b]{2}{*}{ DN } & \multirow[b]{2}{*}{$\mathrm{s}$} & \multicolumn{4}{|c|}{ PARTOS } & \multicolumn{2}{|l|}{$\overline{A B}$. } & \multirow[b]{2}{*}{$\begin{array}{l}\text { HLA } \\
\mathrm{CLI} \\
\end{array}$} & \multirow[b]{2}{*}{$\begin{array}{l}\text { HLA } \\
\text { CL II }\end{array}$} & \multirow[b]{2}{*}{$\begin{array}{c}\mathrm{HNA} \\
1 \mathrm{~A} \\
\end{array}$} & \multirow[b]{2}{*}{$\begin{array}{c}\mathrm{HNA} \\
1 \mathrm{~B} \\
\end{array}$} & \multirow[b]{2}{*}{$\begin{array}{l}\text { HNA } \\
1 \mathrm{C}\end{array}$} & \multirow[b]{2}{*}{$\begin{array}{c}\mathrm{HNA} \\
2\end{array}$} & \multirow[b]{2}{*}{$\begin{array}{c}\text { HNA } \\
3 \mathrm{~A}\end{array}$} & \multirow[b]{2}{*}{$\begin{array}{c}\text { HNA } \\
3 B\end{array}$} & \multirow[b]{2}{*}{$\begin{array}{l}\mathrm{HNA} \\
4 \mathrm{~A}\end{array}$} & \multirow[b]{2}{*}{$\begin{array}{c}\text { HNA } \\
5 \mathrm{~A}\end{array}$} & \multirow[b]{2}{*}{$\begin{array}{l}\text { HNA } \\
5 B\end{array}$} \\
\hline & & & $G$ & $\begin{array}{c}\text { PAI } \\
1 \\
\end{array}$ & $\begin{array}{c}\text { PAl } \\
2 \\
\end{array}$ & $\begin{array}{c}\text { PAl } \\
3 \\
\end{array}$ & $\begin{array}{c}\text { PAI } \\
1 \\
\end{array}$ & $\begin{array}{c}\text { ÚLTIMO } \\
\text { PARTO/AB. }\end{array}$ & & & & & & & & & & & \\
\hline 1 & $25 / 01 / 2001$ & $\mathrm{~F}$ & 0 & & & & & * & neg & neg & neg & neg & neg & neg & neg & neg & neg & neg & neg \\
\hline 2 & $27 / 12 / 2000$ & $\mathrm{~F}$ & 0 & & & & & * & neg & neg & neg & neg & neg & neg & neg & neg & neg & neg & neg \\
\hline 3 & 07/12/2000 & $\mathrm{F}$ & 0 & & & & & * & neg & neg & neg & neg & neg & neg & neg & neg & neg & neg & neg \\
\hline 4 & $07 / 11 / 2000$ & $\mathrm{~F}$ & 0 & & & & & * & neg & neg & neg & neg & neg & neg & neg & neg & neg & neg & neg \\
\hline 5 & $24 / 10 / 2000$ & $\mathrm{~F}$ & 0 & & & & & * & neg & neg & neg & neg & neg & neg & neg & neg & neg & neg & neg \\
\hline 6 & $12 / 09 / 2000$ & $\mathrm{~F}$ & 0 & & & & & * & neg & neg & neg & neg & neg & neg & neg & neg & neg & neg & neg \\
\hline 7 & 07/06/2000 & $\mathrm{F}$ & 0 & & & & & * & neg & pos & neg & neg & neg & neg & neg & neg & neg & neg & neg \\
\hline 8 & $11 / 05 / 2000$ & $\mathrm{~F}$ & 0 & & & & & * & neg & neg & neg & neg & neg & neg & neg & neg & neg & neg & neg \\
\hline 9 & 17/03/1999 & $\mathrm{F}$ & 0 & & & & & * & neg & neg & neg & neg & neg & neg & neg & neg & neg & neg & neg \\
\hline 10 & 03/03/1999 & $\mathrm{F}$ & 0 & & & & & * & neg & neg & neg & neg & neg & neg & neg & neg & neg & neg & neg \\
\hline 11 & 17/01/1999 & $\mathrm{F}$ & 0 & & & & & * & neg & neg & neg & neg & neg & neg & neg & neg & neg & neg & neg \\
\hline 12 & 20/12/1998 & $\mathrm{F}$ & 0 & & & & & * & neg & neg & neg & neg & neg & neg & neg & neg & neg & neg & neg \\
\hline 13 & $12 / 10 / 1998$ & $\mathrm{~F}$ & 0 & & & & & * & neg & neg & neg & neg & neg & neg & neg & neg & neg & neg & neg \\
\hline 14 & 04/10/1998 & $\mathrm{F}$ & 0 & & & & & * & neg & neg & neg & neg & neg & neg & neg & neg & neg & neg & neg \\
\hline 15 & 19/01/1998 & $\mathrm{F}$ & 0 & & & & & * & neg & neg & neg & neg & neg & neg & neg & neg & neg & pos & neg \\
\hline 16 & 10/12/1997 & $\mathrm{F}$ & 0 & & & & & * & neg & neg & neg & neg & neg & neg & neg & neg & neg & neg & neg \\
\hline 17 & $31 / 05 / 1997$ & $\mathrm{~F}$ & 0 & & & & & * & neg & neg & neg & neg & neg & neg & neg & neg & neg & neg & neg \\
\hline 18 & 17/02/1997 & $\mathrm{F}$ & 0 & & & & & $*$ & neg & neg & neg & neg & neg & neg & neg & neg & neg & neg & neg \\
\hline 19 & 02/02/1976 & $\mathrm{F}$ & 4 & 2 & 1 & & 1 & 11/11/2016 & neg & neg & neg & neg & neg & neg & neg & neg & neg & neg & neg \\
\hline 20 & $15 / 01 / 1996$ & $\mathrm{~F}$ & 0 & & & & & $*$ & neg & neg & neg & neg & neg & neg & neg & neg & neg & neg & neg \\
\hline 21 & 05/01/1996 & $\mathrm{F}$ & 0 & & & & & * & neg & neg & neg & neg & neg & neg & neg & neg & neg & neg & neg \\
\hline 22 & 19/11/1995 & $\mathrm{F}$ & 0 & & & & & * & neg & neg & neg & neg & neg & neg & neg & neg & neg & neg & neg \\
\hline 23 & 19/04/1993 & $\mathrm{F}$ & 1 & 1 & & & & $06 / 11 / 2015$ & neg & neg & neg & neg & neg & neg & neg & neg & neg & neg & neg \\
\hline $\begin{array}{l}24 \\
25\end{array}$ & $\begin{array}{l}28 / 06 / 1995 \\
04 / 05 / 1995\end{array}$ & $\begin{array}{l}F \\
F\end{array}$ & $\begin{array}{l}0 \\
0\end{array}$ & & & & & * & $\begin{array}{l}\text { neg } \\
\text { neg }\end{array}$ & $\begin{array}{l}\text { neg } \\
\text { neg }\end{array}$ & $\begin{array}{l}\text { neg } \\
\text { neg }\end{array}$ & $\begin{array}{l}\text { neg } \\
\text { neg }\end{array}$ & $\begin{array}{l}\text { neg } \\
\text { neg }\end{array}$ & $\begin{array}{l}\text { neg } \\
\text { neg }\end{array}$ & $\begin{array}{l}\text { neg } \\
\text { neg }\end{array}$ & $\begin{array}{l}\text { neg } \\
\text { neg }\end{array}$ & $\begin{array}{l}\text { neg } \\
\text { neg }\end{array}$ & $\begin{array}{l}\text { neg } \\
\text { neg }\end{array}$ & $\begin{array}{l}\text { neg } \\
\text { neg }\end{array}$ \\
\hline
\end{tabular}




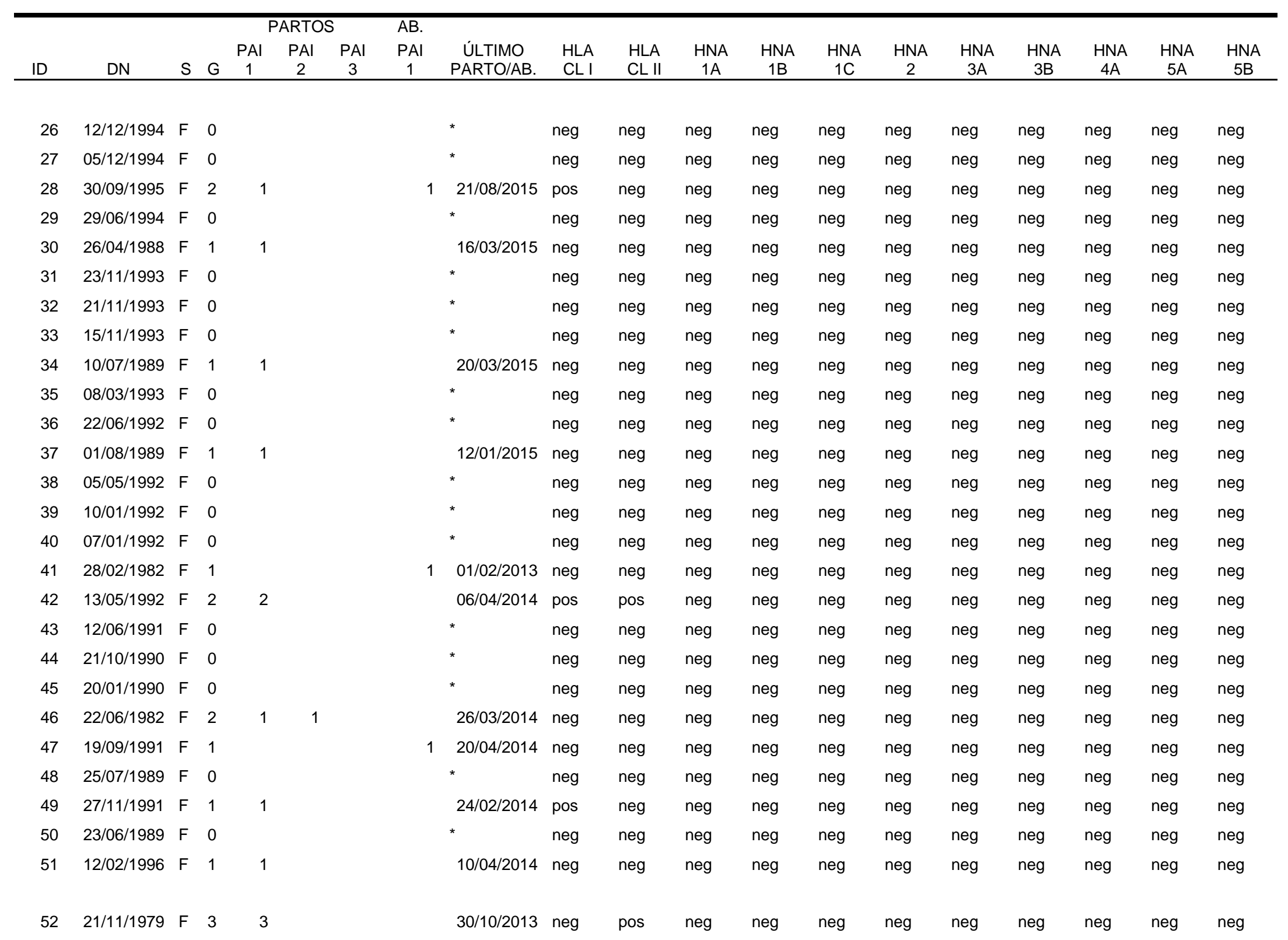




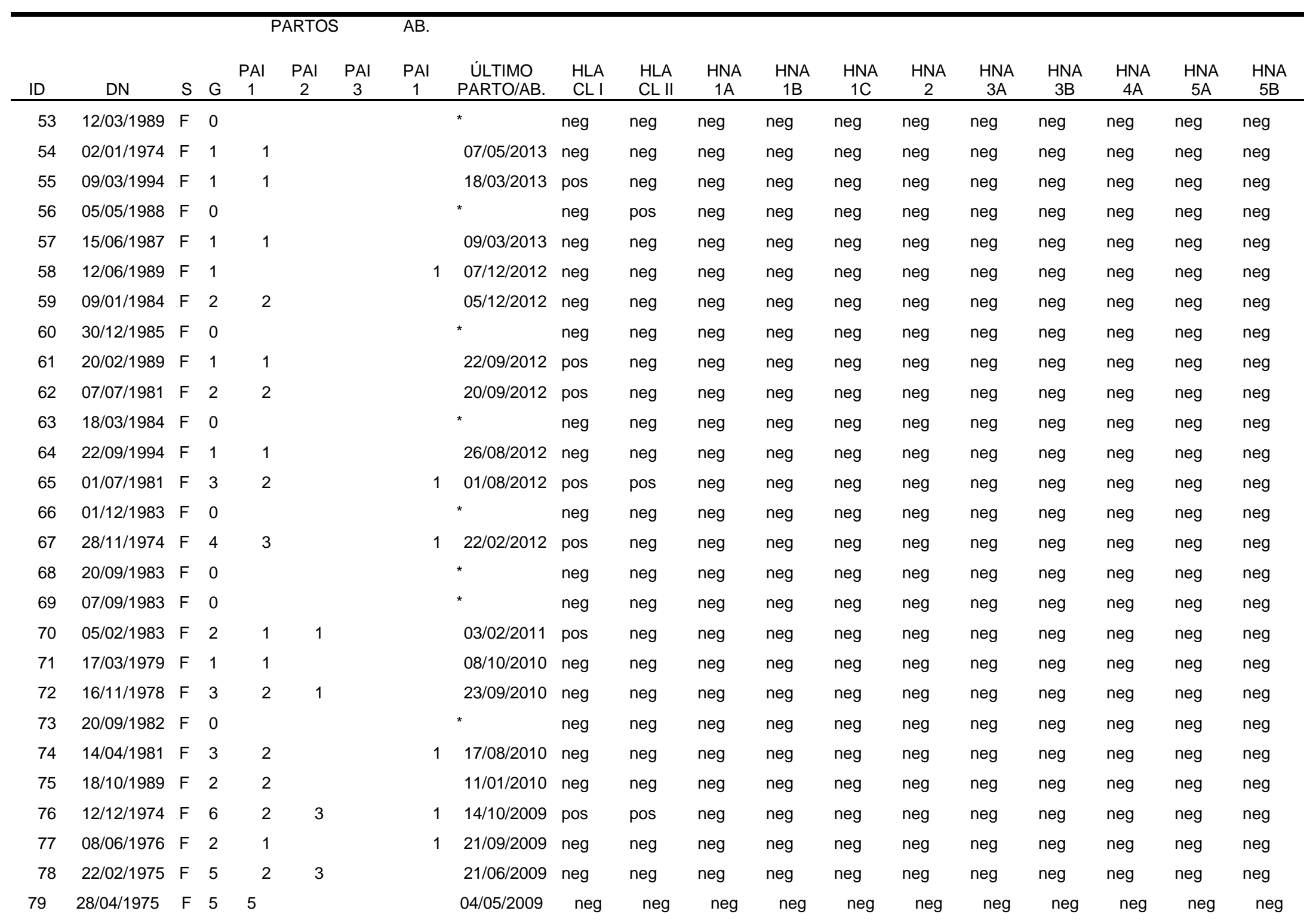




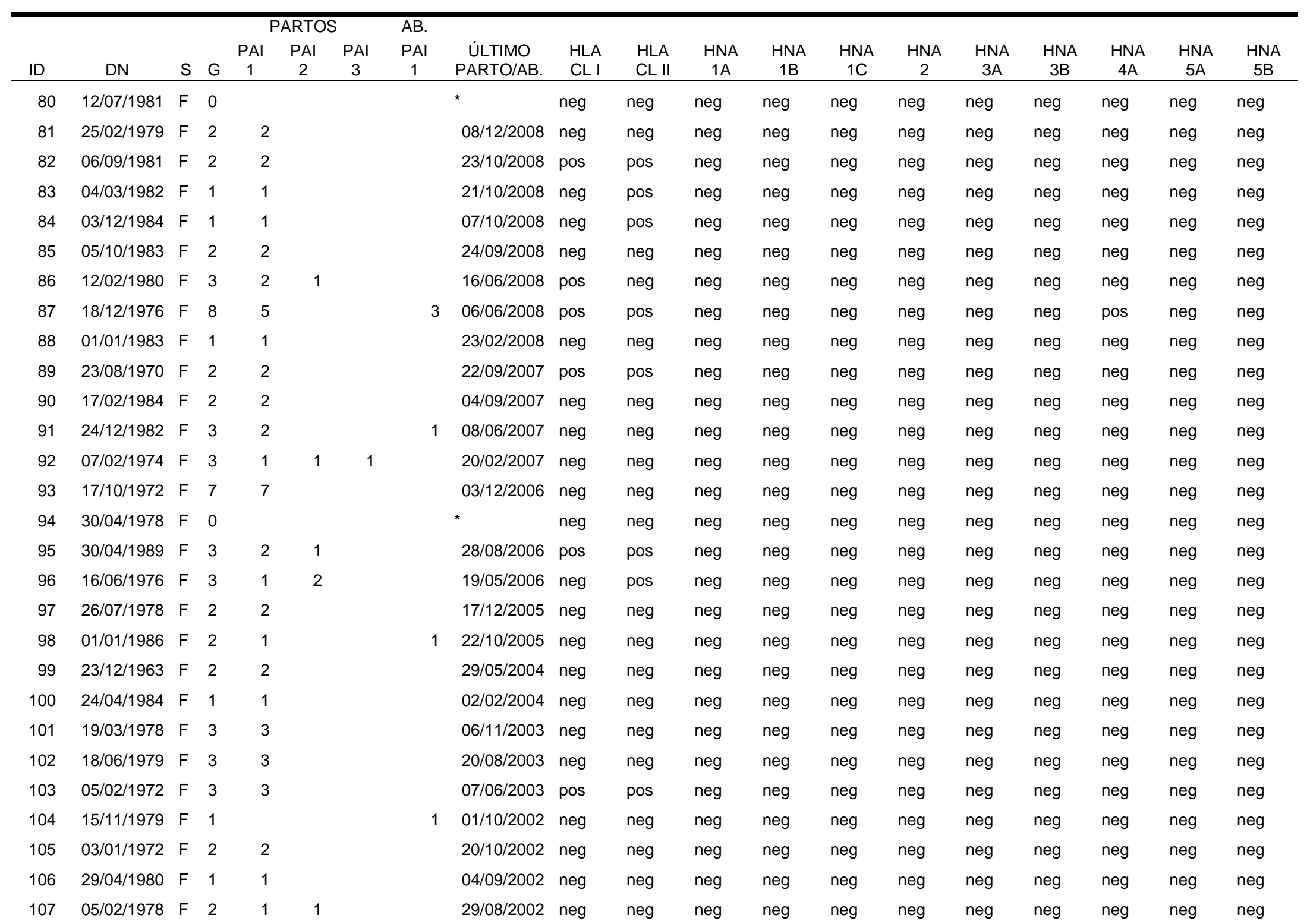




\begin{tabular}{|c|c|c|c|c|c|c|c|c|c|c|c|c|c|c|c|c|c|c|c|}
\hline \multirow[b]{2}{*}{ ID } & \multirow[b]{2}{*}{$\mathrm{DN}$} & \multirow[b]{2}{*}{$\mathrm{S}$} & \multicolumn{4}{|c|}{ PARTOS } & \multicolumn{2}{|l|}{$\mathrm{AB}$. } & \multirow[b]{2}{*}{$\begin{array}{l}\text { HLA } \\
\text { CL I }\end{array}$} & \multirow[b]{2}{*}{$\begin{array}{l}\text { HLA } \\
\text { CL II }\end{array}$} & \multirow[b]{2}{*}{$\begin{array}{c}\mathrm{HNA} \\
1 \mathrm{~A} \\
\end{array}$} & \multirow[b]{2}{*}{$\begin{array}{c}\text { HNA } \\
1 \mathrm{~B} \\
\end{array}$} & \multirow[b]{2}{*}{$\begin{array}{c}\text { HNA } \\
1 \mathrm{C} \\
\end{array}$} & \multirow[b]{2}{*}{$\begin{array}{c}\mathrm{HNA} \\
2 \\
\end{array}$} & \multirow[b]{2}{*}{$\begin{array}{c}\text { HNA } \\
3 \mathrm{~A} \\
\end{array}$} & \multirow[b]{2}{*}{$\begin{array}{c}\text { HNA } \\
3 \mathrm{~B} \\
\end{array}$} & \multirow[b]{2}{*}{$\begin{array}{c}\text { HNA } \\
4 \mathrm{~A} \\
\end{array}$} & \multirow[b]{2}{*}{$\begin{array}{c}\text { HNA } \\
5 \mathrm{~A} \\
\end{array}$} & \multirow[b]{2}{*}{$\begin{array}{c}\text { HNA } \\
5 \mathrm{~B} \\
\end{array}$} \\
\hline & & & $\mathrm{G}$ & $\begin{array}{c}\text { PAI } \\
1 \\
\end{array}$ & $\begin{array}{c}\text { PAI } \\
2 \\
\end{array}$ & $\begin{array}{c}\text { PAl } \\
3 \\
\end{array}$ & $\begin{array}{c}\text { PAI } \\
1 \\
\end{array}$ & $\begin{array}{c}\text { ÚLTIMO } \\
\text { PARTO/AB. }\end{array}$ & & & & & & & & & & & \\
\hline 108 & $13 / 11 / 1973$ & $\mathrm{~F}$ & 2 & 2 & & & & $17 / 12 / 2001$ & pos & pos & neg & neg & neg & neg & neg & neg & neg & neg & neg \\
\hline 109 & 22/08/1973 & $\mathrm{F}$ & 3 & 3 & & & & $11 / 09 / 2001$ & neg & pos & neg & neg & neg & neg & neg & neg & neg & neg & neg \\
\hline 110 & $20 / 04 / 1978$ & $\mathrm{~F}$ & 2 & 2 & & & & $01 / 03 / 2001$ & neg & neg & neg & neg & neg & neg & neg & neg & neg & neg & neg \\
\hline 111 & $14 / 09 / 1982$ & $\mathrm{~F}$ & 1 & 1 & & & & $29 / 07 / 2000$ & neg & neg & neg & neg & neg & neg & neg & neg & neg & neg & neg \\
\hline 112 & 08/10/1981 & $\mathrm{F}$ & 1 & 1 & & & & $11 / 04 / 2000$ & neg & neg & neg & neg & neg & neg & neg & neg & neg & neg & neg \\
\hline 113 & $22 / 07 / 1988$ & $\mathrm{~F}$ & 1 & 1 & & & & $10 / 02 / 2000$ & neg & neg & neg & neg & neg & neg & pos & pos & neg & neg & neg \\
\hline 114 & $27 / 09 / 1965$ & $\mathrm{~F}$ & 2 & 2 & & & & 07/12/1999 & neg & pos & neg & neg & neg & neg & neg & neg & neg & neg & neg \\
\hline 115 & 02/07/1971 & $\mathrm{F}$ & 2 & 2 & & & & $21 / 08 / 1999$ & neg & neg & neg & neg & neg & neg & neg & neg & neg & neg & neg \\
\hline 116 & $15 / 09 / 1972$ & $\mathrm{~F}$ & 4 & 3 & 1 & & & 23/10/1998 & neg & neg & neg & neg & neg & neg & neg & neg & neg & neg & neg \\
\hline 117 & 03/10/1972 & $\mathrm{F}$ & 3 & 3 & & & & 05/04/1998 & neg & neg & neg & neg & neg & neg & neg & neg & neg & neg & neg \\
\hline 118 & $11 / 08 / 1971$ & $\mathrm{~F}$ & 1 & 1 & & & & $16 / 03 / 1998$ & neg & neg & neg & neg & neg & neg & neg & neg & neg & neg & neg \\
\hline 119 & $30 / 01 / 1976$ & $\mathrm{~F}$ & 1 & 1 & & & & 03/02/1998 & neg & neg & neg & neg & neg & neg & neg & neg & neg & neg & neg \\
\hline 120 & $17 / 02 / 1980$ & $\mathrm{~F}$ & 2 & 1 & & & 1 & $15 / 06 / 1997$ & pos & pos & neg & neg & neg & neg & neg & neg & neg & neg & neg \\
\hline 121 & $15 / 06 / 1966$ & $\mathrm{~F}$ & 1 & 1 & & & & $31 / 03 / 1997$ & neg & neg & neg & neg & neg & neg & neg & neg & neg & neg & neg \\
\hline 122 & $05 / 05 / 1971$ & $\mathrm{~F}$ & 5 & 5 & & & & $12 / 04 / 1996$ & neg & neg & neg & neg & neg & neg & neg & neg & neg & neg & neg \\
\hline 123 & $29 / 04 / 1964$ & $\mathrm{~F}$ & 3 & 2 & & & 1 & $16 / 02 / 1996$ & neg & neg & neg & neg & neg & neg & neg & neg & neg & neg & neg \\
\hline 124 & $04 / 09 / 1969$ & $\mathrm{~F}$ & 0 & & & & & * & neg & neg & neg & neg & neg & neg & neg & neg & neg & neg & neg \\
\hline 125 & $14 / 02 / 1975$ & $\mathrm{~F}$ & 3 & 2 & 1 & & & $14 / 12 / 1995$ & pos & neg & neg & neg & neg & neg & neg & neg & neg & neg & neg \\
\hline 126 & $24 / 06 / 1961$ & $\mathrm{~F}$ & 2 & & & & 2 & 13/10/1995 & neg & pos & neg & neg & neg & neg & neg & neg & neg & neg & neg \\
\hline 127 & 09/11/1975 & $\mathrm{F}$ & 1 & 1 & & & & 15/09/1995 & neg & neg & neg & neg & neg & neg & neg & neg & neg & neg & neg \\
\hline 128 & $07 / 12 / 1966$ & $\mathrm{~F}$ & 2 & 2 & & & & 09/01/1995 & neg & neg & neg & neg & neg & neg & neg & neg & neg & neg & neg \\
\hline 129 & $01 / 06 / 1965$ & $\mathrm{~F}$ & 2 & 2 & & & & 03/03/1994 & neg & neg & neg & neg & neg & neg & neg & neg & neg & neg & neg \\
\hline 130 & $17 / 04 / 1967$ & $\mathrm{~F}$ & 2 & & & & 2 & $17 / 01 / 1994$ & neg & neg & neg & neg & neg & neg & neg & neg & neg & neg & neg \\
\hline 131 & $20 / 02 / 1959$ & $\mathrm{~F}$ & 3 & 1 & 1 & 1 & & 13/10/1992 & neg & neg & neg & neg & neg & neg & neg & neg & neg & neg & neg \\
\hline 132 & $22 / 12 / 1969$ & $\mathrm{~F}$ & 1 & 1 & & & & $23 / 05 / 1991$ & neg & neg & neg & neg & neg & neg & neg & neg & neg & neg & neg \\
\hline 133 & $30 / 05 / 1963$ & $\mathrm{~F}$ & 1 & 1 & & & & $10 / 10 / 1990$ & neg & neg & neg & neg & neg & neg & neg & neg & neg & neg & neg \\
\hline 134 & $27 / 10 / 1967$ & $\mathrm{~F}$ & 2 & 2 & & & & $10 / 10 / 1988$ & pos & neg & neg & neg & neg & neg & neg & neg & neg & neg & neg \\
\hline 135 & $16 / 02 / 1958$ & $\mathrm{~F}$ & 2 & 2 & & & & 03/05/1988 & neg & neg & neg & neg & neg & neg & neg & neg & neg & neg & neg \\
\hline
\end{tabular}




\begin{tabular}{|c|c|c|c|c|c|c|c|c|c|c|c|c|c|c|c|c|c|c|c|}
\hline \multirow[b]{2}{*}{ ID } & \multirow[b]{2}{*}{$\mathrm{DN}$} & \multirow[b]{2}{*}{$\mathrm{S}$} & \multicolumn{4}{|c|}{ PARTOS } & \multicolumn{2}{|l|}{$\mathrm{AB}$. } & \multirow[b]{2}{*}{$\begin{array}{l}\text { HLA } \\
\text { CL I }\end{array}$} & \multirow[b]{2}{*}{$\begin{array}{l}\text { HLA } \\
\mathrm{CL} \mathrm{II}\end{array}$} & \multirow[b]{2}{*}{$\begin{array}{c}\mathrm{HNA} \\
1 \mathrm{~A}\end{array}$} & \multirow[b]{2}{*}{$\begin{array}{c}\text { HNA } \\
1 \mathrm{~B} \\
\end{array}$} & \multirow[b]{2}{*}{$\begin{array}{c}\text { HNA } \\
1 \mathrm{C} \\
\end{array}$} & \multirow[b]{2}{*}{$\begin{array}{c}\mathrm{HNA} \\
2 \\
\end{array}$} & \multirow[b]{2}{*}{$\begin{array}{c}\text { HNA } \\
3 \mathrm{~A} \\
\end{array}$} & \multirow[b]{2}{*}{$\begin{array}{c}\text { HNA } \\
3 \mathrm{~B} \\
\end{array}$} & \multirow[b]{2}{*}{$\begin{array}{c}\text { HNA } \\
4 \mathrm{~A} \\
\end{array}$} & \multirow[b]{2}{*}{$\begin{array}{c}\text { HNA } \\
5 \mathrm{~A} \\
\end{array}$} & \multirow[b]{2}{*}{$\begin{array}{c}\text { HNA } \\
5 \mathrm{~B} \\
\end{array}$} \\
\hline & & & $\mathrm{G}$ & $\begin{array}{c}\text { PAI } \\
1 \\
\end{array}$ & $\begin{array}{c}\text { PAl } \\
2 \\
\end{array}$ & $\begin{array}{c}\text { PAl } \\
3 \\
\end{array}$ & $\begin{array}{c}\text { PAI } \\
1 \\
\end{array}$ & $\begin{array}{c}\text { ÚLTIMO } \\
\text { PARTO/AB. }\end{array}$ & & & & & & & & & & & \\
\hline 136 & 03/06/1963 & $\mathrm{F}$ & 2 & 2 & & & & $12 / 01 / 1987$ & neg & neg & neg & neg & neg & neg & neg & neg & neg & neg & neg \\
\hline 137 & 19/07/1966 & $\mathrm{F}$ & 3 & 2 & & 1 & & $30 / 01 / 1985$ & neg & pos & neg & neg & neg & neg & neg & neg & neg & neg & neg \\
\hline 138 & $12 / 04 / 1959$ & $\mathrm{~F}$ & 3 & 3 & & & & $24 / 08 / 1983$ & neg & neg & neg & neg & neg & neg & neg & neg & neg & neg & neg \\
\hline 139 & 06/09/1974 & $\mathrm{F}$ & 4 & 2 & 2 & & & 06/09/1974 & neg & neg & neg & neg & neg & neg & neg & neg & neg & neg & neg \\
\hline 140 & $06 / 12 / 1958$ & $\mathrm{~F}$ & 3 & 3 & & & & $06 / 12 / 1958$ & neg & pos & neg & neg & neg & neg & neg & neg & neg & neg & neg \\
\hline 141 & $25 / 08 / 1997$ & $M$ & 0 & & & & & 0 & * & não & neg & neg & neg & neg & neg & neg & neg & neg & neg \\
\hline 142 & $24 / 07 / 1996$ & $M$ & 0 & & & & & 0 & * & não & neg & neg & neg & neg & neg & neg & neg & neg & neg \\
\hline 143 & $27 / 05 / 1996$ & $M$ & 0 & & & & & 0 & * & não & neg & neg & neg & neg & neg & neg & neg & neg & neg \\
\hline 144 & 20/09/1995 & $M$ & 0 & & & & & 0 & * & não & neg & neg & neg & neg & neg & neg & neg & neg & neg \\
\hline 145 & 12/07/1995 & $M$ & 0 & & & & & 0 & * & não & neg & neg & neg & neg & neg & neg & neg & neg & neg \\
\hline 146 & $20 / 12 / 1994$ & $M$ & 0 & & & & & 0 & * & não & neg & neg & neg & neg & neg & neg & neg & neg & neg \\
\hline 147 & $02 / 11 / 1993$ & $M$ & 0 & & & & & 0 & * & não & neg & neg & neg & neg & neg & neg & neg & neg & neg \\
\hline 148 & $15 / 06 / 1992$ & $M$ & 0 & & & & & 0 & * & não & neg & neg & neg & neg & neg & neg & neg & neg & neg \\
\hline 149 & $14 / 06 / 1989$ & M & 0 & & & & & 0 & * & não & neg & neg & neg & neg & neg & neg & neg & neg & neg \\
\hline 150 & $28 / 11 / 1988$ & $M$ & 0 & & & & & 0 & * & não & neg & neg & neg & neg & neg & neg & neg & neg & neg \\
\hline 151 & 07/01/1988 & $M$ & 0 & & & & & 0 & * & não & neg & neg & neg & neg & neg & neg & neg & neg & neg \\
\hline 152 & $24 / 08 / 1987$ & $M$ & 0 & & & & & 0 & * & não & neg & neg & neg & neg & neg & neg & neg & neg & neg \\
\hline 153 & $24 / 08 / 1987$ & $M$ & 0 & & & & & 0 & * & não & neg & neg & neg & neg & neg & neg & neg & neg & neg \\
\hline 154 & $27 / 04 / 1987$ & $M$ & 0 & & & & & 0 & * & não & neg & neg & neg & neg & neg & neg & neg & neg & neg \\
\hline 155 & 19/11/1986 & $\mathrm{M}$ & 0 & & & & & 0 & * & não & neg & neg & neg & neg & neg & neg & neg & neg & neg \\
\hline 156 & $25 / 07 / 1985$ & $M$ & 0 & & & & & 0 & * & não & neg & neg & neg & neg & neg & neg & neg & neg & neg \\
\hline 157 & $01 / 07 / 1985$ & $M$ & 0 & & & & & 0 & * & não & neg & neg & neg & neg & neg & neg & neg & neg & neg \\
\hline 158 & $04 / 05 / 1985$ & $M$ & 0 & & & & & 0 & * & não & neg & neg & neg & neg & neg & neg & neg & neg & neg \\
\hline 159 & $17 / 10 / 1984$ & $M$ & 0 & & & & & 0 & * & não & neg & neg & neg & neg & neg & neg & neg & neg & neg \\
\hline 160 & $20 / 05 / 1984$ & $M$ & 0 & & & & & 0 & * & não & neg & neg & neg & neg & neg & neg & neg & neg & neg \\
\hline 161 & $22 / 10 / 1983$ & $M$ & 0 & & & & & 0 & * & não & neg & neg & neg & neg & neg & neg & neg & neg & neg \\
\hline 162 & 02/06/1983 & $M$ & 0 & & & & & 0 & * & não & neg & pos & neg & neg & neg & neg & neg & neg & neg \\
\hline 163 & $27 / 11 / 1982$ & $M$ & 0 & & & & & 0 & * & não & neg & neg & neg & neg & neg & neg & neg & neg & neg \\
\hline
\end{tabular}




\begin{tabular}{|c|c|c|c|c|c|c|c|c|c|c|c|c|c|c|c|c|c|c|c|}
\hline \multirow[b]{2}{*}{ ID } & \multirow[b]{2}{*}{ DN } & \multicolumn{5}{|c|}{ PARTOS } & \multicolumn{2}{|l|}{$\mathrm{AB}$. } & \multirow[b]{2}{*}{$\begin{array}{l}\text { HLA } \\
\text { CLI }\end{array}$} & \multirow[b]{2}{*}{$\begin{array}{l}\text { HLA } \\
\text { CL II }\end{array}$} & \multirow[b]{2}{*}{$\begin{array}{c}\text { HNA } \\
1 \mathrm{~A} \\
\end{array}$} & \multirow[b]{2}{*}{$\begin{array}{c}\mathrm{HNA} \\
1 \mathrm{~B} \\
\end{array}$} & \multirow[b]{2}{*}{$\begin{array}{c}\text { HNA } \\
1 \mathrm{C} \\
\end{array}$} & \multirow[b]{2}{*}{$\begin{array}{c}\mathrm{HNA} \\
2 \\
\end{array}$} & \multirow[b]{2}{*}{$\begin{array}{c}\mathrm{HNA} \\
3 \mathrm{~A}\end{array}$} & \multirow[b]{2}{*}{$\begin{array}{c}\text { HNA } \\
3 \mathrm{~B} \\
\end{array}$} & \multirow[b]{2}{*}{$\begin{array}{c}\mathrm{HNA} \\
4 \mathrm{~A} \\
\end{array}$} & \multirow[b]{2}{*}{$\begin{array}{c}\text { HNA } \\
5 \mathrm{~A}\end{array}$} & \multirow[b]{2}{*}{$\begin{array}{c}\text { HNA } \\
5 \mathrm{~B}\end{array}$} \\
\hline & & $\mathrm{s}$ & $\mathrm{G}$ & $\begin{array}{c}\text { PAI } \\
1 \\
\end{array}$ & $\begin{array}{c}\text { PAI } \\
2 \\
\end{array}$ & $\begin{array}{c}\text { PAI } \\
3\end{array}$ & $\begin{array}{c}\text { PAI } \\
1 \\
\end{array}$ & $\begin{array}{c}\text { ÚLTIMO } \\
\text { PARTO/AB. }\end{array}$ & & & & & & & & & & & \\
\hline 164 & 03/09/1982 & $M$ & 0 & & & & & 0 & * & não & neg & neg & neg & neg & neg & neg & neg & neg & neg \\
\hline 165 & $28 / 11 / 1981$ & $M$ & 0 & & & & & 0 & * & não & neg & neg & neg & neg & neg & neg & neg & neg & neg \\
\hline 166 & $13 / 11 / 1981$ & $M$ & 0 & & & & & 0 & * & não & neg & neg & neg & neg & neg & pos & neg & neg & neg \\
\hline 167 & $01 / 10 / 1981$ & $M$ & 0 & & & & & 0 & * & não & neg & neg & neg & neg & neg & neg & neg & neg & neg \\
\hline 168 & $04 / 06 / 1981$ & $M$ & 0 & & & & & 0 & * & não & neg & neg & neg & neg & neg & neg & neg & neg & neg \\
\hline 169 & $22 / 01 / 1981$ & $M$ & 0 & & & & & 0 & * & não & neg & neg & neg & neg & neg & neg & neg & neg & neg \\
\hline 170 & $02 / 01 / 1980$ & $M$ & 0 & & & & & 0 & * & não & neg & neg & neg & neg & neg & neg & neg & neg & neg \\
\hline 171 & $25 / 11 / 1979$ & M & 0 & & & & & 0 & * & não & neg & neg & neg & neg & neg & neg & neg & neg & neg \\
\hline 172 & $27 / 12 / 1977$ & $M$ & 0 & & & & & 0 & * & não & neg & neg & neg & neg & neg & neg & neg & neg & neg \\
\hline 173 & $15 / 05 / 1977$ & $M$ & 0 & & & & & 0 & * & não & neg & neg & neg & neg & neg & neg & neg & neg & neg \\
\hline 174 & 03/08/1976 & M & 0 & & & & & 0 & * & não & neg & neg & neg & neg & neg & neg & neg & neg & neg \\
\hline 175 & $31 / 07 / 1975$ & $M$ & 0 & & & & & 0 & * & não & neg & neg & neg & neg & neg & neg & neg & neg & neg \\
\hline 176 & $18 / 12 / 1974$ & M & 0 & & & & & 0 & * & não & neg & neg & neg & neg & neg & neg & neg & neg & neg \\
\hline 177 & $01 / 11 / 1974$ & $M$ & 0 & & & & & 0 & * & não & neg & neg & neg & neg & neg & neg & neg & neg & neg \\
\hline 178 & $15 / 09 / 1973$ & M & 0 & & & & & 0 & * & não & neg & neg & neg & neg & neg & neg & neg & neg & neg \\
\hline 179 & $25 / 04 / 1972$ & $M$ & 0 & & & & & 0 & * & não & neg & neg & neg & neg & neg & neg & neg & neg & neg \\
\hline 180 & $14 / 03 / 1972$ & $M$ & 0 & & & & & 0 & * & não & neg & neg & neg & neg & neg & neg & neg & neg & neg \\
\hline 181 & $07 / 02 / 1971$ & $M$ & 0 & & & & & 0 & * & não & neg & neg & neg & neg & neg & neg & neg & neg & neg \\
\hline 182 & $16 / 10 / 1970$ & $M$ & 0 & & & & & 0 & * & não & neg & neg & neg & neg & neg & neg & neg & neg & neg \\
\hline 183 & $15 / 09 / 1968$ & $M$ & 0 & & & & & 0 & * & não & neg & neg & neg & neg & neg & neg & neg & neg & neg \\
\hline 184 & 02/09/1966 & $M$ & 0 & & & & & 0 & * & não & neg & neg & neg & neg & neg & neg & neg & neg & neg \\
\hline 185 & $26 / 02 / 1966$ & $M$ & 0 & & & & & 0 & * & não & neg & neg & neg & neg & neg & neg & neg & neg & neg \\
\hline 186 & $03 / 12 / 1965$ & $M$ & 0 & & & & & 0 & * & não & neg & neg & neg & neg & neg & neg & neg & neg & neg \\
\hline 187 & $15 / 07 / 1964$ & $M$ & 0 & & & & & 0 & * & não & neg & neg & neg & neg & neg & neg & neg & neg & neg \\
\hline 188 & $22 / 10 / 1961$ & M & 0 & & & & & 0 & * & não & neg & neg & neg & neg & neg & neg & neg & neg & neg \\
\hline 189 & $31 / 07 / 1959$ & $M$ & 0 & & & & & 0 & * & não & neg & neg & neg & neg & neg & neg & neg & neg & neg \\
\hline 190 & $10 / 03 / 1956$ & $M$ & 0 & & & & & 0 & * & não & neg & neg & neg & neg & neg & neg & neg & neg & neg \\
\hline
\end{tabular}




\section{ANEXO A - Parecer de Aprovação Comitê de Ética da Instituição Principal}

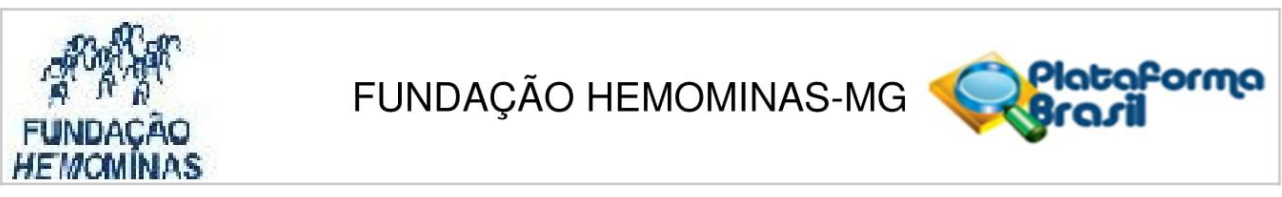

PARECER CONSUBSTANCIADO DO CEP

\section{DADOS DO PROJETO DE PESQUISA}

Título da Pesquisa: Pesquisa de anticorpos anti-HLA, anti-HNA e DNA cromossômico residual em hemocomponentes como ferramentas para definição de risco para TRALI e qimerismo HLA pós-transfusional

Pesquisador: Felipe Carlos Brito de Souza

Área Temática:

Versão: 2

CAAE: 62359816.1 .0000 .5118

Instituição Proponente: FUND CENTRO HEMATOLOGIA E HEMOTERAPIA DE MINAS GERAIS

Patrocinador Principal: FUND CENTRO HEMATOLOGIA E HEMOTERAPIA DE MINAS GERAIS

\section{DADOS DO PARECER}

Número do Parecer: 1.913.743

\section{Apresentação do Projeto:}

Uma das mais graves reações transfusionais é a lesão pulmonar aguda relacionada à transfusão ou TRALI (Transfusion related acute lung injury). Dados recentes indicam que a síndrome representa a principal causa de mortalidade diretamente relacionada a transfusão. Seu risco de aparecimento se dá sobretudo em transfusão de componentes do plasma e plaquetas. A TRALI é definida por aparecimento de insuficiência respiratória após transfusão sanguínea. Trata-se de uma reação imune que é desencadeada pela transfusão de hemocomponentes contendo plasma com anticorpos anti-HLA e anti-HNA. Estes anticorpos aparecem nos doadores na maioria das vezes em mulheres multíparas, que são frequentemente imunizadas contra antígenos leucocitários durante a gravidez. Os hemocomponentes plasmáticos, concentrados de plaquetas tanto randômicos, em pool ou produzidos por plaquetaférese, por possuírem conteúdo plasmático, são, potenciais fontes de anticorpos anti-HLA e anti-HNA, que são a provável causa da lesão pulmonar aguda associada à transfusão. A utilização de métodos de identificação desses anticorpos pode dar mais qualidade e segurança ao processo transfusional. A Fundação Hemominas, bem como outros Hemocentros, utiliza a estratégia da seleção exclusiva de doadores do sexo masculino para a doação de plaquetaférese, como tentativa de driblar a presença de anticorpos anti-HLA, sem necessariamente realizar a pesquisa destes. Isso reduz a possibilidade de se encontrar anticorpos

Endereço: Alameda Ezequiel Dias. 321

Bairro: Santa Efigênia

UF: MG Município: BELO HORIZONTE

Telefone: (31)3768-4587 Fax: $(31) 3768-4600$ CEP: $30.130-110$ 


\section{FUNDAÇÃO HEMOMINAS-MG Platoforma}

FUNDACAO

HEMOMINAS

Continuação do Parecer: 1.913 .743

anti-HLA no plasma doado, no entanto é uma estratégia que restringe a captação de doadores a somente um sexo e, pode dependendo da situação ser um impeditivo para manutenção dos estoques em quantidades ideais. Considerando a gravidade da TRALI e a importância dos anticorpos anti-HLA/HNA na patogenia desta síndrome, o presente estudo propõe avaliar o panorama da presença ou não de anticorpos anti-HLA/HNA nos hemocomponentes plasmáticos produzidos na Fundação Hemominas com foco a dar subsídio para a implantação de estratégias de prevenção da TRALI e definição de um protocolo de rejeição seletiva de doadoras do sexo feminino assim de não gerar impacto para a manutenção dos estoques. Adicionalmente, pretende-se com o estudo, investigar a viabilidade de um teste de triagem de larga escala para detecção de anticorpos anti-HLA/HNA por PRA-Labscreen utilizando uma plataforma de testes em pool de plasma ou a implantação do teste de triagem qualitativa para anticorpos anti-HLA/HNA. Para atingir esse objetivo, será realizado um estudo prospectivo experimental onde serão utilizadas 125 segmentos de $15 \mathrm{~cm}$ das bolsas (cerca de $1 \mathrm{~mL}$ ) ou 125 bolsas de hemocomponentes plasmáticos sendo: 25 amostras de Plasma Congelado doadores do sexo masculino, 25 amostras de Plasma Fresco Congelado de doadoras do sexo feminino com nenhuma gestação ou aborto, 25 amostras de Plasma Fresco Congelado de doadoras do sexo feminino com 1 gestação, 25 amostras de Plasma Fresco Congelado de doadoras do sexo feminino com 2 gestações, 25 amostras de Plasma Fresco Congelado de doadoras do sexo feminino com 3 ou mais gestações. Para todos os hemocomponentes acima descritos serão utilizadas bolsas com sorologia negativa e fora da validade ou que tenham algum motivo de descarte que não interfira na concentração de leucócitos normalmente encontrada quando não existir possibilidade técnica de uso do segmento das bolsas. $\mathrm{Na}$ oportunidade do uso do segmento de bolsas a amostra não se restringirá às bolsas descartadas. As amostras serão testadas utilizando o Kit Labscreen Multi® (One Lambda Inc.) para identificação da presença de anticorpos anti-HLA/HNA. Além disso, deseja-se realizar um estudo com o objetivo de avaliar a possibilidade de ocorrência do fenômeno do microquimera in vitro após transfusão. Noestudo de microquimerismo serão utilizadas 100 fragmentos de $15 \mathrm{~cm}$ das bolsas ou amostra de 100 bolsas de hemocomponentes eritrocitários ou: 20 amostras de Concentrados de Hemácias (Camada Leucoplaquetária Removida), 20 amostras de Concentrados de Hemácias Lavadas, 20 amostras de Concentrados de Hemácias Deleucocitados, 20 amostras de Bolsas de Sangue total. Será realizada leucograma das amostras dos hemocomponentes celulares antes da realização da extração de DNA. Concentração de DNA extraído e valores de éxons serão utilizados para avaliação da possibilidade de ocorrência do fenômeno do microquimera in vitro após transfusão de cada tipo de hemocomponente.

Endereço: Alameda Ezequiel Dias. 321

Bairro: Santa Efigênia CEP: $30.130-110$

UF: MG Município: BELO HORIZONTE

Telefone: (31)3768-4587 Fax: (31)3768-4600 E-mail: cep@hemominas.mg.gov.br 


\section{FUNDAÇÃO HEMOMINAS-MG Q Platooforma}

FUNDACÀO

HEMOMINAS

Continuação do Parecer: 1.913 .743

\section{Objetivo da Pesquisa:}

Objetivo Primário:

Definir o risco relativo dos hemocomponentes produzidos desencadearem TRALI e mosaicismo HLA póstransfusional quando em uso na prática hemoterápica.

Objetivo Secundário:

-Identificar qual a quantidade de DNA residual viável cada hemocomponente apresenta e seu risco relativo de gerar mosaicismo pós transfusional.

-Caracterizar o mosaicismo HLA pós transfusional in vitro.

-Definir os limites de deteç̧ão e sensibilidade dos testes de extração e amplificação HLA.

-Analisar o carry over como fator gerador de falsa heterozigose na tipagem molecular HLA em larga escala. -Identificar qual hemocomponente plasmático advindo de doadores do sexo masculino ou feminino apresenta maior frequência de anticorpos anti-HLA/HNA.

- Definir um ponto de corte para o risco aumentado da presença de anticorpos anti-HLA/HNA.

-Avaliar o desempenho de um ensaio de PRA Labscreen em pool como triagem de anticorpos anti-HLA frente ao teste comercial misto de anti-HLA/HNA.

\section{Avaliação dos Riscos e Benefícios:}

Riscos (de acordo com os pesquisadores): "Em consonância com a Resolução 466/11 que dispõe sobre os requisitos éticos na pesquisa científica, não podemos negar a existência de risco e possível dano gerado pelo projeto dado que é inerente a este tal característica sendo portanto, mesmo que pequeno indissociável à natureza do ato de se realizar uma pesquisa envolvendo seres humanos. Dado o exposto, todas as medidas possíveis serão tomadas para minimizar os riscos e a dimensão de um eventual dano que este trabalho possa ocasionar. $O$ protocolo em questão propõe a utilização de bolsas de hemocomponente que por validade e ou outros motivos vierem a ser segregadas do estoque para descarte, fazendo com que esse procedimento não existiria ao utilizarmos esse material o risco de quebra de sigilo, uma vez que os dados que serão utilizados para a análise não permitem identificação somente sendo necessários para caracterização dos grupos. Os dados de cadastro serão solicitados ao setor responsável e os pesquisadores só terão acesso a uma listagem com os códigos de identificação dos doadores seguido das informações de idade, sexo, número de gestações, quantidade de doações. As estratégias serão tomadas para permitir total anonimato dos participantes da pesquisa".

Endereço: Alameda Ezequiel Dias. 32

$\begin{array}{ll}\text { Bairro: Santa Efigênia } & \text { CEP: } \\ \text { UF: } M G \text { Municipio: } & \text { BELO HORIZONTE }\end{array}$

Telefone: (31)3768-4587 Fax: (31)3768-4600 E-mail: cep@hemominas.mg.gov.br 


\section{FUNDAÇÃO HEMOMINAS-MG Prateoforma}

Continuação do Parecer: 1.913.743

Benefícios (de acordo com os pesquisadores): "Os doadores aos quais seu material será selecionado para o projeto não terão benefícios diretos nem mesmo poderão receber os resultados dos testes feitos dado que não serão identificados quando da realização do projeto, no entanto contribuirão sobremaneira com o conhecimento da qualidade dos hemocomponentes produzidos pela Fundação Hemominas além de por ventura permitirem com a conclusão do estudo alterar a forma de inaptidão das doadoras".

\section{Comentários e Considerações sobre a Pesquisa:}

A pesquisa é relevante e poderá contribuir para a melhoria da segurança transfusional. As pendências apontadas foram devidamente solucionadas.

Considerações sobre os Termos de apresentação obrigatória:

Foi apresentada documentação referente à constituição de biorrepositório.

Recomendações:

Não se aplica.

Conclusões ou Pendências e Lista de Inadequações:

1. O projeto não traz referencial teórico quanto ao estudo de microquimerismo. Solicitamos adequação. RESPOSTA: "Referencial teórico acrescido ao projeto completo e às informações básicas do projeto." ANÁLISE: PENDÊNCIA ATENDIDA

2. No item "Haverá retenção de amostras para armazenamento em banco?" o pesquisador selecionou a opção "não". Entretanto, o projeto prevê a guarda temporária de amostras biológicas de 410 participantes de pesquisa. Solicitamos adequação.

RESPOSTA: A adequação foi feita no documento das informações básicas do projeto.

ANÁLISE: PENDÊNCIA ATENDIDA

3. No item "Informe o número de indivíduos abordados pessoalmente, recrutados, ou que sofrerão algum tipo de intervenção neste centro de pesquisa", os pesquisadores informaram "410". No entanto, a metodologia apresentada deixa entender que nenhum indivíduo será abordado pessoalmente. Solicitamos adequação.

RESPOSTA: A Plataforma Brasil não permite que coloquemos um valor diferente do somatório dos

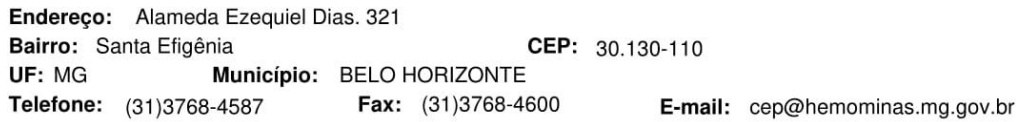




\section{FUNDAÇÃO HEMOMINAS-MG Plotoforma}

FUNDACAMO

HEMOMINAS

Continuação do Parecer: 1.913 .743

grupos definidos na casuística. Os grupos estão detalhados no projeto completo. Foi acrescida a informação de um grupo somente para o atendimento do sistema da plataforma que não permite que o campo não seja preenchido.

ANÁLISE: PENDÊNCIA ATENDIDA.

4. Solicitamos apresentação de declaração de que toda nova pesquisa a ser realizada com o material armazenado será submetida para aprovação do Comitê de Ética em Pesquisa institucional (CEP Hemominas) e, quando for o caso, da Comissão Nacional de Ética em Pesquisa (CONEP).

RESPOSTA: Declaração anexada aos documentos na Plataforma Brasil, arquivo denominado "Declaração_Biorrepositorio_pesquisador.pdf" ANÁLISE: PENDÊNCIA ATENDIDA

5. É necessário informar o prazo de armazenamento de material biológico humano em Biorrepositório. Esclarecemos que este prazo deve estar de acordo com o cronograma da pesquisa correspondente. RESPOSTA: O material biológico será armazenado somente durante a execução do projeto em questão. Definições no documento "Regimento Biorrepositório HLA CAAE: 1 62359816.1.0000.5118" arquivo nomeado como "Regimento Biorrepositório HLA.pdf".

ANÁLISE: PENDÊNCIA ATENDIDA.

6. Solicitamos informar o destino das amostras após a finalização do estudo.

RESPOSTA: Texto incorporado no Protocolo de Pesquisa:

"Não está previsto armazenamento de amostras além do período de realização do protocolo em questão. Após a realização dos testes as amostras serão descartadas de acordo com a legislação sanitária pertinente, dado que não se trata de casuística rara."

Demais definições estão apresentadas no documento "Regimento Biorrepositório HLA CAAE: 1 62359816.1.0000.5118", arquivo nomeado como "Regimento Biorrepositório HLA.pdf ".

ANÁLISE: PENDÊNCIA ATENDIDA.

7. De acordo com a Resolução CNS 441/11, "as condições associadas ao armazenamento de material biológico humano devem estar explicitadas no Projeto de Pesquisa respectivo, devendo seu Regulamento ser apreciado pelo CEP institucional". Solicita-se que seja apresentado o Regimento do Biorrepositório a ser criado no projeto de pesquisa ou, alternativamente, a descrição

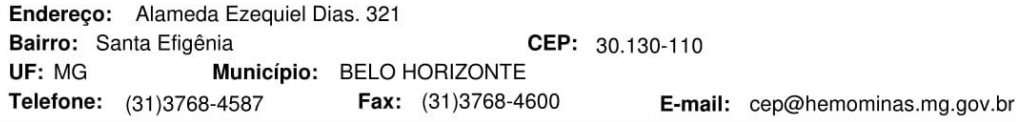




\section{FUNDAÇÃO HEMOMINAS-MG Q Plotorforma}

FUNDACÃO

HEMOMINAS

Continuação do Parecer: 1.913 .743

da armazenagem do material.

RESPOSTA: Apresentado documento em anexo na Plataforma Brasil "Regimento Biorrepositório HLA CAAE: 1 62359816.1.0000.5118"

ANÁLISE: PENDÊNCIA ATENDIDA

8) De acordo com a Resolução CNS 441/11, "No caso de pesquisa envolvendo mais de uma instituição deve haver acordo firmado entre as instituições participantes, contemplando formas de operacionalização, compartilhamento e utilização do material biológico humano armazenado em Biobanco ou Biorrepositório, inclusive a possibilidade de dissolução futura da parceria e a consequente partilha e destinação dos dados e materiais armazenados, conforme previsto no TCLE.", sendo necessário "explicitar o tipo e a quantidade dos materiais compartilhados, informando sua destinação após a utilização". Solicita-se adequação e apresentação dos documentos. Alternativamente, o pesquisador da Fundação Hemominas poderá apresentar uma documento assinado pelo representante legal da instituição parceira declarando ausência de interesse nas amostras do biorrepositório.

RESPOSTA: Não está previsto compartilhamento de material biológico. Declaração assinada pela instituição coparticipante no estudo está apresentada em anexo na Plataforma Brasil. Demais informações acerca das amostras biológicas do estudo encontram-se no documento "Regimento Biorrepositório HLA CAAE: 1 62359816.1.0000.5118"

ANÁLISE: PENDÊNCIA ATENDIDA

9. Existe uma discrepância no número de amostras informadas no item "Tamanho da Amostra no Brasil", que foi informado como sendo igual 410, e as amostras apresentadas no item "Metodologia Proposta" Solicitamos adequação.

RESPOSTA: Adequado no projeto, correto é um total de 410 amostras.

ANÁLISE: PENDÊNCIA ATENDIDA

10. Solicitamos a adequação do cronograma para que as etapas metodológicas que dependem das amostras biológicas iniciem apenas após a aprovação do projeto pelo CEP Hemominas.

RESPOSTA: Cronograma adequado no projeto completo e nas informações básicas na Plataforma. ANÁLISE: PENDÊNCIA ATENDIDA

11. Solicitamos a adequação do orçamento do projeto.

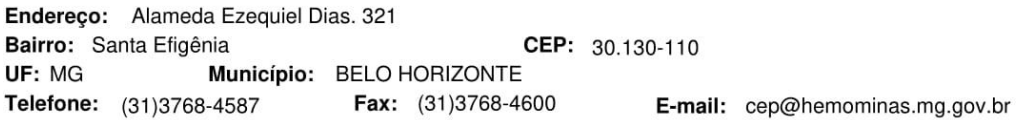




\section{FUNDAÇÃO HEMOMINAS-MG Patoril}

FUNDACAR

Continuação do Parecer: 1.913.743

RESPOSTA: Orçamento adequado no projeto completo e nas informações básicas na Plataforma.

ANÁLISE: PENDÊNCIA ATENDIDA.

Considerações Finais a critério do CEP:

Este parecer foi elaborado baseado nos documentos abaixo relacionados:

\begin{tabular}{|c|c|c|c|c|}
\hline Tipo Documento & Arquivo & Postagem & Autor & Situação \\
\hline $\begin{array}{l}\text { Informações Básicas } \\
\text { do Projeto }\end{array}$ & $\begin{array}{l}\text { PB_INFORMAÇÕES_BÁSICAS_DO_P } \\
\text { ROJETO 809925.pdf }\end{array}$ & $\begin{array}{c}05 / 02 / 2017 \\
03: 22: 40\end{array}$ & & Aceito \\
\hline $\begin{array}{l}\text { Projeto Detalhado / } \\
\text { Brochura } \\
\text { Investigador }\end{array}$ & $\begin{array}{l}\text { Projeto_CEP_Anti_HLA_HNA_TRALI_v } \\
\text { ersao_02_destacado.docx }\end{array}$ & $\begin{array}{c}05 / 02 / 2017 \\
03: 12: 41\end{array}$ & $\begin{array}{l}\text { Felipe Carlos Brito de } \\
\text { Souza }\end{array}$ & Aceito \\
\hline $\begin{array}{l}\text { Declaração de } \\
\text { Manuseio Material } \\
\text { Biológico / } \\
\text { Biorepositório / } \\
\text { Biobanco } \\
\end{array}$ & $\begin{array}{l}\text { DECLARACAO_MANUSEIO_GUARDA } \\
\text { DE_AMOSTRAS_BIOLOGICAS.pdf }\end{array}$ & $\begin{array}{c}24 / 01 / 2017 \\
01: 50: 13\end{array}$ & $\begin{array}{l}\text { Felipe Carlos Brito de } \\
\text { Souza }\end{array}$ & Aceito \\
\hline Brochura Pesquisa & Projeto_CEP_01_201216.pdf & $\begin{array}{c}20 / 12 / 2016 \\
16: 59: 47\end{array}$ & $\begin{array}{l}\text { Felipe Carlos Brito de } \\
\text { Souza }\end{array}$ & Aceito \\
\hline $\begin{array}{l}\text { Recurso Anexado } \\
\text { pelo Pesquisador }\end{array}$ & $\begin{array}{l}\text { Resposta_do_pesquisador_ao_parecer_ } \\
\text { CEP 1852960.pdf }\end{array}$ & $\begin{array}{c}20 / 12 / 2016 \\
16: 59: 19\end{array}$ & $\begin{array}{l}\text { Felipe Carlos Brito de } \\
\text { Souza }\end{array}$ & Aceito \\
\hline $\begin{array}{l}\text { Declaração de } \\
\text { Manuseio Material } \\
\text { Biológico / } \\
\text { Biorepositório / } \\
\text { Biobanco } \\
\end{array}$ & $\begin{array}{l}\text { Declaracao_Biorrepositorio_Coparticipa } \\
\text { nte.pdf }\end{array}$ & $\begin{array}{c}20 / 12 / 2016 \\
16: 57: 37\end{array}$ & $\begin{array}{l}\text { Felipe Carlos Brito de } \\
\text { Souza }\end{array}$ & Aceito \\
\hline $\begin{array}{l}\text { Declaração de } \\
\text { Manuseio Material } \\
\text { Biológico / } \\
\text { Biorepositório / } \\
\text { Biobanco } \\
\end{array}$ & $\begin{array}{l}\text { Declaracao_Biorrepositorio_pesquisador } \\
\text {.pdf }\end{array}$ & $\begin{array}{c}20 / 12 / 2016 \\
16: 57: 15\end{array}$ & $\begin{array}{l}\text { Felipe Carlos Brito de } \\
\text { Souza }\end{array}$ & Aceito \\
\hline Outros & Cadastro_de_Pesquisa.pdf & $\begin{array}{c}24 / 11 / 2016 \\
16: 41: 22 \\
\end{array}$ & $\begin{array}{l}\text { Felipe Carlos Brito de } \\
\text { Souza }\end{array}$ & Aceito \\
\hline Folha de Rosto & Folha_de_Rosto.pdf & $\begin{array}{c}24 / 11 / 2016 \\
09: 53: 11 \\
\end{array}$ & $\begin{array}{l}\text { Felipe Carlos Brito de } \\
\text { Souza }\end{array}$ & Aceito \\
\hline $\begin{array}{l}\text { Declaração de } \\
\text { Pesquisadores }\end{array}$ & $\begin{array}{l}\text { Termo_compromisso_Pesquisador_Hem } \\
\text { ominas.pdf }\end{array}$ & $\begin{array}{c}24 / 11 / 2016 \\
09: 51: 50\end{array}$ & $\begin{array}{l}\text { Felipe Carlos Brito de } \\
\text { Souza }\end{array}$ & Aceito \\
\hline $\begin{array}{l}\text { Declaração de } \\
\text { Pesquisadores }\end{array}$ & $\begin{array}{l}\text { Termo_compromisso_HLA_HNA_Donad } \\
\text { i.pdf }\end{array}$ & $\begin{array}{c}24 / 11 / 2016 \\
05: 27: 22 \\
\end{array}$ & $\begin{array}{l}\text { Felipe Carlos Brito de } \\
\text { Souza }\end{array}$ & Aceito \\
\hline $\begin{array}{l}\text { Projeto Detalhado / } \\
\text { Brochura } \\
\text { Investigador }\end{array}$ & Projeto_Anti_HLA_HNA_TRALI.pdf & $\begin{array}{c}20 / 11 / 2016 \\
22: 45: 29\end{array}$ & $\begin{array}{l}\text { Felipe Carlos Brito de } \\
\text { Souza }\end{array}$ & Aceito \\
\hline $\begin{array}{l}\text { TCLE / Termos de } \\
\text { Assentimento / }\end{array}$ & DISPENSA_DE_TCLE.pdf & $\begin{array}{c}20 / 11 / 2016 \\
18: 28: 29 \\
\end{array}$ & $\begin{array}{l}\text { Felipe Carlos Brito de } \\
\text { Souza }\end{array}$ & Aceito \\
\hline
\end{tabular}

Endereço: Alameda Ezequiel Dias. 321

Bairro: Santa Efigênia

UF: MG Município: BELO HORIZONTE

Telefone: (31)3768-4587 Fax: (31)3768-4600 E-mail: cep@hemominas.mg.gov.br 


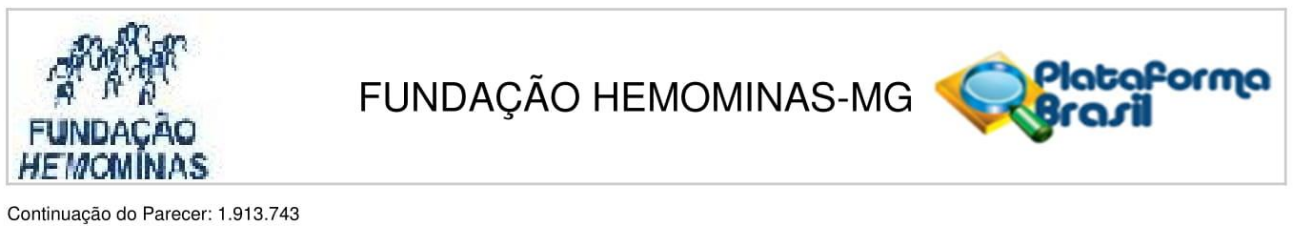

Continuação do Parecer: 1.913 .743

\begin{tabular}{|l|l|c|l|c|}
\hline Justificativa de & DISPENSA_DE_TCLE.pdf & $20 / 11 / 2016$ & Felipe Carlos Brito de & Aceito \\
\hline
\end{tabular}

Susência

Aprovado

Necessita Apreciação da CONEP:

Não

BELO HORIZONTE, 09 de Fevereiro de 2017

Assinado por:

Daniel Gonçalves Chaves

(Coordenador)

Endereço: Alameda Ezequiel Dias. 321 


\section{ANEXO B - Parecer de Aprovação da Instituição Coparticipante}

USP - HOSPITAL DAS
CLÍNICAS DA FACULDADE DE Q Platoformo
MEDICINA DE RIBEIRÃO

\section{PARECER CONSUBSTANCIADO DO CEP}

Elaborado pela Instituição Coparticipante DADOS DO PROJETO DE PESQUISA

Título da Pesquisa: Pesquisa de anticorpos anti-HLA, anti-HNA e DNA cromossômico residual em hemocomponentes como ferramentas para definição de risco para TRALI e qimerismo HLA pós-transfusional

Pesquisador: Felipe Carlos Brito de Souza

Área Temática:

Versão: 1

CAAE: 62359816.1 .3001 .5440

Instituição Proponente:FUND CENTRO HEMATOLOGIA E HEMOTERAPIA DE MINAS GERAIS

Patrocinador Principal: FUND CENTRO HEMATOLOGIA E HEMOTERAPIA DE MINAS GERAIS

DADOS DO PARECER

Número do Parecer: 1.933 .677

\section{Apresentação do Projeto:}

Trata-se de projeto de pesquisa da Instituição Proponente Escola de Enfermagem de Ribeirão Preto - USP e o HCFMRP_USP será uma coparticipante da pesquisa.

Objetivo da Pesquisa:

De acordo com o parecer da Instituição Proponente.

\section{Avaliação dos Riscos e Benefícios:}

De acordo com o parecer da Instituição Proponente.

Comentários e Considerações sobre a Pesquisa:

De acordo com o parecer da Instituição Proponente.

Considerações sobre os Termos de apresentação obrigatória:

Todos os termos de apresentação obrigatória foram anexados na Plataforma Brasil e estão de acordo com as normas éticas vigentes. Apresentou carta de anuência do responsável pelo local de

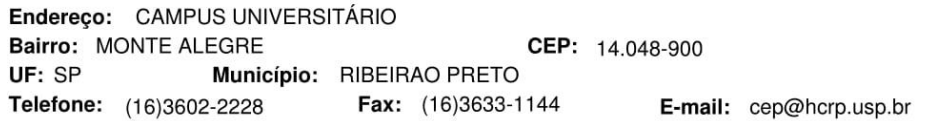




\section{Q⿻日土寸 USP - RIBEIRĀO \\ USP - HOSPITAL DAS \\ CLÍNICAS DA FACULDADE DE MEDICINA DE RIBEIRÃO}

Continuação do Parecer: 1.933 .677

coleta no HCFMRP-USP

\section{Recomendações:}

Não há.

Conclusões ou Pendências e Lista de Inadequações:

O CEP concorda com o parecer da instituição proponente e aprova a Fundação Hemocentro de Ribeirão Preto HCFMRP-USP como coparticipante da pesquisa.

\section{Considerações Finais a critério do CEP:}

"O CEP do HC e da FMRP-USP concorda com o parecer ético emitido pelo CEP da Instituição Proponente, que cumpre as Resoluções Éticas Brasileiras, em especial a Resolução CNS 466/12. Diante disso, o HCFMRP-USP, como instituição co-participante do referido projeto de pesquisa, está ciente de suas coresponsabilidades e de seu compromisso no resguardo da segurança e bem-estar dos sujeitos desta pesquisa, dispondo de infra-estrutura necessária para a garantia de tal segurança e bem-estar".

Este parecer foi elaborado baseado nos documentos abaixo relacionados:

\begin{tabular}{|c|c|c|c|c|}
\hline Tipo Documento & Arquivo & Postagem & Autor & Situação \\
\hline $\begin{array}{l}\text { Informações Básicas } \\
\text { do Projeto }\end{array}$ & $\begin{array}{l}\text { PB_INFORMAÇŌES_BÁSICAS_DO_P } \\
\text { ROJETO 809925.pdf }\end{array}$ & $\begin{array}{c}05 / 02 / 2017 \\
03: 22: 40\end{array}$ & & Aceito \\
\hline $\begin{array}{l}\text { Projeto Detalhado / } \\
\text { Brochura } \\
\text { Investigador }\end{array}$ & $\begin{array}{l}\text { Projeto_CEP_Anti_HLA_HNA_TRALI_V } \\
\text { ersao_02_destacado.docx }\end{array}$ & $\begin{array}{c}05 / 02 / 2017 \\
03: 12: 41\end{array}$ & $\begin{array}{l}\text { Felipe Carlos Brito de } \\
\text { Souza }\end{array}$ & Aceito \\
\hline $\begin{array}{l}\text { Informações Básicas } \\
\text { do Projeto }\end{array}$ & $\begin{array}{l}\text { PB_INFORMAÇÖES_BÁSICAS_DO_P } \\
\text { ROJETO 809925.pdf }\end{array}$ & $\begin{array}{c}24 / 01 / 2017 \\
01: 57: 33\end{array}$ & & Aceito \\
\hline $\begin{array}{l}\text { Informações Básicas } \\
\text { do Projeto }\end{array}$ & $\begin{array}{l}\text { PB_INFORMAÇÕES_BÁSICAS_DO_P } \\
\text { ROJETO 809925.pdf }\end{array}$ & $\begin{array}{c}24 / 01 / 2017 \\
01: 54: 33 \\
\end{array}$ & & Aceito \\
\hline $\begin{array}{l}\text { Informações Básicas } \\
\text { do Projeto }\end{array}$ & $\begin{array}{l}\text { PB_INFORMAÇÕES_BÁSICAS_DO_P } \\
\text { ROJETO 809925.pdf }\end{array}$ & $\begin{array}{c}24 / 01 / 2017 \\
01: 50: 33 \\
\end{array}$ & & Aceito \\
\hline $\begin{array}{l}\text { Declaração de } \\
\text { Manuseio Material } \\
\text { Biológico / } \\
\text { Biorepositório / } \\
\text { Biobanco } \\
\end{array}$ & $\begin{array}{l}\text { DECLARACAO_MANUSEIO_GUARDA } \\
\text { DE_AMOSTRAS_BIOLOGICAS.pdf }\end{array}$ & $\begin{array}{c}24 / 01 / 2017 \\
01: 50: 13\end{array}$ & $\begin{array}{l}\text { Felipe Carlos Brito de } \\
\text { Souza }\end{array}$ & Aceito \\
\hline Informações & PB_INFORMAÇÕES_BÁSICAS_DO_P & 20/12/2016 & & Aceito \\
\hline
\end{tabular}

Endereço: CAMPUS UNIVERSITÁRIO

Bairro: MONTE ALEGRE CEP: $14.048-900$

UF: SP Município: RIBEIRAO PRETO

Telefone: (16)3602-2228 Fax: (16)3633-1144 E-mail: cep@hcrp.usp.br 


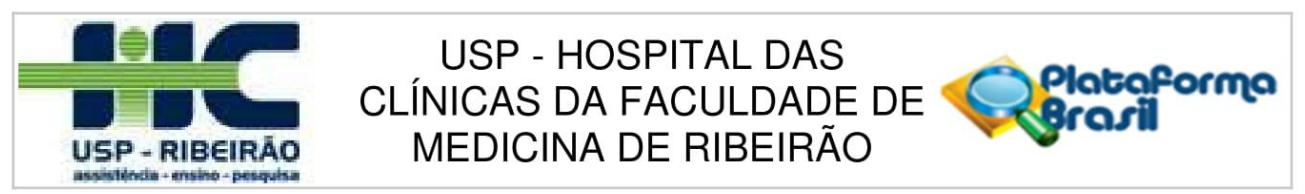

Continuação do Parecer: 1.933.677

\begin{tabular}{|c|c|c|c|c|}
\hline Básicas do Projeto & ETO_809925.pdf & $17: 00: 15$ & & Aceito \\
\hline Brochura Pesquisa & Projeto_CEP_01_201216.pdf & $\begin{array}{c}20 / 12 / 2016 \\
16: 59: 47\end{array}$ & $\begin{array}{l}\text { Felipe Carlos Brito de } \\
\text { Souza }\end{array}$ & Aceito \\
\hline $\begin{array}{l}\text { Recurso Anexado } \\
\text { pelo Pesquisador }\end{array}$ & $\begin{array}{l}\text { Resposta_do_pesquisador_ao_parecer_ } \\
\text { CEP 1852960.pdf }\end{array}$ & $\begin{array}{c}20 / 12 / 2016 \\
16: 59: 19 \\
\end{array}$ & $\begin{array}{l}\text { Felipe Carlos Brito de } \\
\text { Souza }\end{array}$ & Aceito \\
\hline $\begin{array}{l}\text { Declaração de } \\
\text { Manuseio Material } \\
\text { Biológico / } \\
\text { Biorepositório / } \\
\text { Biobanco } \\
\end{array}$ & $\begin{array}{l}\text { Declaracao_Biorrepositorio_Coparticipa } \\
\text { nte.pdf }\end{array}$ & $\begin{array}{c}20 / 12 / 2016 \\
16: 57: 37\end{array}$ & $\begin{array}{l}\text { Felipe Carlos Brito de } \\
\text { Souza }\end{array}$ & Aceito \\
\hline $\begin{array}{l}\text { Declaração de } \\
\text { Manuseio Material } \\
\text { Biológico / } \\
\text { Biorepositório / } \\
\text { Biobanco } \\
\end{array}$ & $\begin{array}{l}\text { Declaracao_Biorrepositorio_pesquisador } \\
\text {.pdf }\end{array}$ & $\begin{array}{c}20 / 12 / 2016 \\
16: 57: 15\end{array}$ & $\begin{array}{l}\text { Felipe Carlos Brito de } \\
\text { Souza }\end{array}$ & Aceito \\
\hline $\begin{array}{l}\text { Informações Básicas } \\
\text { do Projeto }\end{array}$ & $\begin{array}{l}\text { PB_INFORMAÇŌES_BÁSICAS_DO_P } \\
\text { ROJETO 809925.pdf }\end{array}$ & $\begin{array}{c}20 / 12 / 2016 \\
16: 22: 52 \\
\end{array}$ & & Aceito \\
\hline $\begin{array}{l}\text { Informações Básicas } \\
\text { do Projeto }\end{array}$ & $\begin{array}{l}\text { PB_INFORMAÇÖES_BÁSICAS_DO_P } \\
\text { ROJETO 809925.pdf }\end{array}$ & $\begin{array}{c}24 / 11 / 2016 \\
16: 41: 51 \\
\end{array}$ & & Aceito \\
\hline Outros & Cadastro_de_Pesquisa.pdf & $\begin{array}{c}24 / 11 / 2016 \\
16: 41: 22 \\
\end{array}$ & $\begin{array}{l}\text { Felipe Carlos Brito de } \\
\text { Souza }\end{array}$ & Aceito \\
\hline $\begin{array}{l}\text { Informações Básicas } \\
\text { do Projeto }\end{array}$ & $\begin{array}{l}\text { PB_INFORMAÇÖES_BÁSICAS_DO_P } \\
\text { ROJETO 809925.pdf }\end{array}$ & $\begin{array}{c}24 / 11 / 2016 \\
09: 54: 31 \\
\end{array}$ & & Aceito \\
\hline Folha de Rosto & Folha_de_Rosto.pdf & $\begin{array}{c}24 / 11 / 2016 \\
09: 53: 11\end{array}$ & $\begin{array}{l}\text { Felipe Carlos Brito de } \\
\text { Souza }\end{array}$ & Aceito \\
\hline $\begin{array}{l}\text { Declaração de } \\
\text { Pesquisadores }\end{array}$ & $\begin{array}{l}\text { Termo_compromisso_Pesquisador_Hem } \\
\text { ominas.pdf }\end{array}$ & $\begin{array}{c}24 / 11 / 2016 \\
09: 51: 50\end{array}$ & $\begin{array}{l}\text { Felipe Carlos Brito de } \\
\text { Souza }\end{array}$ & Aceito \\
\hline $\begin{array}{l}\text { Declaração de } \\
\text { Pesquisadores }\end{array}$ & $\begin{array}{l}\text { Termo_compromisso_HLA_HNA_Donad } \\
\text { i.pdf }\end{array}$ & $\begin{array}{c}24 / 11 / 2016 \\
05: 27: 22\end{array}$ & $\begin{array}{l}\text { Felipe Carlos Brito de } \\
\text { Souza }\end{array}$ & Aceito \\
\hline $\begin{array}{l}\text { Projeto Detalhado / } \\
\text { Brochura } \\
\text { Investigador }\end{array}$ & Projeto_Anti_HLA_HNA_TRALI.pdf & $\begin{array}{c}20 / 11 / 2016 \\
22: 45: 29\end{array}$ & $\begin{array}{l}\text { Felipe Carlos Brito de } \\
\text { Souza }\end{array}$ & Aceito \\
\hline $\begin{array}{l}\text { TCLE / Termos de } \\
\text { Assentimento / } \\
\text { Justificativa de } \\
\text { Ausência }\end{array}$ & DISPENSA_DE_TCLE.pdf & $\begin{array}{l}\text { 20/11/2016 } \\
18: 28: 29\end{array}$ & $\begin{array}{l}\text { Felipe Carlos Brito de } \\
\text { Souza }\end{array}$ & Aceito \\
\hline
\end{tabular}

Ausência

Situação do Parecer:

Aprovado

Necessita Apreciação da CONEP:

Não

Endereço: CAMPUS UNIVERSITÁRIO

Bairro:
UF: SP

Telefone: (16)3602-2228 Fax: (16)3633-1144 E-mail: cep@hcrp.usp.br 


\section{USP - HOSPITAL DAS
CLIINICAS DA FACULDADE DE
MEDICINA DE RIBEIRÃO}

Continuação do Parecer: 1.933.677

RIBEIRAO PRETO, 13 de Fevereiro de 2017

Assinado por:

MARCIA GUIMARÃES VILLANOVA

(Coordenador)

Endereço: CAMPUS UNIVERSITÁRIO

Bairro: MONTE ALEGRE

CEP: $\quad 14.048-900$

UF: SP Município: RIBEIRAO PRETO

Telefone: (16)3602-2228 Fax: (16)3633-1144 E-mail: cep@hcrp.usp.br

Página 04 de 04 


\section{ANEXO C - Carta de Solicitação de Dispensa de Termo de Consentimento Livre e Esclarecido}

\section{CARTA DE SOLICITAÇÃO DE DISPENSA DE TERMO DE CONSENTIMENTO LIVRE E ESCLARECIDO}

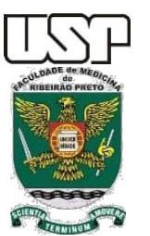

Ao Comitê de Ética em Pesquisa da Fundação Hemominas,

Prezado Coordenador,

O protocolo de pesquisa em questão intitulado " Pesquisa de anticorpos anti-HLA, antiHNA e DNA cromossômico residual em hemocomponentes como ferramentas para definição de risco para TRALI e mosaicismo HLA pós-transfusional" propõe a utilização de bolsas de hemocomponente que por validade e ou outros motivos vierem a ser segregadas do estoque para descarte, ou ainda caso metodologicamente possível uso de segmentos das bolsas que durante o processo de produção são descartados mas possuem material suficiente para as análises do estudo.

Dado que a Resolução 466/12, especificamente no seu item IV.8 define que:

"Nos casos em que seja inviável a obtenção do Termo de Consentimento Livre e Esclarecido ou que esta obtenção signifique riscos substanciais à privacidade e confidencialidade dos dados do participante ou aos vínculos de confiança entre pesquisador e pesquisado, a dispensa do TCLE deve ser justificadamente solicitada pelo pesquisador responsável ao Sistema CEP/CONEP, para apreciação, sem prejuízo do posterior processo de esclarecimento."

Resolução N 466, de 12 de Dezembro de 2012

Devido as características do estudo entendemos que a coleta dos TCLE's significaria um contato desnecessário de quebra de sigilo dos doadores já que nenhum dado individual dos doadores será necessário para a condução do estudo, somente aqueles essenciais para a definição dos grupos (idade, sexo, número de gestações (quando aplicável), quantidade de doações, ausência de histórico transfusional). Além disso, os dados secundários poderão ser solicitados ao setor responsável (Cadastro) o que faria com que os pesquisadores só tenham acesso a uma listagem com os códigos de identificação dos doadores seguido das informações necessárias, sem portanto, acessarem demais dados dos doadores.

Soma-se ao apresentado o fato de que todo o material utilizado será de doadores de sangue os quais já deram seu consentimento no documento "Termo de Consentimento Pós 
Informado" que traz em seu item 4 no qual é dado esclarecimento acerca do uso do material coletado em pesquisas:

"4 - Declaro que compreendi as questões a mim formuladas e que as informações que eu prestei são verdadeiras e desde que atendam aos requisitos para doação de sangue, autorizo a retirada de meu sangue e que a Fundação Hemominas realize todos os testes de laboratório exigidos pelas leis e normas técnicas vigentes e utilize este sangue na atividade hemoterápica no atendimento à população, ou para a produção de insumos e hemoderivados autorizados legalmente, bem como para pesquisas, de acordo com as normas que regulamentam a ética em pesquisa no Brasil."

Termo de Consentimento Pós Informado (Fundação Hemominas, FPSIS-T.GCC-01-Ficha de Doação)

Diante do exposto, solicito a este comitê aprovação da dispensa de coleta de Termo de Consentimento Livre e Esclarecido específico para o projeto de pesquisa em questão.

Cordialmente,

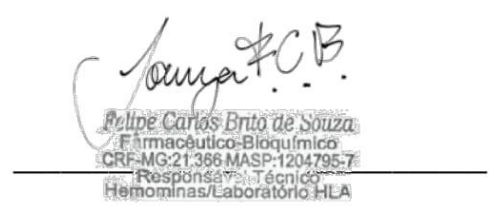

Felipe Carlos Brito de Souza 


\section{ANEXO D -Ficha para Coleta de Dados dos Participantes}

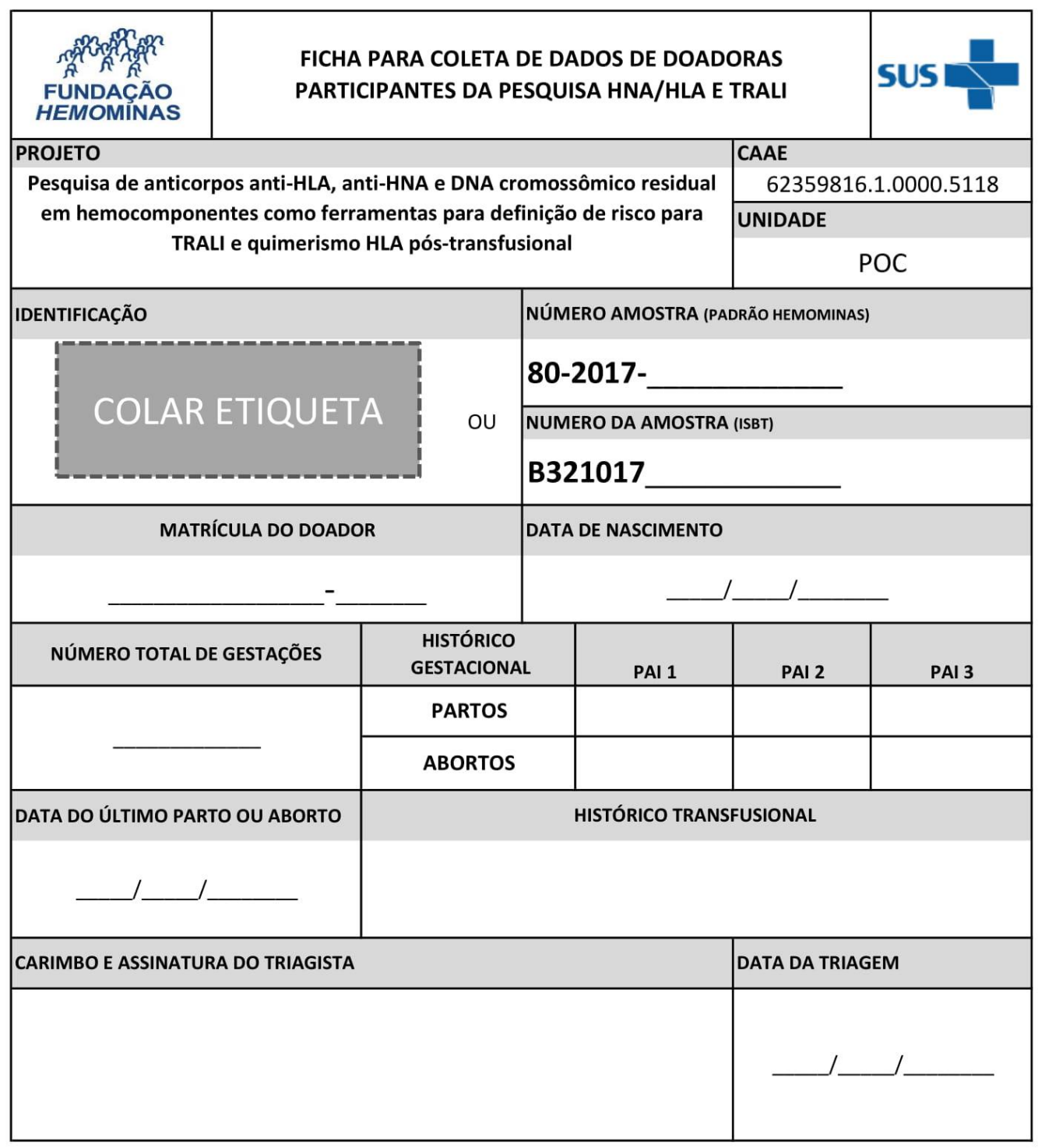

